\title{
Cerebral circulation and metabolic properties in patients undergoing normothermic cardiopulmonary bypass
}

Citation for published version (APA):

Ševerdija, E. E. (2016). Cerebral circulation and metabolic properties in patients undergoing normothermic cardiopulmonary bypass. [Doctoral Thesis, Maastricht University]. Datawyse / Universitaire Pers Maastricht. https://doi.org/10.26481/dis.20160128es

Document status and date:

Published: 01/01/2016

DOI:

10.26481/dis.20160128es

Document Version:

Publisher's PDF, also known as Version of record

Please check the document version of this publication:

- A submitted manuscript is the version of the article upon submission and before peer-review. There can be important differences between the submitted version and the official published version of record.

People interested in the research are advised to contact the author for the final version of the publication, or visit the DOI to the publisher's website.

- The final author version and the galley proof are versions of the publication after peer review.

- The final published version features the final layout of the paper including the volume, issue and page numbers.

Link to publication

\footnotetext{
General rights rights.

- You may freely distribute the URL identifying the publication in the public portal. please follow below link for the End User Agreement:

www.umlib.nl/taverne-license

Take down policy

If you believe that this document breaches copyright please contact us at:

repository@maastrichtuniversity.nl

providing details and we will investigate your claim.
}

Copyright and moral rights for the publications made accessible in the public portal are retained by the authors and/or other copyright owners and it is a condition of accessing publications that users recognise and abide by the legal requirements associated with these

- Users may download and print one copy of any publication from the public portal for the purpose of private study or research.

- You may not further distribute the material or use it for any profit-making activity or commercial gain

If the publication is distributed under the terms of Article $25 \mathrm{fa}$ of the Dutch Copyright Act, indicated by the "Taverne" license above, 
(c) Copyright E.E. Ševerdija, Maastricht 2016

ISBN 9789461595201

Printed by Datawyse I Universitaire Pers Maastricht

Cover design: Guus Vrencken

The author appreciates financial support for his dissertation.

Financial support by Stichting Hartsvrienden RESCAR and the Netherlands Heart Foundation for the publication of this thesis is gratefully acknowledged.

Additional financial support was granted by Sorin Groep Nederland NV, Laguna Health BV, QP\&S NV, Maquet Netherlands BV, Terumo Europe NV, New Medical Technologies, Werfen BV, Krijnen Medical Innovation BV, and Covidien Nederland BV. 


\section{CEREBRAL CIRCULATION AND METABOLIC PROPERTIES IN PATIENTS UNDERGOING NORMOTHERMIC CARDIOPULMONARY BYPASS}

\section{PROEFSCHRIFT}

Ter verkrijging de graad van doctor aan de Universiteit Maastricht, op gezag van de Rector Magnificus, Prof. dr. L.L.G. Soete, volgens het besluit van het College van Decanen, in het openbaar te verdedigen op donderdag 28 januari 2016 om 10:00 uur

door

\section{Ervin Emil Ševerdija}

geboren op 30 mei 1943 te Dubrovnik, Kroatië

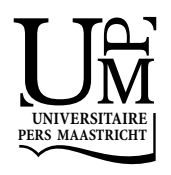




\section{Promotor}

Prof. dr. J.G. Maessen

\section{Copromotores}

Dr. P.W. Weerwind

Dr. J.H. Heijmans

\section{Beoordelingscommissie}

Prof. dr. O. Bekers (voorzitter)

Prof. dr. W.F.F.A. Buhre

Prof. dr. B. Mochtar

Prof. dr. J.M. Murkin (University of Western Ontario, Canada)

Prof. dr. R.B. Panerai (University of Leicester, United Kingdom) 
In memoriam of my wife Ljiljana, wish you were here today

To Karlo, Maja, Lucija, Luka, Nino, and Fabio

Potius sero quam numquam 



\section{CONTENTS}

Chapter 2 Assessment of dynamic cerebral autoregulation and cerebral carbon dioxide reactivity during normothermic cardiopulmonary bypass

Chapter 3 Hemodilution combined with hypercapnia impairs cerebral autoregulation during normothermic cardiopulmonary bypass

Chapter 4 Retrograde autologous priming reduces transfusion requirements in coronary artery bypass surgery

Chapter 5 Can minimized cardiopulmonary bypass systems be safer?

Chapter 6 Impact of intraoperative events on cerebral tissue oximetry in patients undergoing cardiopulmonary bypass

Chapter 7 General discussion

Summary

Samenvatting

Sažetak

Valorisation

Acknowledgment

Curriculum vitae

Publications 



\section{CHAPTER 1}

\section{GENERAL INTRODUCTION}

When human life may be at stake, there can be no compromise with quality. Harris Willis 

During more than sixty years of cardiac surgery comprising cardiopulmonary bypass (CPB), mortality drastically declined. However, the neurocognitive dysfunction after surgery did not decline in a similar degree. The most common neurological complications observed in coronary artery bypass graft (CABG) surgery performed with $\mathrm{CPB}$ are stroke, delirium, cognitive decline, and depressed mood in the days and weeks after surgery, as well as a long-term decline in cognitive function [1]. The exact causes of these injuries are unknown, but the most likely area of concern is emboli delivered to the brain [2-8] and altered cerebral perfusion [9-12]. Moreover, extreme hemodilution resulted from bloodless priming of the CPB circuit, may aggravate poor neurological outcome even further [13].

This thesis focusses on altered cerebral perfusion in relation to CPB during cardiac surgery, with respect to cerebral autoregulation, cerebral carbon dioxide reactivity, and hemodilution.

\section{Cerebral autoregulation}

In 1959 Lassen [14] defined cerebral autoregulation (CA) as the intrinsic ability of the cerebral vasculature to provide constant cerebral blood flow (CBF) despite changes in cerebral perfusion pressure (CPP). The normal range of $\mathrm{CA}$ is often quoted between mean arterial pressures (MAPs) of approximately $60-160 \mathrm{mmHg}$ [15]. In hypertensive patients this curve is shifted to the right [16], as shown in figure 1.

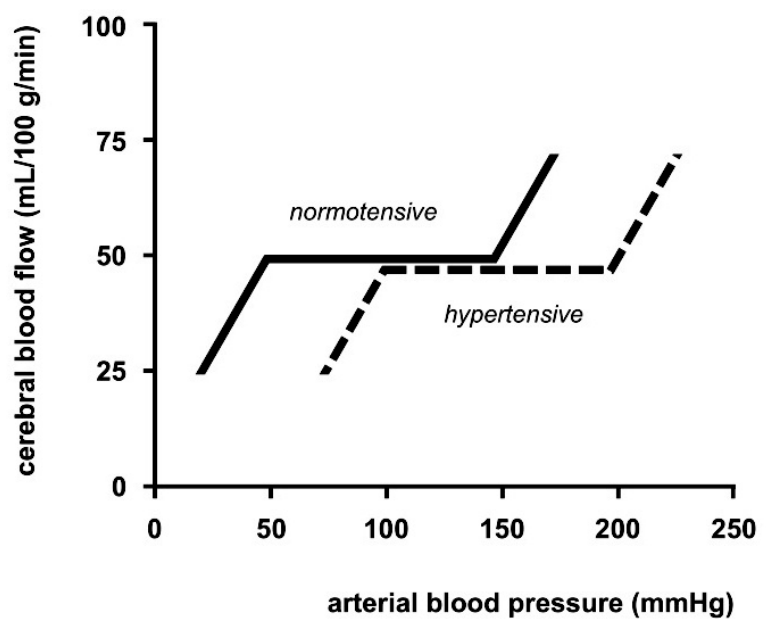

Figure 1 Relation between cerebral blood flows and mean arterial pressures (Lassen's curve) in normotensive (solid curve) and chronically hypertensive patients (dotted curve). 
By means of CA the body is able to deliver sufficient blood containing oxygen and nutrients to the brain for its metabolic need, and remove carbon dioxide $\left(\mathrm{CO}_{2}\right)$ and other waste products. CPP is the pressure gradient between the systemic MAP and the pressure in the cranial compartment of blood - intracranial pressure (ICP) i.e. $(\mathrm{CPP}=\mathrm{MAP}-\mathrm{ICP})$. In clinical practice the ICP under normal condition is synonymous with the central venous pressure (CVP) measured in $\mathrm{mmHg}$. Actually CPP is the driving force of blood to the brain, with optimal values ranging between 70 and $90 \mathrm{mmHg}$ cerebral blood flow is kept constant due to autoregulation [17,18]. Physiologically, the cerebral vascular bed exhibits CBF autoregulation with respect to changes in perfusion pressure by altering the cerebral vascular resistance [19]. The Monroe-Kelly doctrine states that due to the noncompliant skull and dura, small increases in intracranial volume result in sharp ICP increases [20]. Normally the ICP is between 5 and $15 \mathrm{mmHg}$, however during CPB CVP is mostly close to zero or even negative when augmented kinetic venous drainage (centrifugal pump) is used, resulting in a CPP that equals the MAP. If for any reason the CPP falls below the lower limit of autoregulation the body response in dilatation of the cerebral blood vessels i.e. opening of microvascular shunts resulting in maintaining CBF [21]. Continuation of such an iatrogenic situation might increase microvascular shunting with increasing ICP leading to the loss of CBF autoregulation. This widespread reduction in $\mathrm{CBF}$ and perfusion, might lead to brain ischemia. During $\mathrm{CPB}$ the perfusionist controls both the blood flow and systemic blood pressure, and if the MAP is kept below the lower autoregulatory limit, this will lead to cerebral hypoperfusion, as cerebral blood vessels cannot compensate further for the reduction in perfusion pressure [19].

Hypertensive patients are generally accepted to have intact pressure-flow autoregulation, with a rightward shift in the cerebral autoregulation curve such that pressure-dependent flow patterns develop at higher perfusion pressures than in the normotensive population (Figure 1). In hypertensive patients the use of higher perfusion pressure during $\mathrm{CPB}$ should therefore be a common practice. Since decreases in CPP will expose the brain to ischemic insults, that may reduce the chance for good neurological outcome after CPB.

\section{CARBON DIOXIDE REACTIVITY}

The carbon dioxide reactivity $\left(\mathrm{CO}_{2} \mathrm{R}\right)$ affects the change in $\mathrm{CBF}$ in response to changes of arterial $\mathrm{CO}_{2}$ content. High arterial $\mathrm{CO}_{2}$ concentrations lead to vasodilatation and low $\mathrm{CO}_{2}$ concentrations to vasoconstriction of the cerebral arterioles. Impaired $\mathrm{CO}_{2} \mathrm{R}$ before and during $\mathrm{CPB}$ might contribute to neurological morbidity 
after cardiac surgery [22]. Due to inadequate control of $\mathrm{p}_{\mathrm{a}} \mathrm{CO}_{2}$ during cardiac surgery like in the course of $\mathrm{CO}_{2}$ flooding of thorax in valve replacement, $\mathrm{CBF}$ can fluctuate and the potential danger of excessive CBF includes cerebral oedema and intracranial haemorrhage [23]. Non-physiological values of arterial carbon dioxide tension $\left(\mathrm{p}_{\mathrm{a}} \mathrm{CO}_{2}\right)$ can result in cerebral hypoperfusion [10], or hyperperfusion [9], depending on the auto-regulatory reserve capacity of the cerebral vasculature. Besides the global changes in cerebral blood supply, changes in $\mathrm{p}_{\mathrm{a}} \mathrm{CO}_{2}$ can also lead to local alteration of systemic vascular resistance and hence an undesired redistribution of blood flow [24]. Therefore, monitoring and tightly controlling $\mathrm{paCO}_{2}$ in addition to perfusion pressures is of immense importance during CPB.

\section{HeModilution}

Bloodless prime of the CPB circuit was introduced in 1960 by Panico and Neptune [25]. Though, the method was not accepted until Denton Cooley demonstrated the safety and feasibility of using $5 \%$ dextrose in water as a priming solution [26]. The advent of hypothermic CPB has made intentional hemodilution a standard practice, because it was believed that the increase in blood viscosity without hemodilution adversely affects microcirculatory flow. In the 80s and 90s, the acceptable level of CPB hemodilution was decreased to hematocrit values less than $18 \%$ as a consequence of the heightened concern and of viral transmission by blood transfusion. Large priming volume of the CPB system can result in seriously low hematocrit levels that might lead to brain ischemia via reduction of oxygen carrying capacity, despite increases in CBF $[27,28]$. Moreover, the literature provides increasing evidence that a low hematocrit during $\mathrm{CPB}$ is associated with increased postoperative morbidity and mortality [29-32]. Hemodilution used in everyday practice reduces oxygen content of blood and blood viscosity augmenting CBF. Furthermore, acute hemodilution caused by large prime volume of the CPB system can result in seriously low hematocrit levels, mandating transfusion of packed red blood cells which is also charged for poor patient's outcome.

Mathew et al. [13] performed a prospective, randomized study of 374 patients older than 65 years undergoing CABG surgery with $\mathrm{CPB}$. Patients were divided into two groups based on their hematocrit i.e. $15-18 \%$ and more than $27 \%$. Due to an increase in adverse neurological events in low hematocrit group, the study was terminated early. Despite the incomplete enrolment, they reported that older patients experiencing profound hemodilution were more likely to express cognitive decline. Further, their results suggest that both extreme hemodilution in the elderly and aggressive transfusion should be used with caution in the management of $\mathrm{CPB}$ 
during cardiac surgery. Habib and associates [30] in a retrospective analysis of 5000 CABG patients found that stroke, myocardial infarction, low cardiac output, renal failure, multi-organ failure, prolonged ventilation times, pulmonary oedema and sepsis were all significantly increased with hematocrit levels less than $22 \%$. In an even larger cohort (11,000 CABG patients) Karkouti and colleagues [31] found that the risk of a perioperative stroke increased $10 \%$ with each percentage decrease in lowest hematocrit with best results when the lowest hematocrit was between $27 \%$ and 29\%. Ranucci and colleagues [32] performed a retrospective analysis of 1766 CABG patients in a multicentre study and found that hemodilutional anaemia on $\mathrm{CPB}$ increases morbidity and mortality after coronary surgery. The hematocrit cutoff values were similar for renal failure (23\%) and low-output syndrome $(24 \%)$. They also found that blood transfusions were significant associated with both renal failure and low-output syndrome.

Obviously, as the number of older patients with a higher rate of comorbidities for more complex and prolonged cardiac surgery increases, there is a need to understand the mechanisms leading to end-organ injury after cardiac surgery and to identify strategies to attenuate them. One of the mechanisms clearly includes the reduction of hemodilution. To counteract these problems, CPB technology has evolved with advances in oxygenator design, biocompatible surface coatings, centrifugal pumps, and more recently with reduction in CPB circuit size. In an attempt to attenuate the adverse effects of CPB, the use of minimized CPB systems has recently gradually increased. The goal of this diminution has been to reduce systemic inflammation while preserving platelet function and minimizing the need for blood transfusions due to diminished priming volume. This, along with a wellmaintained hematocrit level [33], provides a theoretical basis for a better preservation of tissue perfusion and finally better patient outcome.

\section{OUTLINE OF THIS THESIS}

The general objective of the present thesis is to contribute to a better understanding of the processes associated with $\mathrm{CPB}$, and to attenuate its possible deleterious effect. This was achieved by investigating the influence of hemodilution and $\mathrm{paCO}_{2}$ levels during CPB on dynamic cerebral autoregulation. The influence of hemodilution on cerebral vascular reactivity to $\mathrm{p}_{\mathrm{a}} \mathrm{CO}_{2}$ is part of this investigation. The clinical and methodological aspects together with improvements in measures for patient's safety during $\mathrm{CPB}$ are addressed in subsequent chapters of this thesis. 
To assess dynamic cerebral autoregulation and cerebrovascular reactivity to $\mathrm{p}_{\mathrm{a}} \mathrm{CO}_{2}$ levels during normothermic nonpulsatile $\mathrm{CPB}$, a novel technique for evaluation is introduced. In particular, it was tested whether externally evoked variability of blood pressure through rhythmically changing pump flow is adequate in creating sufficient cerebral blood flow velocity variability to enable the study of dynamic cerebral autoregulation (Chapter 2).

The influence of hemodilution and $\mathrm{paCO}_{2}$ levels on cerebral autoregulation and cerebral vascular reactivity during normothermic $\mathrm{CPB}$ were investigated in the study described in Chapter 3.

To avoid excessive hemodilution during $\mathrm{CPB}$, the technique of retrograde autologous priming was retrospectively evaluated in patients undergoing elective CABG surgery (Chapter 4). It was hypothesized that retrograde autologous priming results in less hemodilution with subsequent reduction in transfusion requirements of packed red blood cells.

Another approach to restrict hemodilution is the use of a low-volume CPB circuit. However, limited venous return can result in severe fluctuations of venous line pressure that can result in gaseous emboli. Therefore, the influence of subatmospheric pressures and volume buffer capacity added to the venous line on the generation of gaseous microemboli were investigated, both in a clinical and in vitro setting (Chapter 5).

In Chapter 6 intraoperative events were recorded in order to qualify the effects on cerebral tissue oxygen saturation in patients undergoing cardiac surgery with pulsatile CPB.

Lastly, the general discussion (Chapter 7) is dedicated to the method and clinical application of cerebral autoregulation and cerebral $\mathrm{CO}_{2}$ reactivity during $\mathrm{CPB}$, as well as to the coherence of the above-mentioned studies. 


\section{REFERENCES}

1. Roach GW, Kanchuger M, Mora-Mangano C, et al. Adverse cerebral outcome after coronary bypass surgery. New Engl J Med 1996; 335:1857-1863.

2. Taylor RL, Borger MA, Weisel RD, et al. Cerebral microemboli during cardiopulmonary bypass: Increased emboli during perfusionist interventions. Ann Thorac Surg 1999; 68:89-93.

3. Taylor KM. Retinal microembolism during cardiopulmonary bypass demonstrated by fluorescin angiography. Lancet 1986; 2:837-839.

4. Fearn SJ, Pole R. Cerebral injury during cardiopulmonary bypass: emboli impair memory. J Thorac Cardiovasc Surg 2001; 121:1150-1160.

5. Ascione R, Ghosh A, Reeves BC, et al. Retinal and cerebral microembolization during coronary artery bypass surgery: a randomized, controlled trial. Circulation 2005; 112:3833-3838.

6. Lund C, Hol PK, Lundblad R, et al. Comparison of cerebral embolization during off-pump and on-pump coronary artery bypasses surgery. Ann Thorac Surg 2003; 76:765-770.

7. Pugsley W, Klinger L, Paschalis C, et al. The impact of microemboli during cardiopulmonary bypass on neuropsychological functioning. Stroke 1994; 25:1393-1399.

8. Prasongsukarn K. Reducing cerebral emboli during cardiopulmonary bypass. Semin Cardiothoracic Vasc Anesth 2005; 9:153-158.

9. Henriksen L. Brain luxury perfusion during cardiopulmonary bypass in humans. A study of the cerebral blood flow response to changes in $\mathrm{CO}_{2}, \mathrm{O}_{2}$ and blood pressure. J Cereb Blood Flow Metab 1986; 6:366-378.

10. Millar SM, Alston RP, Souter MJ, Andrews PJ. Cerebral hypoperfusion during and after cardiac surgery. Br J Anaesth 1999; 83:936-939.

11. Nevin M, Colchester AC, Adams S, Pepper JR. Evidence for involvement of hypocapnia and hypoperfusion in aetiology of neurological deficit after cardiopulmonary bypass. Lancet 1987; 44:725-729.

12. Levy JH, Tanaka KA. Inflammatory response to cardiopulmonary bypass. Ann Thorac Surg 2003; 75(Suppl):S715-S720.

13. Mathew JP, Mackensen GB, Phillips-Bute B, et al. Effects of extreme hemodilution during cardiac surgery on cognitive function in the elderly. Anesthesiology 2007; 107:577-584.

14. Lasen NA. Cerebral blood flow and oxygen consumption in man. Physiol Rev 1959; 39:183-238.

15. Paulson OB, Strandgaard S, Edvinson L. Cerebral autoregulation. Cerebrovasc Brain Metab Rev 1990; 2:161-92.

16. Lassen NA, Christensen MS. Physiology of cerebral blood flow. Br J Anaesth 1976; 48:719-734.

17. Steiner LA, Andrews PJ. Monitoring the injured brain: ICP and CBF. Br J Anaesth 2006; 97:2638.

18. Duschek S, Schandry R. Reduced brain perfusion and cognitive performance due to constitutional hypotension. Clin Auton Res 2007; 17:69-76.

19. Panerai RB, White RP, Markus HS, Evans DH. Grading of cerebral dynamic autoregulation from spontaneous fluctuations in arterial blood pressure. Stroke 1998; 29: 2341-2346.

20. Mokri B. The Monroe-Kellie hypothesis: applications in CSF volume depletion. Neurology 2001; 56:1746-1748.

21. Nemoto E, Bragin DE, Statom G, et al. Role of microvascular shunts in the loss of cerebral blood flow autoregulation. Adv Exp Med Biol 2014; 2812:43-49.

22. Murkin JM. The role of CPB management in neurobehavioral outcomes after cardiac surgery. Ann Thorac Surg 1995; 59:1308-1311. 
23. Harris DN, Bailey SM, Smith PL, Taylor KM, Oatridge A, Bydder GM. Brain swelling in first hour after coronary artery bypass surgery. Lancet 1993; 342:586-587.

24. Buhre W, Weyland A, Grüne F, et al. Influence of arterial carbon dioxide tension on systemic vascular resistance in patients undergoing cardiopulmonary bypass. Acta Anaesthesiol Scand 1998; 42:167-171.

25. Panico FG, Neptune WB. A mechanism to eliminate the donor blood prime from the pump oxygenator. Surg Forum 1959; 10:605-609.

26. Cooley DA, Beall AC, Grondin P. Open-heart operation with disposable oxygenators, 5 per cent dextrose, and normothermia. Surgery 1962; 52:713-719.

27. Tu YK, Liu HM. Effects of isovolemic hemodilution on hemodynamics, cerebral perfusion, and cerebral vascular reactivity. Stroke 1996; 27:441-445.

28. Hino A, Ueda S, Mizukawa N, Imahori $Y$ and Tenjin H. Effect of hemodilution on cerebral hemodynamics and oxygen metabolism. Stroke 1992; 23:423-426.

29. DeFoe GR, Ross CS, Olmstead EM, et al. Lowest hematocrit on bypass and adverse outcomes associated with coronary artery bypass grafting. Northern New England Cardiovascular Disease Study Group. Ann Thorac Surg 2001; 71:769-776.

30. Habib RH, Zacharias A, Schwann TA, et al. Adverse effect of low hematocrit during cardiopulmonary bypass in the adult: should current practice be changed? J Thorac Cardiovasc Surg 2003; 125:1438-1450.

31. Karkouti K, Beattie WS, Wijeysundera DN, et al. Hemodilution during cardiopulmonary bypass is an independent risk factor for acute renal failure in adult cardiac surgery. $J$ Thorac Cardiovasc Surg 2005; 129:391-400.

32. Ranucci M, Biagioli B, Scolletta S, et al. Lowest hematocrit on cardioplulmonary bypass impairs outcome in coronary surgery: an Italian Multicenter study from the national cardioanesthesia database. Tex Heart J 2006; 33:300-305.

33. Benedetto U, Angeloni E, Refice S, et al. Is minimized extracorporeal circulation effective to reduce the need for red blood cell transfusion in coronary artery bypass grafting? Metaanalysis of randomized controlled trial. J Thorac Cardiovasc Surg 2009; 138:1450-1453. 



\section{CHAPTER 2}

\section{ASSESSMENT OF DYNAMIC CEREBRAL AUTOREGULATION AND CEREBRAL CARBON DIOXIDE REACTIVITY DURING NORMOTHERMIC CARDIOPULMONARY BYPASS}

EE Ševerdija, ED Gommer, PW Weerwind, JP Reulen, WH Mess, JG Maessen.

Published in Med Biol Eng Comput 2015; 53:195-203. 


\section{Abstract}

Despite increased risk of neurological complications after cardiac surgery, monitoring of cerebral hemodynamics during cardiopulmonary bypass (CPB) is still not common practice. Therefore, a technique to evaluate dynamic cerebral autoregulation (dCA) and cerebral carbon dioxide reactivity $\left(\mathrm{CO}_{2} \mathrm{R}\right)$ during normothermic nonpulsatile $\mathrm{CPB}$ is presented. The technique uses continuous recording of invasive arterial blood pressure, middle cerebral artery blood flow velocity, absolute cerebral tissue oxygenation, in-line continuous arterial carbon dioxide levels, and pump flow measurement in 37 male patients undergoing elective CPB. Cerebral autoregulation is estimated by transfer function analysis and the autoregulatory index, based on the response to blood pressure variation induced by cyclic $6 / \mathrm{min}$ changes of indexed pump flow from 2.0 to 2.4 up to $2.8 \mathrm{~L} \mathrm{~min} / \mathrm{m}^{2}$. $\mathrm{CO}_{2} \mathrm{R}$ was calculated from recordings of both cerebral blood flow velocity and cerebral tissue oxygenation. Cerebral autoregulation and $\mathrm{CO}_{2} \mathrm{R}$ were estimated at hypocapnia, normocapnia, and hypercapnia. $\mathrm{CO}_{2} \mathrm{R}$ was preserved during $\mathrm{CPB}$, but significantly lower for hypocapnia compared to hypercapnia $(p<0.01)$. Conversely, cerebral autoregulation parameters such as gain, phase, and autoregulation index were significantly higher $(p<0.01)$ during hypocapnia compared with both normocapnia and hypercapnia. Assessing cerebral autoregulation and $\mathrm{CO}_{2} \mathrm{R}$ during $\mathrm{CPB}$, by cyclic alteration of pump flow, showed an impaired cerebral autoregulation during hypercapnia. 


\section{INTRODUCTION}

Dysfunction of cerebral autoregulation (CA) and impaired carbon dioxide reactivity $\left(\mathrm{CO}_{2} \mathrm{R}\right)$ before and during cardiopulmonary bypass (CPB) might contribute to neurological morbidity after cardiac surgery [20]. Despite this fact, evaluation of cerebral hemodynamics is not commonly practiced. Two of the most important factors influencing cerebral blood flow (CBF), i.e. arterial blood pressure (ABP) and arterial $\mathrm{CO}_{2}$ level $\left(\mathrm{p}_{2} \mathrm{CO}_{2}\right)$, are still not tightly controlled during $\mathrm{CPB}$. Currently, blood pressure management during $\mathrm{CPB}$ is based on maintaining a mean $\mathrm{ABP}$ of 50$60 \mathrm{mmHg}$ [21], and $\mathrm{p}_{\mathrm{C}} \mathrm{CO}_{2}$ is measured intermittently. However, there is no control for adequate functionality of $\mathrm{CA}$ and/or $\mathrm{CO}_{2} \mathrm{R}$.

In general, increasing $\mathrm{ABP}$ beyond $\mathrm{CA}$ range may cause hyperperfusion with edema formation [34], whereas reduction of CBF due to decreased ABP below the autoregulatory range may cause cerebral hypoperfusion and ischemia [27]. Moreover, mean $\mathrm{CBF}$ and mean $\mathrm{ABP}$ are not influenced by the $\mathrm{CPB}$ pump flow, provided that the mean $A B P$ is kept within the autoregulatory range [8]. However, a mean $\mathrm{ABP}$ below a sub-critical perfusion pressure induced by a fall in pump flow will proportionally decrease CBF. Likewise, an increase in pump flow with a resultant mean $A B P$ rising above the autoregulation upper limit may lead to hyperperfusion. Thus, individualizing $\mathrm{ABP}$ during $\mathrm{CPB}$ to be within a patient's $\mathrm{CA}$ range might prevent both cerebral hypoperfusion and cerebral edema.

Unfortunately, the autoregulation lower and upper limits are not known preoperatively. In addition, it is unethical to change $\mathrm{ABP}$ over such large ranges to determine the level of CBF regulation in patients. Consequently, dynamic cerebral autoregulation ( $\mathrm{dCA}$ ) should be determined during $\mathrm{CPB}$. Therefore, the present study describes a technique to evaluate $\mathrm{dCA}$ and $\mathrm{CO}_{2} \mathrm{R}$ during normothermic nonpulsatile $\mathrm{CPB}$. We hypothesize that $\mathrm{CA}$ is preserved during hypocapnia and normocapnia, whilst it is disturbed during hypercapnia.

\section{METHODS}

\section{Patients}

Thirty-seven adult male patients undergoing elective coronary artery bypass surgery using nonpulsatile normothermic $\mathrm{CPB}$ were investigated. Institutional review board approval was granted (NTR1723), and written informed consent was obtained from all subjects. Since the prevalence of inadequate temporal acoustic window is significantly higher in females than in males (12\% vs. 6\%) [18] and 
women have a stronger vasodilatory response to changes in $\mathrm{p}_{\mathrm{a}} \mathrm{CO}_{2}$ than men [11], female patients were not investigated. Exclusion criteria consisted of neurological disorders (e.g. cerebrovascular accident), renal diseases (e.g. renal failure, defined as laboratory tests indicating values of twice the normal values (urea $\geq 50 \mathrm{U} / \mathrm{L}$, creatinine $\geq 170 \mu \mathrm{mol} / \mathrm{L}$ ) or more], liver diseases (defined as laboratory tests indicating values of twice the normal values [ASAT $\geq 50 \mathrm{U} / \mathrm{L}, \mathrm{ALAT} \geq 60 \mathrm{U} / \mathrm{L}, \mathrm{LD} \geq 600 \mathrm{U} / \mathrm{L}, \gamma-$ GT $\geq 90 \mathrm{U} / \mathrm{L}$ ) or more], severe pulmonary disorders (e.g. chronic obstructive pulmonary disease, emphysema), insulin and non-insulin dependent diabetics, severe atherosclerosis of carotid or middle cerebral artery, and participation in an investigational drug trial within the preceding 30 days.

\section{Cardiopulmonary bypass}

General anesthesia was induced using weight-related dosing of sufentanil and etomidate, and muscle relaxation was achieved with pancuronium bromide. Anesthesia was maintained during surgery using propofol. An initial dose of heparin, $300 \mathrm{IU} / \mathrm{kg}$ of body weight (Leo Pharmaceutical Products, Ballerup ${ }^{\circledR}$, Denmark), was injected into a central venous catheter before initiation of CPB. When the target activated clotting time exceeded $400 \mathrm{~s}$, CPB was initiated by two perfusionists. At the end of $\mathrm{CPB}$, heparin was reversed by protamine chloride (Valeant Pharmaceuticals $^{\circledR}$, Eschborn, Germany) at a 1:1 ratio of the total loading dose before CPB. The centrifugal pump-based phosphorylcholine-coated CPB system (S5, Sorin Group Italia S.r.l., Mirandola, Italy) consisted of a $1.1 \mathrm{~m}^{2}$ hollow fiber oxygenator with 3/8" arterial and venous lines (ECC.O, Sorin Group Italia). Shed blood was processed using a cell-saving device (Dideco Electa, Sorin Group Italia).

\section{Measurements}

$\mathrm{ABP}$, cerebral blood flow velocity ( $\mathrm{CBFV}), \mathrm{p}_{\mathrm{a}} \mathrm{CO}_{2}$, absolute cerebral tissue oxygenation, and CPB pump flow were continuously recorded for assessment of dCA and $\mathrm{CO}_{2} \mathrm{R}$. ABP was recorded from an intra-arterial pressure module (Philips Medical, The Netherlands). Two transcranial Doppler (TCD, $2 \mathrm{MHz}$ ) probes were mounted on a head frame (ST3, Spencer Technologies, Seattle, USA) and recorded CBFV of left and right middle cerebral artery at a depth between 45 and $56 \mathrm{~mm}$. Continuous in-line arterial temperature, $\mathrm{paO}_{2}, \mathrm{p}_{\mathrm{a}} \mathrm{CO}_{2}, \mathrm{pH}$, and hematocrit were measured via an optical fluorescence and reflectance-based system (CDI-500, Terumo, Japan). Measurement started after both arterial bladder temperatures were confirmed to have stabilized, and all data are presented at $37^{\circ} \mathrm{C}$. Noninvasive absolute cerebral tissue oxygen saturation $\left(\mathrm{S}_{\mathrm{ct}} \mathrm{O}_{2}\right)$ was monitored continuously via near-infrared spectroscopy (ForeSight ${ }^{\circledR}$, Casmed, USA). A fiber optic sensor was positioned on each side on the patient's forehead, whereas pump flow was recorded by an ultrasonic flow 
monitor (Transonic Systems Europe BV ${ }^{\circledR}$, Maastricht, the Netherlands). All data were sampled at $250 \mathrm{~Hz}$ and stored using a 16-channel acquisition system (IDEEQ, Maastricht Instruments ${ }^{\circledR}$, Maastricht, the Netherlands) and were subsequently down sampled to $5 \mathrm{~Hz}$ by averaging over $0.2 \mathrm{~s}$ intervals. $\mathrm{PaCO}_{2}$ was maintained at $30 \mathrm{mmHg}(4.0 \mathrm{kPa}), 40 \mathrm{mmHg}(5.3 \mathrm{kPa})$, and $50 \mathrm{mmHg}(6.6 \mathrm{kPa})$ by titrating sweep gas flows.

All measurements were performed during aortic cross clamping, and after cardioplegia. $\mathrm{FiO}_{2}$ was adjusted to keep $\mathrm{p}_{\mathrm{a}} \mathrm{O}_{2}$ between 98 and $150 \mathrm{mmHg}(13-20 \mathrm{kPa})$, and mean $\mathrm{ABP}$ was maintained in the range of preoperative baseline values using infusion of phenylephrine when necessary. First, $\mathrm{paCO}_{2}$ was set to a hypocapnic level of $30 \mathrm{mmHg}$, and after being stable for 2-3 min mean, CBFV was determined by averaging CBFV over $10 \mathrm{~s}$. Thereafter, $5 \mathrm{~min}$ of cyclic changes of indexed pump flow were induced manually (metronome triggered) to each of the three pump flow levels $\left(2.0,2.4,2.8 \mathrm{~L} / \mathrm{min} / \mathrm{m}^{2}\right)$, indicating the $6 / \mathrm{min}$ rhythm. Subsequently, $\mathrm{p}_{\mathrm{a}} \mathrm{CO}_{2}$ was set to a normocapnic level of $40 \mathrm{mmHg}$ and to a hypercapnic level of $50 \mathrm{mmHg}$, respectively. At each level of $\mathrm{p}_{\mathrm{a}} \mathrm{CO}_{2}$, the first $10 \mathrm{~s}$ of steady flow was used to determine baseline mean CBFV followed by 5 min of cyclic changes of pump flow. The mean CBFV data acquired at each of the three levels of $\mathrm{p}_{\mathrm{C}} \mathrm{CO}_{2}$ were used to calculate $\mathrm{CO}_{2} \mathrm{R}$.

Quantification of dCA was performed by analyzing ABP oscillations as input and $\mathrm{CBFV}$ as output signal in the frequency domain using transfer function analysis, as described by Panerai et al. [24]. Furthermore, dCA was also evaluated by assessing the cerebral autoregulation index (ARI) [33]. The $\mathrm{CO}_{2} \mathrm{R}$ was assessed using TCD and near-infrared spectroscopy. Normal TCD $\mathrm{CO}_{2} \mathrm{R}$ is estimated to be $2-3 \%$ decrease in $\mathrm{CBF}$ per $\mathrm{mmHg}$ decrease in $\mathrm{p}_{\mathrm{a}} \mathrm{CO}_{2}$ and between $3 \%$ and $4 \%$ increase per $\mathrm{mmHg}$ increase in $\mathrm{p}_{\mathrm{C}} \mathrm{CO}_{2}$, as described elsewhere [7].

\section{Data analysis}

After recording and downsampling of the data, transfer function yielding coherence, gain, and phase shift angle between oscillation in CBFV and ABP was calculated, as described by Gommer et al. [12]. In short, the transfer function $H(f)$ was calculated by 


$$
H(F)=\frac{S_{x y}(f)}{S_{x x}(f)}
$$

where $S_{x x}(f)$ is the auto-spectrum of changes in $\mathrm{ABP}$, and $S_{x y}(f)$ is the cross-spectrum between the $\mathrm{ABP}$ and $\mathrm{CBFV}$ signals. Additionally, the power spectral densities (PSD) of $\mathrm{ABP}$ and CBFV were calculated. The transfer function magnitude $|H(f)|$ and phase spectrum $\Phi(f)$ were derived from the real part $H R(f)$ and imaginary part $H I(f)$ of the complex transfer function as

$$
\begin{aligned}
& |H(f)|=\sqrt{\left[H_{R}(f)\right]^{2}+\left[H_{I}(f)\right]^{2}} \\
& \Phi(f)=\arctan \frac{H_{I}(f)}{H_{R}(f)}
\end{aligned}
$$

The squared coherence function $\gamma^{2}(f)$ was estimated by

$$
\gamma^{2}(f)=\frac{\left|S_{x y}(f)\right|^{2}}{S_{x x}(f) S_{y y}(f)}
$$

where $S_{y y}(f)$ is the auto-spectrum of changes in CBFV.

The squared coherence reflects the strength of the linear relationship between ABP and CBFV for each frequency on a scale from 0 to 1 . Gain and phase were evaluated at $0.1 \mathrm{~Hz}$, because this equals the frequency induced by varying pump flow. The gain is the magnitude of the transfer function between CBFV and ABP and is expressed as \% change per mmHg. The phase lag between CBFV and ABP, as defined by phase angle shift (expressed in radians), is regarded to be the dominant and most relevant parameter to quantify dCA. Theoretically, phase may range from $-\pi$ to $+\pi$ radians. However, in awake supine resting position, a positive phase angle around $0.9 \pm 0.3 \mathrm{rad}$ indicates normal autoregulation in humans.

ARI was calculated by fitting the first $5 \mathrm{~s}$ of the step response function resulting from the transfer function analysis as described previously [12]. In short, a step response can be calculated from the estimated transfer function, which is based on a set of model parameters. Ten responses to an ABP step decrease were constructed 
as model output. The number of each of these ten responses ranging from 0 to 9 indicates the ARI. An ARI $<4$ represents impaired autoregulation, i.e. CBFV passively follows ABP, whilst an ARI above 6 denotes an overactive autoregulation. From the step response function resulting from this transfer function, the system's ARI can be determined using least squares estimation. For each of the ten ARI responses, the sum of squared differences with the TFA response is determined. A parabolic interpolation through these ten values can be performed to estimate the value of ARI to one decimal space [25] at the minimum of the parabola.

$\mathrm{CO}_{2} \mathrm{R}$ was evaluated by changing $\mathrm{p}_{\mathrm{a}} \mathrm{CO}_{2}$ and calculating the mean $\mathrm{S}_{\mathrm{ct}} \mathrm{O}_{2}$ and mean $\mathrm{CBFV}$ at each $\mathrm{p}_{2} \mathrm{CO}_{2}$ level. $\mathrm{CO}_{2} \mathrm{R}$ is expressed as the absolute change as well as the percentage change in $\mathrm{S}_{\mathrm{ct}} \mathrm{O}_{2}$ and $\mathrm{CBFV}$ per $\mathrm{mmHg}$ change in $\mathrm{p}_{\mathrm{a}} \mathrm{CO}_{2}$ using the following formulae [17]:

Absolute $\mathrm{CO}_{2} \mathrm{R}=\Delta S_{\mathrm{ct}} \mathrm{O}_{2} / \Delta \mathrm{p}_{\mathrm{a}} \mathrm{CO}_{2}$
Absolute $\mathrm{CO}_{2} \mathrm{R}=\Delta C B F V / \Delta p_{\mathrm{a}} \mathrm{CO}_{2}$
and

Relative $\mathrm{CO}_{2} \mathrm{R}=\left(\Delta \mathrm{S}_{\mathrm{ct}} \mathrm{O}_{2} / \Delta \mathrm{p}_{\mathrm{a}} \mathrm{CO}_{2} / \mathrm{S}_{\mathrm{ct}} \mathrm{O}_{2}\right.$ baseline $) \times 100$

Relative $\mathrm{CO}_{2} R=\left(\triangle \mathrm{CBFV} / \Delta p_{a} \mathrm{CO}_{2} / \mathrm{CBFV}_{\text {baseline }}\right) \times 100(8)$

where $\Delta \mathrm{S}_{\mathrm{ct}} \mathrm{O}_{2}$ and $\triangle \mathrm{CBFV}$ are the difference between cerebral tissue oxygen saturation and flow velocity after $\mathrm{p}_{\mathrm{a}} \mathrm{CO}_{2}$ increase or decrease, respectively. Baseline cerebral tissue oxygen saturation and flow velocity are measured at a $\mathrm{p}_{\mathrm{a}} \mathrm{CO}_{2}$ of 40 $\mathrm{mmHg}$, and $\Delta \mathrm{p}_{\mathrm{a}} \mathrm{CO}_{2}$ is the difference between final $\mathrm{p}_{\mathrm{a}} \mathrm{CO}_{2}$ and baseline $\mathrm{p}_{\mathrm{a}} \mathrm{CO}_{2}$.

\section{Statistics}

Statistical analysis was performed using the Statistical Package for Social Sciences version 16.0 (SPSS Inc., Chicago, IL, USA). Data normality was tested using the Kolmogorov-Smirnov test. If normally distributed, the paired Student's $t$ test with Bonferroni correction was used to compare results between different levels of $\mathrm{p}_{\mathrm{a}} \mathrm{CO}_{2}$, otherwise the Wilcoxon signed-rank test was used.

\section{Results}

The baseline demographics are presented in Table 1. Because of technical problems, the measurement at hypocapnia could not be performed in a single patient. All other measurements were recorded without problems. 
Table 1 Baseline demographics.

\begin{tabular}{ll}
\hline $\mathrm{N}=37$ & \\
\hline Age (years) & $61 \pm 6$ \\
Weight $(\mathrm{kg})$ & $86 \pm 11$ \\
Height $(\mathrm{cm})$ & $177 \pm 6$ \\
$\mathrm{BSA}\left(\mathrm{m}^{2}\right)$ & $2.0 \pm 0.2$ \\
$\mathrm{BMI}\left(\mathrm{kg} / \mathrm{cm}^{2}\right)$ & $27.9 \pm 4$ \\
Hematocrit $(\%)$ & $44 \pm 3$ \\
Mean $\mathrm{ABP}(\mathrm{mmHg})$ & $88 \pm 10$ \\
Mean $\mathrm{CBFV}$ left $(\mathrm{cm} / \mathrm{s})$ & $43 \pm 11$ \\
Mean $\mathrm{CBFV}$ right $(\mathrm{cm} / \mathrm{s})$ & $42 \pm 10$ \\
Mean $\mathrm{S}_{\mathrm{ct}} \mathrm{O}_{2}$ left $(\%)$ & $72 \pm 3$ \\
Mean $\mathrm{S}_{\mathrm{ct}} \mathrm{O}_{2}$ right $(\%)$ & $70 \pm 2$ \\
\hline
\end{tabular}

Values are shown as mean $\pm \mathrm{SD}$. $A B P$ arterial blood pressure, $B M I$ body mass index, BSA body surface area, $\mathrm{CBFV}$ cerebral blood flow velocity, $\mathrm{S}_{c t} \mathrm{O}_{2}$ cerebral tissue oxygen saturation.

The signals recorded during the induced changes in pump flow at normocapnia clearly represent the stepwise increase and decrease in indexed pump flow (Figure 1 , example in a single patient). ABP and CBFV vary with the same $6 / \mathrm{min}$ frequency. Based on these wave-shaped signals (ABP and CBFV), dCA was evaluated using transfer function analysis.

As shown in Table 2, the mean and inter-variation in ABP were not statistically significantly different between hypocapnia, normocapnia, and hypercapnia.

The mean hematocrit during $\mathrm{CPB}$ was $27 \pm 4 \%$. The power spectral density at $0.1 \mathrm{~Hz}$ is significantly higher for hypercapnia compared with both hypocapnia $(p<0.05)$ and normocapnia $(p<0.01)$. Additionally, when viewing the power spectral density for $\mathrm{ABP}$ and $\mathrm{CBFV}$ (Figure 2), it is clear that the ABP peak at $0.1 \mathrm{~Hz}$ increases with $\mathrm{p}_{\mathrm{a}} \mathrm{CO}_{2}$, which is not true for the CBFV peak. 

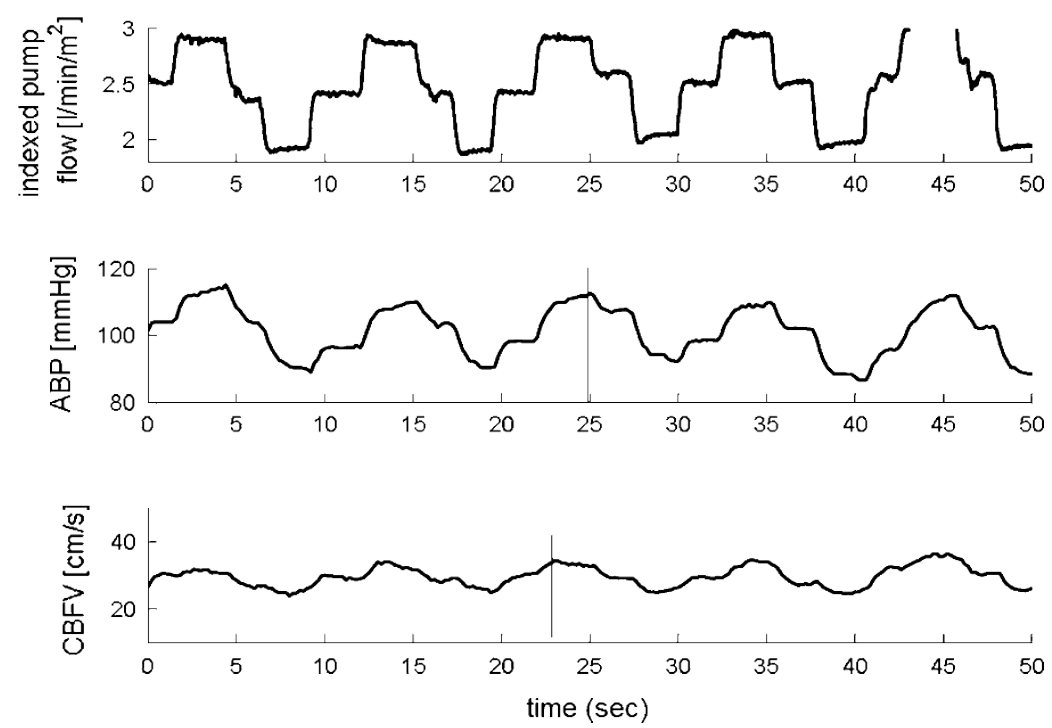

Figure 1 Effect of cyclic pump flow changes (upper panel) on arterial blood pressure (ABP, middle panel) and cerebral blood flow velocity (CBFV) in de middle cerebral arteries (lower panel) in a single patient undergoing cardiopulmonary bypass.
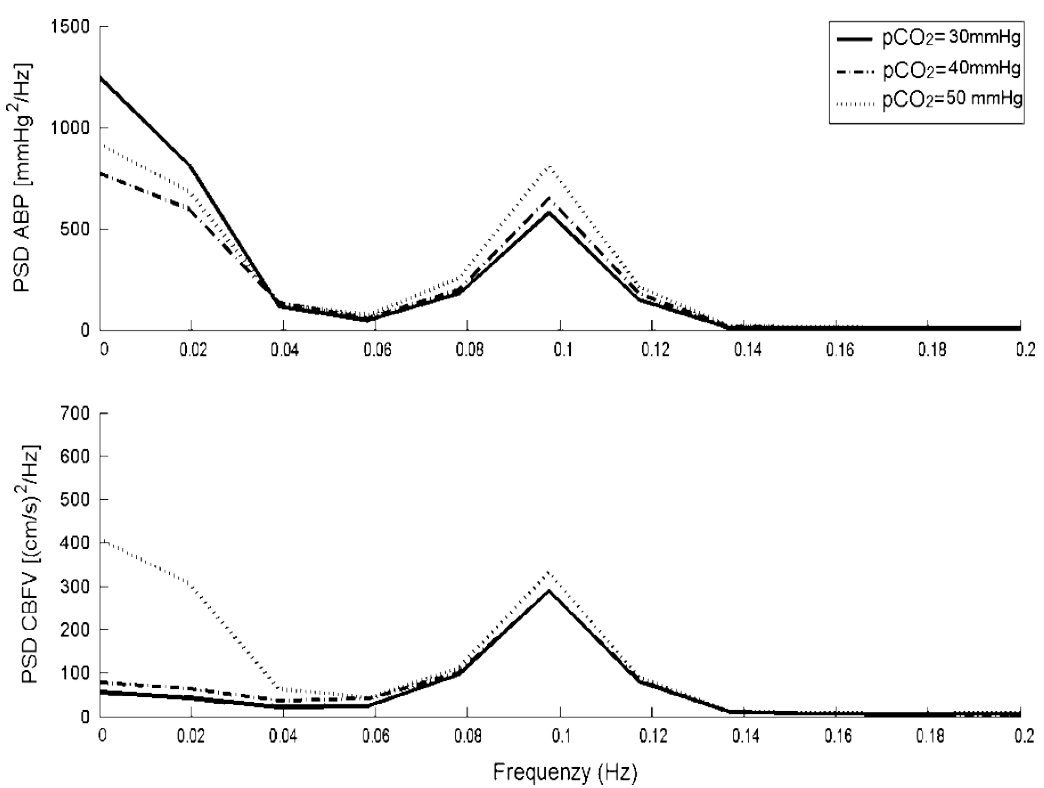

Figure 2 Group-averaged power spectral densities of arterial blood pressure (PSD ABP) and cerebral blood flow velocity (PSD CBFV) during cardiopulmonary bypass at three different $\mathrm{p}_{\mathrm{a}} \mathrm{CO}_{2}$. 
Table 2 Cerebral autoregulation parameters during cardiopulmonary bypass.

\begin{tabular}{|c|c|c|c|c|}
\hline & \multicolumn{3}{|l|}{$\mathrm{p}_{\mathrm{a}} \mathrm{CO}_{2}$} & \\
\hline & $\begin{array}{c}30 \mathrm{mmHg} \\
(4.0 \mathrm{kPa})\end{array}$ & $\begin{array}{c}40 \mathrm{mmHg} \\
(5.3 \mathrm{kPa})\end{array}$ & $\begin{array}{c}50 \mathrm{mmHg} \\
(6.6 \mathrm{kPa})\end{array}$ & \\
\hline & $\mathrm{N}=36$ & $\mathrm{~N}=37$ & $\mathrm{~N}=37$ & \\
\hline Mean ABP (mmHg) & $76 \pm 11$ & $80 \pm 11$ & $80 \pm 10$ & \\
\hline Inter-ABP variance $(\mathrm{mmHg})$ & $7 \pm 3$ & $7 \pm 3$ & $7 \pm 3$ & \\
\hline PSD ABP at $0.1 \mathrm{~Hz}\left(\mathrm{mmHg}^{2} / \mathrm{Hz}\right) \times 1,000$ & $0.6 \pm 0.4$ & $0.7 \pm 0.4$ & $0.8 \pm 0.5$ & $b^{*} c^{* *}$ \\
\hline Mean CBFV left $(\mathrm{cm} / \mathrm{s})$ & $25 \pm 11$ & $33 \pm 12$ & $48 \pm 17$ & $a^{* *} b^{* *} c^{* *}$ \\
\hline Inter-CBFV variance left $(\mathrm{cm} / \mathrm{s})$ & $4 \pm 1$ & $4 \pm 1$ & $5 \pm 3$ & $b^{* *} c^{*}$ \\
\hline PSD CBFV left at $0.1 \mathrm{~Hz}\left[(\mathrm{~cm} / \mathrm{s})^{2} / \mathrm{Hz}\right] \times 1,000$ & $0.3 \pm 0.2$ & $0.3 \pm 0.2$ & $0.3 \pm 0.3$ & \\
\hline Mean CBFV right $(\mathrm{cm} / \mathrm{s})$ & $24 \pm 8$ & $32 \pm 11$ & $46 \pm 16$ & $a^{* *} b^{* *} c^{* *}$ \\
\hline Inter-CBFV variance right $(\mathrm{cm} / \mathrm{s})$ & $3 \pm 1$ & $4 \pm 2$ & $5 \pm 2$ & $b^{* *} c^{*}$ \\
\hline PSD CBFV right at $0.1 \mathrm{~Hz}\left[(\mathrm{~cm} / \mathrm{s})^{2} / \mathrm{Hz}\right] \times 1,000$ & $0.3 \pm 0.2$ & $0.3 \pm 0.3$ & $0.4 \pm 0.3$ & \\
\hline $\mathrm{CO}_{2}$ reactivity $\mathrm{TCD}(\% / \mathrm{mmHg})$ & $3 \pm 1$ & & $5 \pm 2$ & $b^{* *}$ \\
\hline $\mathrm{S}_{\mathrm{ct}} \mathrm{O}_{2} \mathrm{NIRS}(\%)$ & $64 \pm 4$ & $66 \pm 4$ & $70 \pm 3$ & $a^{* *} b^{* *} c^{* *}$ \\
\hline $\mathrm{CO}_{2}$ reactivity NIRS $(\% / \mathrm{mmHg})$ & $0.3 \pm 0.3$ & & $0.5 \pm 0.3$ & $a^{*} c^{*}$ \\
\hline Coherence at $0.1 \mathrm{~Hz}$ & $0.90 \pm 0.10$ & $0.91 \pm 0.09$ & $0.95 \pm 0.06$ & $b^{*} c^{*}$ \\
\hline Gain at $0.1 \mathrm{~Hz}(\% / \mathrm{mmHg})$ & $3.4 \pm 2.0$ & $2.2 \pm 0.9$ & $1.4 \pm 0.4$ & $a^{* *} b^{* *} c^{* *}$ \\
\hline Phase at $0.1 \mathrm{~Hz}(\mathrm{rad})$ & $0.6 \pm 0.3$ & $0.3 \pm 0.2$ & $0.1 \pm 0.1$ & $a^{* *} b^{* *} c^{* *}$ \\
\hline ARI & $6 \pm 1$ & $5 \pm 1$ & $3 \pm 2$ & $a^{* *} b^{* *} c^{* *}$ \\
\hline
\end{tabular}

Values are shown as mean $\pm \mathrm{SD}$. $A B P$ arterial blood pressure, $A R I$ autoregulatory index, $C B F V$ cerebral blood flow velocity, NIRS near-infrared spectroscopy, PSD power spectral density, TCD transcranial Doppler. The letters a, b, and c represent a comparison between 30 versus $40 \mathrm{mmHg}, 30$ versus $50 \mathrm{mmHg}$, and 40 versus $50 \mathrm{mmHg}$, respectively ${ }^{*} p<0.05$; ${ }^{* *} p<0.01$.

Since no significant differences were found between left and right middle cerebral artery blood flow velocities, only left and right averaged results are presented for $\mathrm{CO}_{2} \mathrm{R}$ and $\mathrm{dCA}$. The mean CBFV of the middle cerebral artery is significantly lower $(p<0.01)$ during hypocapnia compared with both normocapnia and hypercapnia, whilst ABP was not significantly different. No significant differences were found for CBFV power spectral density at $0.1 \mathrm{~Hz}$. Coherence is significantly higher $(p<0.05)$ for hypercapnia compared with both hypocapnia and normocapnia. The dCA parameters such as gain, phase, and ARI are significantly higher $(p<0.01)$ for hypocapnia compared with both normocapnia and hypercapnia. Moreover, normocapnia values are significantly higher $(p<0.01)$ than hypercapnia values as shown in Figure 3. 

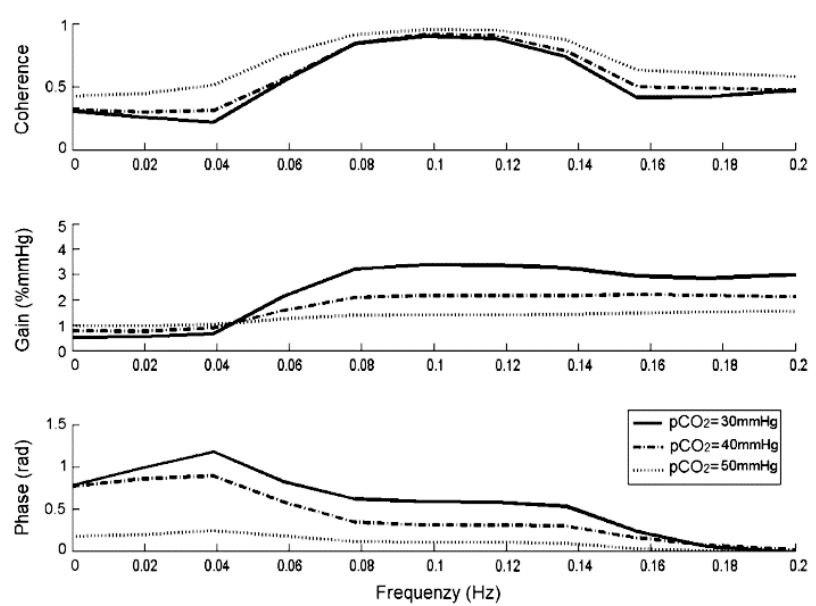

Figure 3 Group-averaged transfer function analysis showing averaged coherence (upper panel), gain (middle panel), and phase (lower panel) during cardiopulmonary bypass at three different $\mathrm{p}_{\mathrm{a}} \mathrm{CO}_{2}$ levels.

The group-averaged dCA step responses to a pressure drop for the three $\mathrm{p}_{\mathrm{a}} \mathrm{CO}_{2}$ levels are depicted in Figure 4.

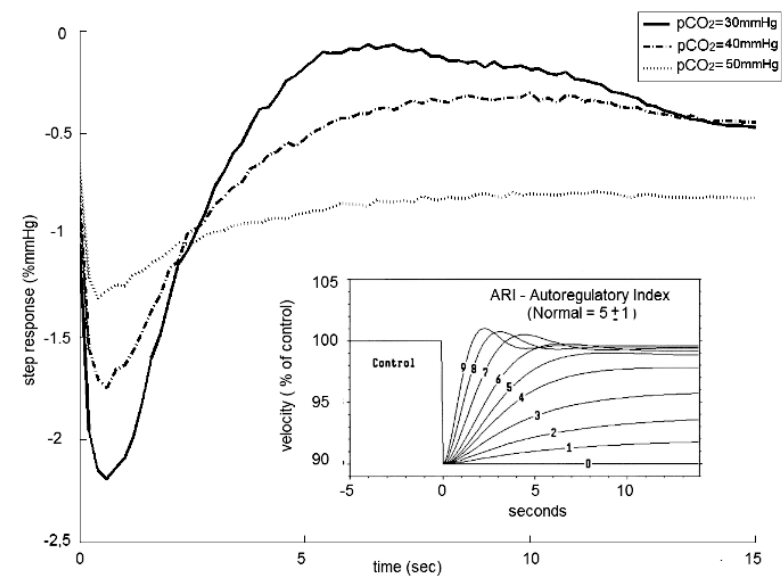

Figure 4 Group-averaged step responses during cardiopulmonary bypass at three different $\mathrm{p}_{\mathrm{a}} \mathrm{CO}_{2}$ levels.

The initial fall of the step response decreases from hypocapnia to normocapnia and hypercapnia, whereas the end level is lower for hypercapnia indicating impaired autoregulation $(\mathrm{ARI}<4)$. Similar to $\mathrm{TCD}$-based $\mathrm{CO}_{2} \mathrm{R}$, near-infrared spectroscopy based $\mathrm{CO}_{2} \mathrm{R}$ is also significantly higher $(p<0.05)$ for the hypercapnic situation $(0.5 \pm$ 
$0.3 \% / \mathrm{mmHg})$ compared with the hypocapnic condition situation $(0.3 \pm 0.3$ $\% / \mathrm{mmHg}$ ).

Figure 5 shows near-infrared spectroscopy $\mathrm{CO}_{2} \mathrm{R}$ measurements for a typical patient at three $\mathrm{p}_{\mathrm{a}} \mathrm{CO}_{2}$ levels, 30,40 , and $50 \mathrm{mmHg}$. It clearly shows that cerebral saturation increases with the increased $\mathrm{p}_{\mathrm{C}} \mathrm{CO}_{2}$ level.

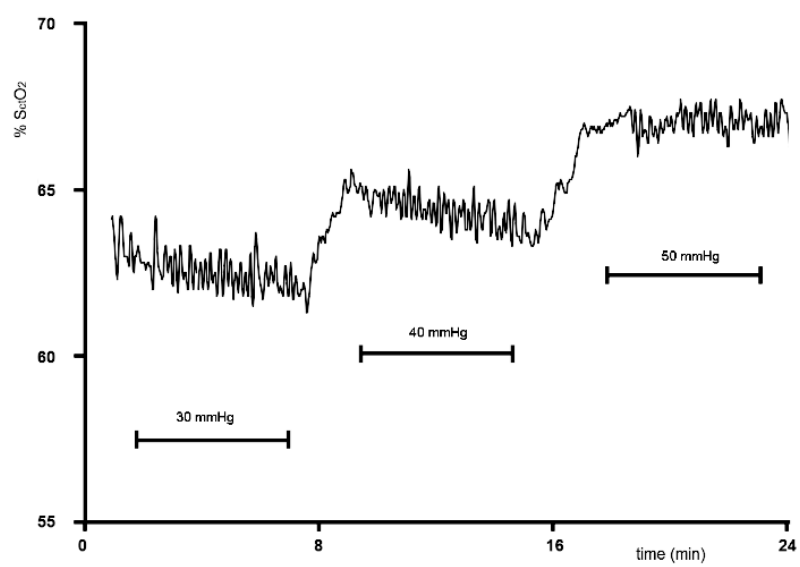

Figure 5 Example measurement of five-minute episodes of cerebral carbon dioxide reactivity testing by near-infrared spectroscopy $\left(\mathrm{S}_{\mathrm{c}} \mathrm{O}_{2}\right)$ at hypocapnia, normocapnia, and hypercapnia in a single patient.

\section{Discussion}

In this study, we demonstrated the feasibility to induce adequate $0.1 \mathrm{~Hz}$ sinusoidal $\mathrm{ABP}$ oscillations for $\mathrm{dCA}$ evaluation by changing $\mathrm{CPB}$ pump flow at 6 cycles $/ \mathrm{min}$. With this technique, consistent $\mathrm{ABP}$ oscillations with specific frequency and amplitude were generated allowing assessment of CBFV response.

Transfer function analysis examines the transfer of the ABP oscillations to CBFV as a measure of autoregulation by gain, phase shift, and coherence. It quantifies the extent to which the input signal (ABP) is related to the output signal (CBFV). To truly examine the cross-spectral relationship between two signals, one needs sufficient amplitude oscillations and significant coherence condition [14], at an optimal $0.1 \mathrm{~Hz}$ frequency of oscillation. However, during nonpulsatile CPB as we applied using a centrifugal pump, hardly any variation in ABP occurred, making study of dCA impossible. Hence, cyclic $0.1 \mathrm{~Hz}$ changes in pump flow induced blood pressure variability. The choice of using $0.1 \mathrm{~Hz}$ is based on studies by Diehl et al. [9,10], who showed that there is a frequency-dependent phase shift between ABP and 
CBFV which approaches a positive value between 0.87 and 1.23 rad. Further, increasing frequency negates this effect. Stepwise changes in pump flow by repetitively switching between three pump flow levels resulted in a staircase-shaped pump flow pattern. Due to compliance of the arterial vascular bed, a smooth almost sinusoidal variation was induced in both the ABP and CBFV curve. The resemblance of ABP and CBFV signals to 'pure' sine waves was confirmed by their power spectral densities, which showed a clear peak at $0.1 \mathrm{~Hz}$ and an almost hundredfold lower peak at the third harmonic at $0.3 \mathrm{~Hz}$. The width of the peak at $0.1 \mathrm{~Hz}$ is partly due to the three-point triangular spectral smoothing that was applied [13]. Since the evoked flow changes were square wave shaped, only odd harmonics (3rd, 5th, etc.) can be expected. In brief, for reliable transfer function dCA analysis, the induced 0.1 $\mathrm{Hz}$ variations in $\mathrm{ABP}$ and $\mathrm{CBFV}$ were well suited as illustrated in Figure 3.

Instead of determining the static lower and upper limits of CA, dCA quantifies the response of $\mathrm{CBF}$ to transient and/or periodic changes in ABP. Brady et al. [5] evaluated CBF autoregulation continuously during CPB using TCD and calculating the cross-correlation $(\mathrm{Mx})$ between slow $(f<0.05 \mathrm{~Hz})$ waves of middle cerebral artery blood flow velocity and mean ABP. Similarly, the near-infrared spectroscopy recorded cerebral oximetry index (COx) was calculated for slow waves of cerebral oximetry and ABP. They showed high values of $\mathrm{Mx}$ and cerebral oximetry index during $\mathrm{CPB}$, suggesting impaired cerebral autoregulation. However, they did not mention whether sufficient ABP variability occurred during CPB in order to be able to reliably calculate signal cross-correlation. This is an important point, since a patient on $\mathrm{CPB}$ using continuous flow with a centrifugal pump shows no spontaneous $\mathrm{ABP}$ variability when the aorta is cross-clamped. Furthermore, $\mathrm{Mx}$ is an intermediate indicator of static CA and dCA, since the phase relationship in the autoregulatory response is not taken into account [1]. In addition to $\mathrm{Mx}$, we are not aware of any other method evaluating dCA during $\mathrm{CPB}$.

Nicolet et al. [22] hypothesized that CPB provokes a highly protective mechanism, thereby reducing $\mathrm{CBF}$ fluctuations by deactivation of so-called $\mathrm{B}$ waves $(70 \mathrm{mHz})$ revealing monotonous so-called UB waves $(9 \mathrm{mHz})$. However, they found no significant coherence between $\mathrm{ABP}$ and $\mathrm{CBFV}$ during $\mathrm{CPB}$, possibly due to different dominant frequencies occurring in $\mathrm{ABP}(9 \mathrm{mHz})$ and $\mathrm{CBFV}(70 \mathrm{mHz})$. Conversely, the $0.1 \mathrm{~Hz}$ we used induced very high $(\geq 0.9)$ coherence between $\mathrm{ABP}$ and CBFV, reflecting a strong linear relation between variability in $\mathrm{ABP}$ and $\mathrm{CBFV}$. The sinusoidal oscillations of $\mathrm{ABP}$ and $\mathrm{CBFV}$ signals also allow visual appreciation of phase shift between $\mathrm{ABP}$ and $\mathrm{CBFV}$. Figure 1 shows a positive phase shift since CBFV waves are occurring earlier than $\mathrm{ABP}$ waves as indicated by the vertical lines. Though, the actual value of this phase shift is hard to estimate due to the variation 
in individual wave shapes, which can reliably be estimated through transfer function analysis.

In addition to the observed findings, reduced phase during CPB may be partly influenced by anesthetics other than propofol [30,32]. Furthermore, Ogawa et al. [23] showed impaired dCA due to hypervolemic hemodilution with increased gain after infusion of $15-30 \mathrm{~mL}$ saline/ $\mathrm{kg}$ with a mean hematocrit of $43 \%$. The dCA phase showed a trend towards lower values with increasing hemodilution, but did not reach statistical significance. Hemodilution during $\mathrm{CPB}$, therefore, seems to be a plausible explanation for the reduced dCA capability, since the hematocrit of $27 \%$ was much lower in our study group.

Studying multiple coherence showed that apart from changes in ABP, other causes for $\mathrm{CBFV}$ variations also exist, like changes in $\mathrm{p}_{\mathrm{a}} \mathrm{CO}_{2}$ and/or sympathetic tone $[25,29] . \mathrm{CO}_{2}$ is a potent cerebral vasodilator, which influences $\mathrm{CBF}$ and thereby the dCA. In our study, gain decreased with increasing $\mathrm{p}_{\mathrm{a}} \mathrm{CO}_{2}$, not only at $0.1 \mathrm{~Hz}$, but also at higher frequencies. In an earlier study with conscious lacunar infarct patients, gain decreased after acetazolamide infusion [13]. Since acetazolamide is an anhydrase inhibitor, it has a similar effect as hypercapnia [31]; however, other studies did not elaborate on dCA gain values [4] or the effect of arterial $\mathrm{CO}_{2}$ changes $[3,35]$. Furthermore, the studies were underpowered $(n=10-14)$. An explanation for our finding of decreased gain with increased $\mathrm{p}_{\mathrm{a}} \mathrm{CO}_{2}$ might be due to increased vessel dilation causing less responsiveness to changes in pressure. The contradictory results for dCA gain seems not to be a very robust parameter of dCA, as Panerai [26] demonstrated using simulations with the Tieck's model [33].

For phase, the impairment of dCA with increasing $\mathrm{paCO}_{2}$ is much clearer. At $0.1 \mathrm{~Hz}$, phase angle clearly decreases with increasing $\mathrm{p}_{\mathrm{a}} \mathrm{CO}_{2}$, whereas at $0.2 \mathrm{~Hz}$, phase angle was close to zero for $\mathrm{p}_{\mathrm{C}} \mathrm{CO}_{2}$ levels. Moreover, the decrease in ARI with increasing $\mathrm{p}_{\mathrm{a}} \mathrm{CO}_{2}$ confirmed diminished dCA function. Similarly, other studies using a thigh cuff deflation method or transfer function analysis confirmed impairment of dCA with hypercapnia [2,3].

Assessing dynamic cerebral autoregulation, based on high coherence and worsened autoregulation during hypercapnia, demonstrated that the technique is feasible and permits dCA quantification during $\mathrm{CPB}$. In this way, testing of dCA may facilitate e.g. the effect of different perfusion strategies or the outcome of impaired dCA on post-surgery stroke incidence. Consistent with the effect of $\mathrm{p}_{\mathrm{a}} \mathrm{CO}_{2}$ on $\mathrm{CBFV}$ and cerebral tissue saturation, $\mathrm{CO}_{2} \mathrm{R}$ showed to be intact in the range between 30 and 50 $\mathrm{mmHg}$ during $\mathrm{CPB}$, although there is a clear $\mathrm{CO}_{2} \mathrm{R}$ difference for hypocapnia com- 
pared with hypercapnia. Other investigators showed an exponential relationship between end tidal $\mathrm{CO}_{2}$ and $\mathrm{CBFV}[16,19]$. Since arterial $\mathrm{pCO}_{2}$, which is strongly correlated to end tidal $\mathrm{CO}_{2}[6,28]$, was tightly controlled, the relationship between arterial $\mathrm{CO}_{2}$ and $\mathrm{CBFV}$ can also be considered to be exponential. This explains why $\mathrm{CO}_{2} \mathrm{R}$ for hypocapnia is lower compared with $\mathrm{CO}_{2} \mathrm{R}$ for hypercapnia.

In this study, only male patients were studied, limiting the scope of our findings. Additionally, we did not assess cognitive outcome in our patients to evaluate whether autoregulation performance during $\mathrm{CPB}$ correlates with cognitive outcome. With TCD, due to unknown blood vessel diameter, no absolute flow but instead blood flow velocity is measured. However, Huber et al. [15] showed via angiography that cerebral arteries with a diameter of at least $2.5 \mathrm{~mm}$ do not show changes in diameter with hypercapnia, hyperventilation, hypertonic glucose, and administration of papaverine. Therefore, the assumption of constant vessel diameter seems legitimate for this study.

\section{CONCLUSION}

Assessing $\mathrm{dCA}$ and cerebral $\mathrm{CO}_{2} \mathrm{R}$, by changing pump flow at a 6 cycles/min, showed an impaired CA during hypercapnia. Therefore, hypercapnia during normothermic CPB should be avoided.

\section{ACKNOWLEDGEMENTS}

The authors thank Prof. R.B. Panerai (University of Leicester, UK) and Dr. A.S. Sharma (Maastricht University Medical Centre and Cardiovascular Research Institute Maastricht - CARIM, Maastricht, the Netherlands) for their valuable contributions to the manuscript. 


\section{REFERENCES}

1. Aaslid R. Cerebral autoregulation and vasomotor reactivity. Front Neurol Neurosci 2006; 66:825832.

2. Aaslid R, Lindegaard KF, Sorteberg W, Nornes H. Cerebral autoregulation dynamics in humans. Stroke 1989; 20:45-52.

3. Ainslie PN, Celi L, Mc Grattan K, Peebles K, Ogoh S. Dynamic cerebral autoregulation and baroreflex sensitivity during modest and severe step changes in arterial $\mathrm{PCO}_{2}$. Brain Res 2008; 1230:115-124.

4. Birch AA, Dirnhuber MJ, Hartley-Davies R, Lannotti F, Neil-Dwyer G. Assessment of autoregulation by means of periodic changes in blood pressure. Stroke 1995; 26:834-837.

5. Brady K, Joshi B, Zweifel C, Smielewski P, Czosnyka M, Easley RB, Hogue CW Jr. Real-time continuous monitoring of cerebral blood flow autoregulation using near-infrared spectroscopy in patients undergoing cardiopulmonary bypass. Stroke 2010; 41:1951-1956.

6. Brothers RM, Ganio MS, Hubing KA, Hastings JL, Crandall CG. End-tidal carbon dioxide tension reflects arterial carbon dioxide tension in the heat-stressed human with and without simulated hemorrhage. Am J Physiol Regul Integr Comp Physiol 2011; 300:R978-R983.

7. Brugniaux JV, Hodges AN, Hanly PJ, Poulin MJ. Cerebrovascular responses to altitude. Respir Physiol Neurobiol 2007; 158:212-223.

8. Cook DJ, Proper JA, Orszulak TA, Daly RC, Oliver WC Jr. Effect of pump flow rate on cerebral blood flow during hypothermic cardiopulmonary bypass in adults. J Cardiothorac Vasc Anesth 1997; 11:415-419.

9. Diehl RR, Linden D, Lucke D, Berlit P. Phase relationship between cerebral blood flow velocity and blood pressure. A clinical test of autoregulation. Stroke 1995; 26:1801-1804.

10. Diehl RR, Linden D, Lucke D, Berlit P. Spontaneous blood pressure oscillations and cerebral autoregulation. Clin Auton Res 1998; 8:7-12.

11. Edgell $\mathrm{H}$, Robertson AD, Hughson RL. Hemodynamics and brain blood flow during posture change in younger women and postmenopausal women compared with age-matched men. $J$ Appl Physiol 2012; 112:1482-1493.

12. Gommer E, Shijaku E, Mess W, Reulen J. Dynamic cerebral autoregulation: different signal processing methods without influence on results and reproducibility. Med Biol Eng Comput 2010; 48:1243-1250.

13. Gommer ED, Staals J, van Oostenbrugge RJ, Lodder J, Mess WH, Reulen JPH. Dynamic cerebral autoregulation and cerebrovascular reactivity: a comparative study in lacunar infarct patients. Physiol Meas 2008; 29:1293-1303.

14. Hamner JW, Cohen MA, Mukai S, Lipsitz LA, Taylor JA. Spectral indices of human cerebral blood flow control: responses to augmented blood pressure oscillations. J Physiol 2004; 559:965973.

15. Huber P, Handa J.Effect of contrast material, hypercapnia, hyperventilation, hypertonic glucose and papaverine on the diameter of the cerebral arteries: angiographic determination in man. Invest Radiol 1967; 2:17-32.

16. Ide $\mathrm{K}$, Eliasziw M, Poulin MJ. Relationship between middle cerebral artery blood velocity and end-tidal $\mathrm{PCO}_{2}$ in the hypocapnic-hypercapnic range in humans. J Appl Physiol 2003; 95:129137.

17. Kadoi Y, Saito S, Goto F, Fujita N. The effect of diabetes on the interrelationship between jugular venous oxygen saturation responsiveness to phenylephrine infusion and cerebrovascular carbon dioxide reactivity. Anesth Analg 2004; 99:325-331. 
18. Marinoni M, Ginanneschi A, Forleo P, Amaducci L. Technical limits in transcranial doppler recording: inadequate acoustic windows. Ultrasound Med Biol 1997; 23:1275-1277.

19. Markwalder T-M, Grolimund P, Seiler RW, Roth F, Aaslid R. Dependency of blood flow velocity in the middle cerebral artery on end-tidal carbon dioxide partial pressure: a transcranial ultrasound Doppler study. J Cereb Blood Flow Metab 1984; 4:368-372.

20. Murkin JM. The role of CPB management in neurobehavioral outcomes after cardiac surgery. Ann Thorac Surg 1995; 59:1308-1311.

21. Murphy GS, Hessel EA II, Groom RC. Optimal perfusion during cardiopulmonary bypass: an evidence-based approach. Anest Analg 2009; 108:1394-1417.

22. Nicolet J, Gillard T, Gindre G, Cervenansky F, Duale C, Bazin JE, De Riberolles C, Schoeffler P, Lemaire JJ. Modifications of spontaneous cerebral blood flow oscillations during cardiopulmonary bypass. Acta Neurochir 2005; 95 (Suppl):337-339.

23. Ogawa Y, Iwasaki K, Aoki K, Shibata S, Kato J, Ogawa S. Central hypervolemia with hemodilution impairs dynamic cerebral autoregulation. Anesth Analg 2007; 105:1389-1396.

24. Panerai RB, Deverson ST, Mahony P, Hayes P, Evans DH. Effects of $\mathrm{CO}_{2}$ on dynamic cerebral autoregulation measurement. Physiol Meas 1999; 20:265-275.

25. Panerai RB, Eames PJ, Potter JF. Multiple coherence of cerebral blood flow velocity in humans. Am J Physiol Heart Circ Physiol 2006; 291:H251-H259.

26. Panerai RB. Cerebral autoregulation: from models to clinical applications. Cardiovasc Eng 2008; 8:42-59.

27. Paulson OB, Strandgaard S, Edvinsson L. Cerebral autoregulation. Cerebrovasc Brain Metab Rev 1990; 2:161-192.

28. Peebles K, Celi L, McGrattan K, Murrell C, Thomas K, Ainslie PN. Human cerebrovascular and ventilatory $\mathrm{CO}_{2}$ reactivity to end-tidal, arterial and internal jugular vein $\mathrm{PCO}_{2}$. J Physiol 2007; 584:347-357.

29. Peng T, Rowley A, Ainslie P, Poulin M, Payne S. Multivariate system identification for cerebral autoregulation. Ann Biomed Eng 2008; 36:308-320.

30. Petersen KD, Lamdsfeldt U, Cold GE, Petersen CB, Mau S, Hauerberg J, Holst P, SkovgaardOlsen $\mathrm{K}$. Intracranial pressure and cerebral hemodynamic in patients with cerebral tumors: a randomized prospective study of patients subjected to craniotomy in propofol-fentanyl, isoflurane-fentanyl, or sevoflurane-fentanyl anesthesia. Anesthesiology 2003; 98:329-336.

31. Sorteberg W, Lindegaard KF, Rootwelt K, Dahl A, NybergHansen R, Russell D, Nornes H. Effect of acetazolamide on cerebral artery blood velocity and regional cerebral blood flow in normal subjects. Acta Neurochir 1989; 97:139-145.

32. Strebel S, Lam AM, Matta B, Mayberg TS, Aaslid R, Newell DW. Dynamic and static cerebral autoregulation during isoflurane, desflurane, and propofol anesthesia. Anesthesiology 1995; 83:66-76.

33. Tiecks FP, Lam AM, Aaslid R, Newell DW. Comparison of static and dynamic cerebral autoregulation measurements. Stroke 1995; 26:1014-1019.

34. van Mook WNKA, Rennenberg RJMW, Schurink GW, van Oostenbrugge RJ, Mess WH, Hofman PAM, de Leeuw PW. Cerebral hyperperfusion syndrome. Lancet Neurol 2005; 4:877888.

35. Zhang R, Zuckerman JH, Giller CA, Levine BD. Transfer function analysis of dynamic cerebral autoregulation in humans. Am J Physiol 1998; 274:H233-H241. 



\section{CHAPTER 3}

\section{HEMODILUTION COMBINED WITH HYPERCAPNIA IMPAIRS CEREBRAL AUTOREGULATION DURING NORMOTHERMIC CARDIOPULMONARY BYPASS}

EE Ševerdija*, NP Vranken*, AP Simons, ED Gommer, JH Heijmans, JG Maessen, PW Weerwind.

Published in J Cardiothorac Vasc Anesth 2015; 29:1194-1199.

* These authors contributed equally to this study. 


\section{Abstract}

Objective: To investigate the influence of hemodilution and arterial $\mathrm{pCO}_{2}$ on cerebral autoregulation and cerebral vascular $\mathrm{CO}_{2}$ reactivity.

Design: Prospective interventional study.

Setting: University hospital-based single-center study.

Participants: Forty adult patients undergoing elective cardiac surgery using normothermic cardiopulmonary bypass.

Interventions: Blood pressure variations induced by $6 /$ minute metronome triggered breathing (baseline) and cyclic 6/min changes of indexed pump flow at three levels of arterial $\mathrm{pCO}_{2}$.

Measurements and Main results: Based on median hematocrit on bypass, patients were assigned to either a group of a hematocrit $\geq 28 \%$ or $<28 \%$. The autoregulation index was calculated from cerebral blood flow velocity and mean arterial blood pressure using transfer function analysis. Cerebral vascular $\mathrm{CO}_{2}$ reactivity was calculated using cerebral tissue oximetry data.

Cerebral autoregulation as reflected by autoregulation index (baseline 7.5) was significantly affected by arterial $\mathrm{pCO}_{2}$ (median autoregulation index amounted to $5.7,4.8$, and 2.8 for arterial $\mathrm{pCO}_{2}$ of respectively $4.0,5.3$, and $6.6 \mathrm{kPa}, \mathrm{p} \leq 0.002$ ). Hemodilution resulted in a decreased autoregulation index, however, during hypocapnia and normocapnia there were no significant differences between the two hematocrit groups. Moreover, during hypercapnia the autoregulation index further decreased when hematocrit was $<28 \%$ (autoregulation index 2.6 versus 3.3 for hematocrit $<28 \%$ and $\geq 28 \%$, respectively, $p=0.014$ ). Cerebral vascular $\mathrm{CO}_{2}$ reactivity during hypocapnia was significantly lower when perioperative hematocrit was $<28$ $(p=0.018)$.

Conclusions: Hemodilution down to a hematocrit of $<28 \%$ combined with hypercapnia negatively affects dynamic cerebral autoregulation, which underlines the importance of tight control of both hematocrit and $\mathrm{p}_{\mathrm{a}} \mathrm{CO}_{2}$ during $\mathrm{CPB}$. 


\section{INTRODUCTION}

Cardiopulmonary bypass (CPB) enables complex cardiac surgery. Neurologic complications, however, still remain a major concern and may be linked to altered brain perfusion [1]. Pre-existing impaired cerebral autoregulation and/or reduced vasomotor reactivity have been associated with adverse cognitive outcome and even risk of death [1,2]. Others found a clear relationship between perioperative stroke risk and nadir hematocrit values [3]. An interventional study by Mathew et al. on hemodilution with subsequent decreased levels of hematocrit during hypothermic $\mathrm{CPB}$ had to be preliminary terminated because of significant occurrence of adverse events [4]. Moreover, increased levels of arterial $\mathrm{CO}_{2}$ have shown to decrease cerebral autoregulation [5]. To the best of our knowledge, however, there is no literature available that combines cerebral autoregulation and/or cerebral vasomotor reactivity with both hematocrit level and arterial partial gas pressure of $\mathrm{CO}_{2}\left(\mathrm{p}_{\mathrm{a}} \mathrm{CO}_{2}\right)$.

The aim of this study was to investigate cerebral autoregulation and cerebral vascular reactivity, with respect to hemodilution and arterial $\mathrm{CO}_{2}$ levels during normothermic CPB.

\section{PATIENTS AND METHODS}

\section{Study population}

To study dynamic cerebral autoregulation and cerebral vascular reactivity for $\mathrm{CO}_{2}$, forty male patients scheduled for elective coronary bypass surgery were randomly included in this prospective study. Presence of an adequate temporal acoustic window was the main inclusion criterion, next to absence of neurologic, renal, liver, or severe pulmonary disorders, diabetes, and severe atherosclerosis of carotid and/or middle cerebral arteries. The study was approved by the medical ethical committee of the Maastricht University Medical Centre (Dutch trial registration: NTR1723). All patients gave written informed consent.

\section{Patient management and conduct of $C P B$}

General anaesthesia was induced using weight-related dosing of sufentanil and etomidate, and maintained using propofol, whereas pancuronium bromide was used for muscle relaxation. During normothermic non-pulsatile CPB using central cannulation, the centrifugal pump bypass flow rate was targeted at $2.41 / \mathrm{min}$ per $\mathrm{m}^{2}$ body surface area. Either a standard minimized extracorporeal circuit or a conventional extracorporeal circuit was used. Mean arterial blood pressure was kept near the preoperative baseline value (between $70 \mathrm{mmHg}$ and $90 \mathrm{mmHg}$ ) using phe- 
nylephrine titration via an infusion pump, if necessary. Arterial partial gas pressure of $\mathrm{O}_{2}$ was kept between 13 and $20 \mathrm{kPa}$ (98 and $150 \mathrm{mmHg}$ ). Cardiac arrest was induced using crystalloid cardioplegia (St. Thomas 1).

Data from radial arterial blood pressure (ABP), pump flow and cerebral blood flow velocity $(\mathrm{CBFV})$ were measured continuously using a patient monitoring system (Philips Healthcare, Eindhoven, the Netherlands), an ultrasonic flow monitor (Transonic Systems Inc., Ithaca, NY, USA) and a 2 MHz transcranial Doppler (ST3, Spencer Technologies, Seattle, WA, USA), respectively. Data signals of ABP, pump flow, and CBFV were collected and recorded using a data acquisition system (IDEEQ, Maastricht Instruments, Maastricht, the Netherlands). Cerebral tissue oxygen saturation $\left(\mathrm{S}_{\mathrm{c}} \mathrm{O}_{2}\right)$ was monitored continuously using near-infrared spectroscopy (ForeSight, Casmed, Branford, CT, USA). Hematocrit, $\mathrm{p}_{\mathrm{a}} \mathrm{CO}_{2}$ and $\mathrm{pH}$ were measured inline continuously (CDI500, Terumo, Tokyo, Japan).

\section{Dynamic assessment of cerebral autoregulation}

Cerebral autoregulation was assessed dynamically prior to administration of preoperative medication at the patient ward at rest (baseline) and in the operating theatre during CPB. At the ward, autoregulation was assessed analogue to Diehl et al. using metronome triggered 6/minute breathing to vary cardiac preload and resultant cardiac output while measuring ABP and CBFV [6]. The cerebral autoregulation index (ARI) was then estimated using the resulting step response function in $\mathrm{ABP}$ and $\mathrm{CBFV}[7,8]$. In the operating theatre during $\mathrm{CPB}$, autoregulation was assessed with the aorta cross-clamped and after cardioplegia administration. In contrast to the baseline measurement that used manipulations in cardiac output, during CPB the indexed pump flow was changed in a cyclic manner. Flow was varied from $2.01 / \mathrm{min} / \mathrm{m}^{2}$ to $2.41 / \mathrm{min} / \mathrm{m}^{2}$ and to $2.81 / \mathrm{min} / \mathrm{m}^{2}$, with a frequency of 6 cycles/min, $2.5 \mathrm{~s}$ per indexed flow rate, as described elsewhere [9]. ARI then was estimated using the recordings of pump flow, ABP and CBFV.

\section{Assessment of cerebral vascular reactivity}

Cerebral vascular reactivity for $\mathrm{CO}_{2}\left(\mathrm{CO}_{2} \mathrm{R}\right)$ was assessed using the recordings of $\mathrm{S}_{\mathrm{c}} \mathrm{O}_{2}$ and $\mathrm{p}_{\mathrm{a}} \mathrm{CO}_{2}$. The $\mathrm{p}_{\mathrm{a}} \mathrm{CO}_{2}$ was varied stepwise from $4.0 \mathrm{kPa}$ to $5.3 \mathrm{kPa}$ to $6.6 \mathrm{kPa}$. The induced hypocapnic and hypercapnic conditions lasted for approximately 5 minutes each. Subsequently, absolute cerebral $\mathrm{CO}_{2} \mathrm{R}\left(\mathrm{CO}_{2} \mathrm{Rabs}\right)$ and relative cerebral $\mathrm{CO}_{2} \mathrm{R}$ $\left(\mathrm{CO}_{2} \mathrm{R}_{\text {rel }}\right)$ were calculated for each change in $\mathrm{p}_{\mathrm{a}} \mathrm{CO}_{2}$ using the following formulae:

cerebral $\mathrm{CO}_{2} \mathrm{R}_{\mathrm{abs}}=\Delta \mathrm{S}_{\mathrm{ct}} \mathrm{O}_{2} / \Delta \mathrm{p}_{\mathrm{a}} \mathrm{CO}_{2}$

and

cerebral $\mathrm{CO}_{2} \mathrm{R}_{\text {rel }}=\left(\text { cerebral } \mathrm{CO}_{2} \mathrm{R}_{\mathrm{abs}} / \mathrm{S}_{\mathrm{ct}} \mathrm{O}_{2} ; 5.3 \mathrm{kPa}\right)^{*} 100 \%$ 
where $\Delta \mathrm{S}_{\mathrm{ct}} \mathrm{O}_{2}$ represents the difference in $\mathrm{S}_{\mathrm{ct}} \mathrm{O}_{2}$ measured before and after an alteration of $\mathrm{p}_{\mathrm{a}} \mathrm{CO}_{2}$, during $\mathrm{CPB} . \Delta \mathrm{p}_{\mathrm{a}} \mathrm{CO}_{2}$ represents the difference in $\mathrm{p}_{\mathrm{a}} \mathrm{CO}_{2}$. $\mathrm{S}_{\mathrm{ct}} \mathrm{O}_{2} ; 5.3 \mathrm{kPa}$ represents $\mathrm{S}_{\mathrm{c}} \mathrm{O}_{2}$ measured at a $\mathrm{p}_{\mathrm{a}} \mathrm{CO}_{2}$ of $5.3 \mathrm{kPa}$.

\section{Data processing and statistical analysis}

Depending on the on-bypass hematocrit level after induction of cardiac arrest, patients were assigned to a group with a hematocrit value during CPB $\geq 28 \%$ (high hematocrit group) or $<28 \%$ (low hematocrit group), with $28 \%$ corresponding to the median hematocrit value. For data of $\mathrm{CBFV}, \mathrm{ARI}$ and SctO2 an average values of the left and right cerebral hemisphere were calculated and used for statistical analysis. Data distribution was assessed by performing the Shapiro-Wilk test and visual assessment of histograms. Depending on data distribution, numerical parameters are depicted either in mean and standard deviation or median and interquartile range. Values for $\mathrm{CBFV}, \mathrm{ARI}$ and $\mathrm{S}_{\mathrm{c}} \mathrm{O}_{2}$ acquired from both left and right hemispheres were averaged. The independent samples Mann-Whitney U test was used for comparison of numerical variables between the two groups of hematocrit. Cerebral autoregulation was tested between different levels of $\mathrm{p}_{\mathrm{a}} \mathrm{CO}_{2}$ by the related samples Friedman's two-way analysis of variance by ranks. If significant, the related-samples Wilcoxon signed rank test was used as a post-hoc test. Cerebral autoregulation was tested between the two levels of hematocrit for each level of $\mathrm{p}_{\mathrm{a}} \mathrm{CO}_{2}$ by using the independent samples Mann-Whitney $U$ test. A $p$-value $<0.05$ was considered statistically significant for all tests.

\section{Results}

Patient demographics and preoperative data for all patients and according to perioperative hematocrit level are shown in Table 1. Analysis revealed no significant difference between the high and low hematocrit group except for preoperative hematocrit $(p=0.002)$. 
Table 1 Patient demographics and preoperative data, specified for all $(\mathrm{N}=40)$ and intraoperative hematocrit group.

\begin{tabular}{llll}
\hline & $\mathrm{N}=40$ & $\mathbf{2 2 8} \%(\mathrm{~N}=21)$ & $<\mathbf{2 8 \%}(\mathrm{N}=19)$ \\
\hline age (years) & $60.1[55.8-68.6]$ & $58.9[55.4-68.6]$ & $61.2[56.4-68.7]$ \\
BSA $\left(\mathrm{m}^{2}\right)$ & $2.1[1.9-2.2]$ & $2.1[1.9-2.2]$ & $2.0[1.8-2.1]$ \\
preoperative hematocrit $(\%)$ & $44.0[42.3-46.0]$ & $46.0[43.0-47.0]$ & $43.0[40.8-44.3]$ \\
$\mathrm{ABP}(\mathrm{mmHg})$ & $86.0[78.9-97.0]$ & $86.0[79.3-98.7]$ & $85.7[78.1-95.7]$ \\
$\mathrm{ScO}_{2}(\%)$ & $71.9[70.0-73.9]$ & $72.0[70.4-74.7]$ & $71.0[68.8-72.3]$ \\
$\mathrm{CBFV}(\mathrm{m} / \mathrm{s})$ & $40.3[34.5-47.6]$ & $39.3[34.4-47.7]$ & $41.8[36.5-49.7]$ \\
$\mathrm{ARI}$ & $7.5[7.0-8.0]$ & $7.4[6.5-8.0]$ & $7.5[7.1-8.0]$ \\
\hline
\end{tabular}

Data presented as median [interquartile range]. BSA, body surface area; ABP, arterial blood pressure; $\mathrm{S}_{\mathrm{ct}} \mathrm{O}_{2}$, cerebral tissue oximetry; $\mathrm{CBFV}$, cerebral blood flow velocity; $\mathrm{ARI}$, autoregulation index.

Table 2 shows CPB time, aortic cross clamp time, difference in perioperative hematocrit, and the effect of hematocrit on cerebral $\mathrm{CO}_{2} \mathrm{R}$. Hematocrit during hypercapnia affected neither absolute nor relative cerebral $\mathrm{CO}_{2} \mathrm{R}$. During hypocapnia, in contrast, hematocrit revealed to have a significant effect on cerebral $\mathrm{CO}_{2} \mathrm{R}$ (cerebral $\mathrm{CO}_{2} \mathrm{R}_{\text {abs, hypo }}$ and $\mathrm{CO}_{2} \mathrm{R}_{\text {rel, hypo, }} p=0.018$ for both).

Comparing cerebral autoregulation at the three levels of $\mathrm{p}_{\mathrm{a}} \mathrm{CO}_{2}$ for all 40 patients, regardless of hematocrit, showed autoregulation to be significantly affected by $\mathrm{p}_{\mathrm{aCO}}$ level $(p \leq 0.002)$; for $\mathrm{p}_{\mathrm{a}} \mathrm{CO}_{2}=4.0,5.3$, and $6.6 \mathrm{kPa}$, the ARI amounted 5.7 [4.8-6.4], 4.8 [4.0-5.7], and 2.8 [2.3-3.8], respectively. Analysing differences in cerebral autoregulation between the two hematocrit levels for all 40 patients showed no differences at $\mathrm{p}_{\mathrm{a}} \mathrm{CO}_{2}$ levels 4.0 and $5.3 \mathrm{kPa}$. At a $\mathrm{p}_{\mathrm{a}} \mathrm{CO}_{2}$ of $6.6 \mathrm{kPa}$, cerebral autoregulation index (ARI) was significantly different (3.3 [2.5-4.2] for the higher hematocrit group and 2.6 [1.6-3.7] for the lower hematocrit group, $p=0.014)$. 
Table 2 Perioperative data and cerebral vascular reactivity for $\mathrm{CO}_{2}$ for the high and low hematocrit group.

\begin{tabular}{|c|c|c|c|}
\hline & $\geq \mathbf{2 8} \%(\mathrm{~N}=21)$ & $<28 \%(\mathrm{~N}=19)$ & $\mathrm{p}$-value \\
\hline $\mathrm{CPB}$ time (min) & $71.0[58.5-82.5]$ & $82.0[62.0-93.0]$ & 0.231 \\
\hline aortic cross clamp time (min) & $49.0[41.0-58.5]$ & $47.0[38.0-66.0]$ & 0.585 \\
\hline perioperative hematocrit (\%) & $30.0[28.5-31.0]$ & $23.0[22.0-25.0]$ & $<0.001$ \\
\hline cerebral $\mathrm{CO}_{2} \mathrm{R}_{\text {abs,hypo }}\left(\% \mathrm{~S}_{\mathrm{ct}} \mathrm{O}_{2} / \mathrm{kPa}\right)$ & $1.5[1.2-2.3]$ & $0.8[0.4-1.9]$ & 0.018 \\
\hline cerebral $\mathrm{CO}_{2}$ Rabs,hyper $\left(\% \mathrm{~S}_{\mathrm{ct}} \mathrm{O}_{2} / \mathrm{kPa}\right)$ & $2.3[1.7-3.5]$ & $2.7[1.9-3.1]$ & 0.856 \\
\hline cerebral $\mathrm{CO}_{2} \mathrm{R}_{\text {rel, hypo }}\left(\% \mathrm{~S}_{\mathrm{ct}} \mathrm{O}_{2} / \mathrm{kPa}\right)$ & $2.3[1.7-3.3]$ & $1.2[0.6-3.1]$ & 0.018 \\
\hline cerebral $\mathrm{CO}_{2} \mathrm{R}_{\text {rel, hyper }}\left(\% \mathrm{~S}_{\mathrm{ct}} \mathrm{O}_{2} / \mathrm{kPa}\right)$ & $3.6[2.4-5.4]$ & $4.1[2.9-4.7]$ & 0.705 \\
\hline
\end{tabular}

Data presented as median [interquartile range]. $\mathrm{S}_{\mathrm{ct}} \mathrm{O}_{2}$, cerebral tissue oximetry; $\mathrm{CPB}$,

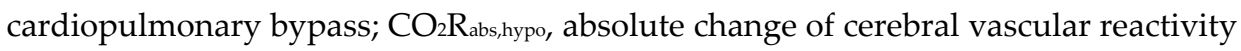

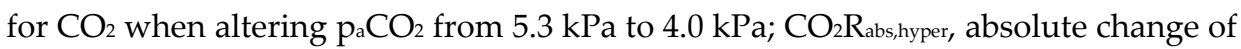
cerebral vascular reactivity for $\mathrm{CO}_{2}$ when altering $\mathrm{p}_{\mathrm{C}} \mathrm{CO}_{2}$ from $5.3 \mathrm{kPa}$ to $6.6 \mathrm{kPa}$;

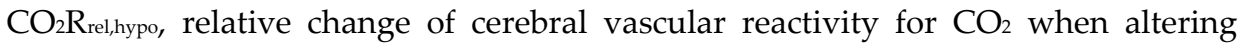

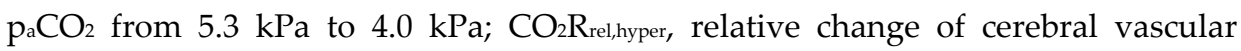
reactivity for $\mathrm{CO}_{2}$ when altering $\mathrm{p}_{\mathrm{a}} \mathrm{CO}_{2}$ from $5.3 \mathrm{kPa}$ to $6.6 \mathrm{kPa}$.

Table 3 shows intraoperative variables at different levels of $\mathrm{p}_{\mathrm{a}} \mathrm{CO}_{2}$ and hematocrit. The ARI proved lowest at a $\mathrm{p}_{\mathrm{a}} \mathrm{CO}_{2}$ level of $6.6 \mathrm{kPa}$ with a hematocrit $<28 \%$. Figure 1 provides a more illustrative presentation.

Table 3 Perioperative variables.

\begin{tabular}{|c|c|c|c|c|c|c|}
\hline \multicolumn{4}{|c|}{ hematocrit $\geq 28 \%$ ( $N=21)$} & \multicolumn{3}{|c|}{ hematocrit < $\mathbf{2 8 \%}(\mathrm{N}=19)$} \\
\hline $\mathrm{p}_{2} \mathrm{CO}_{2}(\mathrm{kPa})$ & 4.0 & 5.3 & 6.6 & 4.0 & 5.3 & 6.6 \\
\hline ARI & $\begin{array}{l}6.1 \\
{[5.5-6.5]}\end{array}$ & $\begin{array}{l}5.6 \\
{[4.6-6.2]}\end{array}$ & $\begin{array}{l}3.3 \\
{[2.5-4.2]}\end{array}$ & $\begin{array}{l}5.5 \\
{[4.1-6.2]}\end{array}$ & $\begin{array}{l}4.4 \\
{[3.9-5.1]}\end{array}$ & $\begin{array}{l}2.6 \\
{[1.6-3.7]}\end{array}$ \\
\hline $\mathrm{CBFV}(\mathrm{cm} / \mathrm{s})$ & $\begin{array}{l}22.7 \\
{[16.7-29.9]}\end{array}$ & $\begin{array}{l}27.6 \\
{[22.7-34.7]}\end{array}$ & $\begin{array}{l}46.2 \\
{[30.0-56.6]}\end{array}$ & $\begin{array}{l}29.1 \\
{[23.1-30.2]}\end{array}$ & $\begin{array}{l}39.3 \\
{[32.5-41.4]}\end{array}$ & $\begin{array}{l}52.8 \\
{[45.5-57.2]}\end{array}$ \\
\hline $\mathrm{ABP}(\mathrm{mmHg})$ & $\begin{array}{l}80.8 \\
{[70.4-85.6]}\end{array}$ & $\begin{array}{l}81.2 \\
{[74.0-90.3]}\end{array}$ & $\begin{array}{l}83.0 \\
{[76.6-93.5]}\end{array}$ & $\begin{array}{l}70.7 \\
{[63.4-79.6]}\end{array}$ & $\begin{array}{l}78.6 \\
{[69.4-89.0]}\end{array}$ & $\begin{array}{l}79.2 \\
{[69.9-85.8]}\end{array}$ \\
\hline $\mathrm{S}_{\mathrm{ct}} \mathrm{O}_{2}(\%)$ & $\begin{array}{l}64.5 \\
{[63.0-67.3]}\end{array}$ & $\begin{array}{l}67.0 \\
{[65.0-69.5]}\end{array}$ & $\begin{array}{l}70.5 \\
\text { [68.3-73.0] }\end{array}$ & $\begin{array}{l}64.5 \\
{[62.0-66.5]}\end{array}$ & $\begin{array}{l}66.0 \\
{[65.0-70.0]}\end{array}$ & $\begin{array}{l}69.5 \\
{[67.0-72.0]}\end{array}$ \\
\hline
\end{tabular}

Data presented as median [interquartile range]. $\mathrm{p}_{\mathrm{a}} \mathrm{CO}_{2}$, arterial partial gas pressure of $\mathrm{CO}_{2}$; $\mathrm{ARI}$, autoregulation index; $\mathrm{CBFV}$, cerebral blood flow velocity; $\mathrm{ABP}$, arterial blood pressure; $\mathrm{S}_{\mathrm{c}} \mathrm{O}_{2}$, cerebral tissue oximetry. 


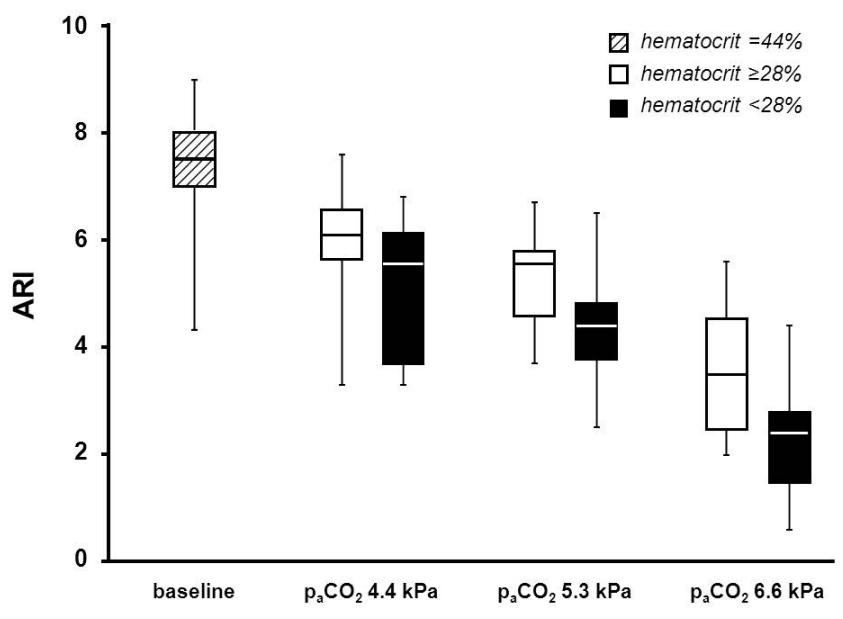

Figure 1 Cerebral autoregulation as indicated by the autoregulation index (ARI) at baseline, at three levels of $\mathrm{paCO}_{2}$ and at two levels of hematocrit during cardiopulmonary bypass.

None of our study patients experienced any adverse neurological complications as expressed by delirium, cerebral vascular accident, and transient ischemic attack during the surgical procedure or in a 30-day follow-up.

\section{DISCUSSION}

This study investigated dynamic cerebral autoregulation (dCA) during normothermic non-pulsatile $\mathrm{CPB}$. Autoregulation proved to be lower compared to preoperative values, and was affected by intraoperative hematocrit and $\mathrm{p}_{\mathrm{a}} \mathrm{CO}_{2}$.

With impaired cerebral autoregulation being reflected by decreased ARI [7], efforts have been made to assess normal values for ARI in both awake and anesthetized patients [10,11]. In our study, the pre-operative median ARI in awake patients at rest was 7.5 (Figure 1). Tiecks et al. found ARI to amount to $5 \pm 1$ in patients at rest during light propofol anaesthesia [7], an index closely corresponding to our results. The authors measured in normocapnic $\left(\mathrm{p}_{\mathrm{C}} \mathrm{CO}_{2}=5.3 \mathrm{kPa}\right)$ patients a median ARI of 4.8 , even though our patients were on full bypass and propofol anesthetized. Engelhard et al. found mean values for ARI to be 5.4 and 5.9 in awake patients prior to induction of anaesthesia [11], which are lower compared to our baseline ARI of 7.5. Gommer et al. [8] showed an average ARI of 6.7 in young healthy volunteers using paced breathing at a 6/min frequency, an ARI higher compared to that for spontaneous breathing. Additionally, Engelhard et al. reported a mean ARI of 4.9 during anaesthesia with combined propofol and remifentanil, which closely correlated to 
our results, showing a median of 4.8 in normocapnic anesthetized patients. Although the hematocrit of the abdominal surgical patients in that study was not mentioned, it may be expected that those patients were not exposed to such a relatively high level of hemodilution with resulting low hematocrit as our patients undergoing CPB (hematocritmedian=28\%). The patients in the study of Engelhard et al., however, showed ARI values relatively similar to those of our patients, therefore suggesting these values to be representative for a normal ARI in the average normocapnic propofol anesthetized cardiac surgical patient on bypass. With literature and our data showing comparable values for ARI, our baseline and perioperative normocapnic measurements of ARI may be considered clinically representative for unimpaired (intact) values for cerebral autoregulation. Concluding, our baseline values measured in awake unanesthetized patients may also be applicable to surgical patients in general.

In surgical patients, impaired cerebral autoregulation, i.e. in our data represented by decreased ARI levels, has been associated with increased occurrence of perioperative stroke [12] or even death [2]. Additionally, a low hematocrit during CPB is known to contribute to postoperative morbidity and mortality $[3,4,13]$. In our study, we investigated the effect of perioperative hematocrit on $\mathrm{ACA}$, and found ARI to be decreased at a hematocrit level $<28 \%$ (at a $\mathrm{p}_{\mathrm{a}} \mathrm{CO}_{2}$ level of $6.6 \mathrm{kPa}$ ). The relation between hemodilution and impaired dCA was previously elucidated by Ogawa et al., but they studied awake subjects and did not include measurements of $\mathrm{p}_{\mathrm{a}} \mathrm{CO}_{2}$ [14]. Ono et al. also studied cerebral autoregulation during CPB, and found hemodilution to be a factor of negative influence as well [12]. In that context, Karkouti et al. found hemodilution to be associated with perioperative stroke [3]. Roach et al. found that impaired cerebral autoregulation is associated with adverse neurological outcome [1]. As a result of lowered perioperative hematocrit negatively influencing both cerebral autoregulation and postoperative neurological outcome, low hematocrit levels due to excessive hemodilution should be avoided, and techniques limiting hemodilution could prove beneficial $[15,16]$.

The arterial $\mathrm{CO}_{2}$ level has been demonstrated to affect cerebral blood flow by altering cerebral vasomotor reactivity [17]. The authors' data also show that ARI decreases with increasing $\mathrm{p}_{\mathrm{a}} \mathrm{CO}_{2}$ (for $\mathrm{p}_{\mathrm{a}} \mathrm{CO}_{2}=4.0,5.3$, and $6.6 \mathrm{kPa}$ the index amounted 5.7, 4.8, and 2.8, respectively). A study conducted by Henriksen and colleagues showed a negative effect on cerebral autoregulation when $\mathrm{p}_{\mathrm{a}} \mathrm{CO}_{2}$ level was increased [5]. Moreover, they found cerebral autoregulation to be near absent at a $\mathrm{p}_{\mathrm{a}} \mathrm{CO}_{2}$ level $>50 \mathrm{mmHg}(>6.7 \mathrm{kPa})$. Although we used such a high $\mathrm{p}_{\mathrm{a}} \mathrm{CO}_{2}$ level as well, our results indicated a decreased but still present level of cerebral autoregulation, as depicted by a $35 \%$ reduction $(A R I=2.6)$ and $44 \%$ reduction (ARI=3.3) of 
autoregulation for the low and high hematocrit group, respectively compared to baseline in awake subjects (ARI=7.5). With decreased cerebral autoregulation being associated with impaired or adverse neurological outcome, these data underline the importance of tight control of $\mathrm{p}_{\mathrm{a}} \mathrm{CO}_{2}$ during $\mathrm{CPB}$.

Cerebral autoregulation is a complex physiological mechanism, which is influenced by several factors including hematocrit and $\mathrm{p}_{\mathrm{a}} \mathrm{CO}_{2}[18,19]$. As indicated by our data, dCA was reduced with a lower hematocrit (Table 3). The data also show that increased levels of $\mathrm{p}_{\mathrm{a}} \mathrm{CO}_{2}$ resulted in decreased ARI as well. Combining hypercapnia with low hematocrit showed the largest decrease in ARI compared to baseline (median ARIbaseline=7.5, Figure 1). Summarized, the difference in ARI between patients with higher $(\geq 28 \%)$ and lower $(<28 \%)$ hematocrit $(\triangle \mathrm{ARI}=4.2$ and $\triangle \mathrm{ARI}=4.9$, respectively) was most pronounced at the lower limit of cerebral autoregulation (2.8 [2.3-3.8]), which is found at a $\mathrm{paCO}_{2}$ level of $6.6 \mathrm{kPa}$. A possible explanation for our finding is that hemodilution induces a reduction in viscosity and compensatory vasodilatation; therefore increasing $\mathrm{CBFV}$ results in a decreased autoregulatory capacity [20]. The detrimental effect of combined hypercapnia and hemodilution underlines once more the importance of adequate $\mathrm{paCO}_{2}$ monitoring and tight perioperative $\mathrm{p}_{\mathrm{a}} \mathrm{CO}_{2}$ control, while avoiding extreme hemodilution, all in order to diminish the risk of cognitive complications and adverse neurologic clinical outcome.

Cerebral $\mathrm{CO}_{2} \mathrm{R}$ plays an intricate part in the vascular autoregulatory system of the brain, and aims at minimizing the effects of fluctuations in arterial blood pressure on cerebral perfusion [21]. The authors' study showed that in hypocapnia there was a significant positive relationship between cerebral $\mathrm{CO}_{2} \mathrm{R}$ and hematocrit (Table 2). $\mathrm{Tu}$ et al. found similar results, reporting a decreased cerebral $\mathrm{CO}_{2} \mathrm{R}$ with isovolemic hemodilution [22]. In contrast to their study, however, we included alterations of $\mathrm{p}_{\mathrm{a}} \mathrm{CO}_{2}$ and showed that both hemodilution and arterial $\mathrm{CO}_{2}$ level affect cerebral $\mathrm{CO}_{2} \mathrm{R}$. Henriksen also found that decreased cerebral $\mathrm{CO}_{2} \mathrm{R}$ during hypocapnia is related to distinct changes in hematocrit [5]. This is in line with our findings of a significant difference in cerebral $\mathrm{CO}_{2} \mathrm{R}$ between the two hematocrit groups at a $\mathrm{p}_{\mathrm{a}} \mathrm{CO}_{2}$ level of $4.0 \mathrm{kPa}$ (Table 2). This can be explained by the fact that although cerebral autoregulation is suppressed during hypercapnia, cerebral blood flow as such is present. Blood flow can even be increased due to lowered viscosity as a result of hemodilution and increased cerebral $\mathrm{CO}_{2} \mathrm{R}$.

This study investigated cerebral autoregulation and found low hematocrit combined with hypercapnia to significantly decrease ARI. None of our study patients, however, experienced any adverse neurological complications as expressed by 
delirium, cerebral vascular accident, and transient ischemic attack during the surgical procedure or in a 30-day follow-up. This could be attributed to the short duration of approximately 5 minutes in which hypercapnia was induced. Another explanation can be found in our protocol of keeping mean arterial blood pressure in the 70-90 $\mathrm{mmHg}$ range, which is close to the baseline values of our patients, and in which cerebral autoregulation is generally considered present [23].

In the authors' study, CBFV was measured using transcranial Doppler, a method that presumes the assumption of a constant vessel diameter [24]. As previously elucidated, both $\mathrm{p}_{\mathrm{a}} \mathrm{CO}_{2}$ and hemodilution significantly affect cerebral $\mathrm{CO}_{2} \mathrm{R}$ and thereby blood flow, two factors that were altered in our study subjects. However, several studies have exemplified that the diameter of larger arteries change minimally during hemodilution and hypercapnia $[25,26]$. Therefore, changes in CBFV in the middle cerebral artery measured by Doppler legitimately reflect changes in cerebral blood flow.

Cerebral autoregulation is estimated by measuring CBFV at the middle cerebral artery using transcranial Doppler via the temporal window [21]. Our study showed preoperative CBFV in resting conditions to be around $40 \mathrm{~cm} / \mathrm{s}$ (Table 1). Liboni et al. found CBFV to amount to approximately $67 \mathrm{~cm} / \mathrm{s}$ [27], whereas Lindegaard et al. found CBFV to vary between 32 to $78 \mathrm{~cm} / \mathrm{s}$ [28]. Lindegaard et al. and our study, however, included male patients, whereas Liboni et al. measured CBFV in women. In women, a proper acoustic optical temporal window is frequently absent, and the measurement of cerebral autoregulation is impeded [29]. Although our study did not include female patients, but women show comparable CBFV values, our results on cerebral autoregulation may be applicable to the full cardiac surgical population including both genders.

\section{CONCLUSION}

Hemodilution down to a hematocrit of $<28 \%$ combined with hypercapnia negatively affects dynamic cerebral autoregulation, which underlines the importance of tight control of $\mathrm{p}_{\mathrm{a}} \mathrm{CO}_{2}$ during $\mathrm{CPB}$. Perioperative cerebral monitoring proves a valuable tool for future studies evaluating cerebral autoregulation during CPB to hopefully clarify optimal perfusion strategies. 


\section{REFERENCES}

1. Roach GW, Kanchuger M, Mangano, et al. Adverse cerebral outcomes after coronary bypass surgery. Multicenter Study of Perioperative Ischemia Research Group and the Ischemia Research and Education Foundation Investigators. N Engl J Med 1996; 335:1857-1863.

2. Portegies ML, de Bruijn RF, Hofman A, et al. Cerebral vasomotor reactivity and risk of mortality: the Rotterdam Study. Stroke 2014; 45:42-47.

3. Karkouti K, Djaiani G, Borger MA, et al. Low hematocrit during cardiopulmonary bypass is associated with increased risk of perioperative stroke in cardiac surgery. Ann Thorac Surg 2005; 80:1381-1387.

4. Mathew JP, Mackensen GB, Phillips-Bute B, et al. Effects of extreme hemodilution during cardiac surgery on cognitive function in the elderly. Anesthesiology 2007; 107:577-584.

5. Henriksen L. Brain luxury perfusion during cardiopulmonary bypass in humans. A study of the cerebral blood flow response to changes in $\mathrm{CO} 2, \mathrm{O} 2$, and blood pressure. J Cereb Blood Flow Metab 1986; 6:366-378.

6. Diehl RR, Linden D, Lucke D, et al. Phase relationship between cerebral blood flow velocity and blood pressure. A clinical test of autoregulation. Stroke 1995; 26:1801-1804.

7. Tiecks FP, Lam AM, Aaslid R, et al. Comparison of static and dynamic cerebral autoregulation measurements. Stroke 1995; 26:1014-1019.

8. Gommer ED, Shijaku E, Mess WH, et al. Dynamic cerebral autoregulation: different signal processing methods without influence on results and reproducibility. Med Biol Eng Comput 2010; 48:1243-1250.

9. Ševerdija EE, Gommer ED, Weerwind PW, et al. Assessment of dynamic cerebral autoregulation and cerebral carbon dioxide reactivity during normothermic cardiopulmonary bypass. Med Biol Eng Comput 2015; 53:195-203.

10. Park CW, Sturzenegger M, Douville CM, et al. Autoregulatory response and $\mathrm{CO} 2$ reactivity of the basilar artery. Stroke 2003; 34:34-39.

11. Engelhard K, Werner C, Mollenberg O, et al. Effects of remifentanil/propofol in comparison with isoflurane on dynamic cerebrovascular autoregulation in humans. Acta Anaesthesiol Scand 2001; 45:971-976.

12. Ono M, Joshi B, Brady $\mathrm{K}$, et al. Risks for impaired cerebral autoregulation during cardiopulmonary bypass and postoperative stroke. Br J Anaesth 2012; 109:391-398.

13. DeFoe GR, Ross CS, Olmstead EM, et al. Lowest hematocrit on bypass and adverse outcomes associated with coronary artery bypass grafting. Northern New England Cardiovascular Disease Study Group. Ann Thorac Surg 2001; 71:769-776.

14. Ogawa Y, Iwasaki K, Aoki K, et al. Central hypervolemia with hemodilution impairs dynamic cerebral autoregulation. Anesth Analg 2007; 105:1389-1396.

15. Ševerdija EE, Heijmans $\mathrm{JH}$, Theunissen $\mathrm{M}$, et al. Retrograde autologous priming reduces transfusion requirements in coronary artery bypass surgery. Perfusion 2011; 26:315-321.

16. Vandewiele K, Bove T, De Somer FM, et al. The effect of retrograde autologous priming volume on haemodilution and transfusion requirements during cardiac surgery. Interact Cardiovasc Thorac Surg 2013; 16:778-783.

17. Battisti-Charbonney A, Fisher J, Duffin J: The cerebrovascular response to carbon dioxide in humans. J Physiol 2011; 589:3039-3048.

18. Buhre W, Weyland A, Grune F, et al. Influence of arterial carbon dioxide tension on systemic vascular resistance in patients undergoing cardiopulmonary bypass. Acta Anaesthesiol Scand 1998; 42:167-171. 
19. Rudolph JL, Sorond FA, Pochay VE, et al. Cerebral hemodynamics during coronary artery bypass graft surgery: the effect of carotid stenosis. Ultrasound Med Biol 2009; 35:1235-1241.

20. von Kummer R, Scharf J, Back T, et al. Autoregulatory capacity and the effect of isovolemic hemodilution on local cerebral blood flow. Stroke 1988; 19:594-597.

21. Aaslid R, Lindegaard KF, Sorteberg W, et al. Cerebral autoregulation dynamics in humans. Stroke 1989; 20:45-52.

22. Tu YK, Liu HM. Effects of isovolemic hemodilution on hemodynamics, cerebral perfusion, and cerebral vascular reactivity. Stroke 1996; 27:441-445.

23. Lassen NA. Cerebral blood flow and oxygen consumption in man. Physiol Rev 1959; 39:183-238.

24. Huber P, Handa J. Effect of contrast material, hypercapnia, hyperventilation, hypertonic glucose and papaverine on the diameter of the cerebral arteries. Angiographic determination in man. Invest Radiol 1967; 2:17-32.

25. Bruder N, Cohen B, Pellissier D, et al. The effect of hemodilution on cerebral blood flow velocity in anesthetized patients. Anesth Analg 1998; 86:320-324.

26. Larsen FS, Olsen KS, Hansen BA, et al. Transcranial Doppler is valid for determination of the lower limit of cerebral blood flow autoregulation. Stroke 1994; 25:1985-1988.

27. Liboni W, Allais G, Mana O, et al. Transcranial Doppler for monitoring the cerebral blood flow dynamics: normal ranges in the Italian female population. Panminerva Med 2006; 48:187-191.

28. Lindegaard KF, Lundar T, Wiberg J, et al. Variations in middle cerebral artery blood flow investigated with noninvasive transcranial blood velocity measurements. Stroke 1987; 18:10251030.

29. Marinoni M, Ginanneschi A, Forleo P, et al. Technical limits in transcranial Doppler recording: inadequate acoustic windows. Ultrasound Med Biol 1997; 23:1275-1277. 



\section{CHAPTER 4}

\section{RETROGRADE AUTOLOGOUS PRIMING REDUCES TRANSFUSION REQUIREMENTS IN CORONARY ARTERY BYPASS SURGERY}

EE Ševerdija, JH Heijmans, M Theunissen, JG Maessen, PH Roekaerts, PW Weerwind.

Published in Perfusion 2011; 26:315-321.

Presented in part at the $9^{\text {th }}$ International Congress of the Croatian Society for Extracorporeal Technology, held April 27-30, 2012 in Dubrovnik, Croatia. 


\section{Abstract}

The hypothesis was tested whether retrograde autologous priming (RAP) of the cardiopulmonary bypass system, compared to a standard primed system (NONRAP group), results in less hemodilution and less transfusion of packed red blood cells. Retrospectively, data was collected from the medical charts of one hundred patients undergoing elective coronary artery bypass grafting using cardiopulmonary bypass. Fifty patients where RAP was used have been compared to fifty patients using NON-RAP. The prime volume in the NON-RAP group was $1,627 \pm 108$ $\mathrm{mL}$ versus $782 \pm 96 \mathrm{~mL}$ in the RAP group $(p<0.001)$. The lowest hematocrit during perfusion was $22 \%$ in the NON-RAP group versus $26 \%$ when the RAP technique was used $(p<0.001)$. In the NON-RAP group, $26 \%$ of the patients received packed red cells in contrast to $6 \%$ in the RAP group $(p<0.012)$. A positive association was found between RAP and less transfusion of packed red blood cells $(p<0.012)$. In conclusion, retrograde autologous priming, reducing the prime volume of the cardiopulmonary bypass system, causes less hemodilution and reduces intraoperative transfusion of packed red blood cells. 


\section{INTRODUCTION}

Despite continued perioperative improvements, cardiac surgery is still associated with blood transfusion [1]. The risks and benefits of packed red blood cell (PRBC) trans- fusion remain an ongoing topic of discussion. Next to allergic reactions, transmission of infectious diseases and acute lung injury, there is mounting evidence that the administration of PRBC increases morbidity and mortality [2,3]. Moreover, acute hemodilution and the resulting low hematocrit have detrimental effects on cognitive function [4,5]. Over the last fifteen years, therefore, the trend in cardiac surgery has been to prevent or reduce hemodilution and transfusion of PRBC.

Acute hemodilution caused by the large priming volume of the cardiopulmonary bypass (CPB) system can result in seriously low hematocrit levels, mandating transfusion of PRBC. A technique to reduce the large assanguinous priming volume is the so-called retrograde autologous priming (RAP), which results in less hemodilution and, possibly, in less transfusion requirements.

The purpose of this retrospective study is to evaluate the impact of RAP on the level of hemodilution and requirements of PRBC in patients undergoing elective coronary artery bypass surgery. We hypothesize that RAP results in less hemodilution and reduces PRBC transfusion.

\section{METHODS}

After institutional approval, the charts of one hundred patients who had coronary artery bypass surgery were analysed. A group of fifty consecutive patients in whom standard cardiopulmonary bypass priming was used (NON-RAP group) was compared to a group of fifty patients in whom the RAP technique was applied (RAP group). The effect of RAP on hemodilution can be confounded by factors such as fluid administration by the anaesthesiologist, cardioplegia volume and blood loss during surgery.

Exclusion criteria were fluid volume administered by the anaesthesiologist $>1,000$ $\mathrm{mL}$, cardioplegic volume $>1,000 \mathrm{~mL}$, blood loss during surgery $>1,000 \mathrm{~mL}$, reoperation, left ventricular ejection fraction $<30 \%$, preoperative inotropic or intra-aortic balloon support, emergency surgery and significant pulmonary, endocrine, metabolic or neurological diseases. The analysis was confined to a single perfusionist for the RAP technique because there is significant variability in perfusion techniques 
between perfusionists, transfusion triggers and the use of blood conservation techniques. All patients continued their anti-aggregant therapy until the day of surgery.

The CPB system used in both groups consisted of a standard closed bypass circuit with a hollow-fibre membrane oxygenator (Capiox SX18R, Terumo, Tokyo, Japan), a cardiotomy reservoir (Capiox CXCRXA, Terumo), and an arterial line filter (Pall LeukoGuard LCG, Pall, Portsmouth, United Kingdom). All circuit components exposed to blood were poly-2-methoxyethylacrylate coated (Terumo). The standard priming of the CPB circuit included 1,300 $\mathrm{mL}$ of $4 \%$ Gelofusine (B. Braun AG, Melsungen, Germany), $200 \mathrm{~mL} \mathrm{20 \%} \mathrm{mannitol,} 100 \mathrm{~mL} 20 \%$ human albumin and 50 $\mathrm{mL} 8.4 \%$ NaHCO3. The total volume of the CPB priming amounted to $1,650 \mathrm{~mL}$ clear fluid, containing 6,500 IU/L heparin (Heparin Leo, Leo Pharmaceutical Products BV, Weesp, the Netherlands).

\section{$R A P$ technique and conduct of $C P B$}

In the RAP group, a transfer bag was attached to the purge line between the oxygenator inlet and the top of the cardiotomy reservoir (Figure 1). The arterial pump was then slowly advanced until the venous reservoir volume dropped to $20 \mathrm{~mL}$, which resulted in a $200 \mathrm{~mL}$ of prime removal before starting CPB. Subsequently, passive leg raising was used to facilitate adequate intravascular filling and maintain the systolic blood pressure $\geq 100 \mathrm{mmHg}$ after aortic cannulation. After removal of the arterial clamp, the arterial blood pressure was used to retrograde prime the arterial line, the arterial filter, and oxygenator, while concomitantly discharging clear prime via the oxygenator purge line into a transfer bag (Figure 1). 


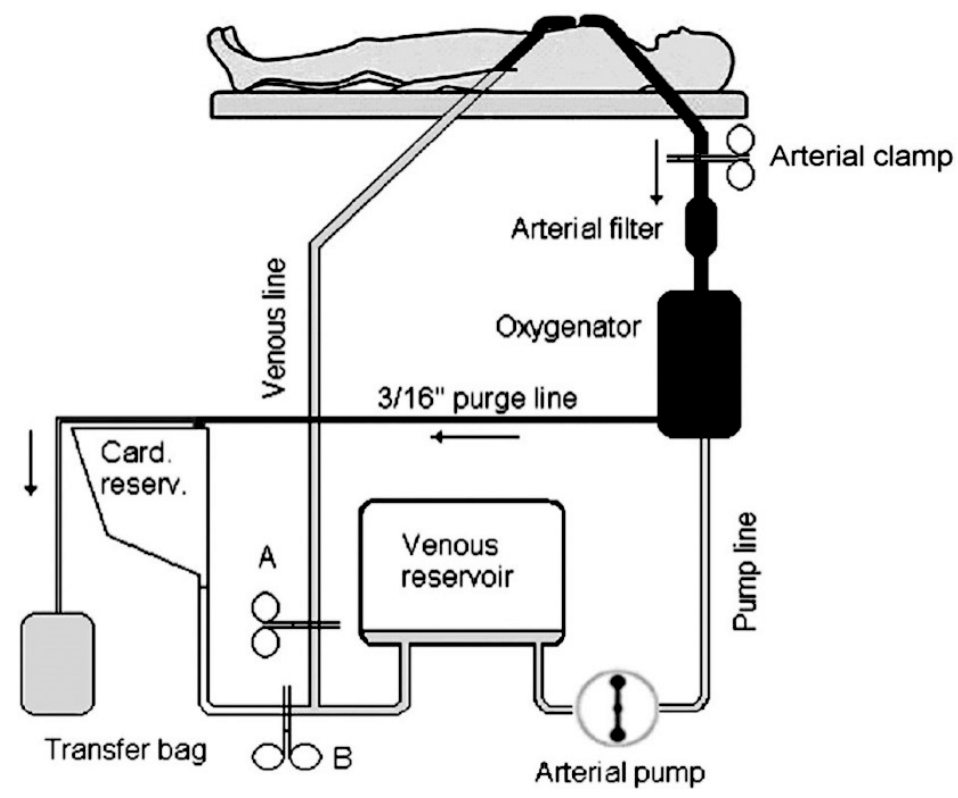

Figure 1 The RAP technique showing retrograde priming of the arterial line, arterial filter and oxygenator, while priming volume is retrieved in a transfer bag.

The arterial pump was then slowly advanced until the venous reservoir volume dropped to $20 \mathrm{~mL}$, which resulted in a $200 \mathrm{~mL}$ of prime removal before starting $\mathrm{CPB}$. Subsequently, passive leg rising was used to facilitate adequate intra- vascular filling and maintain the systolic blood pressure $\geq 100 \mathrm{mmHg}$ after aortic cannulation. After removal of the arterial clamp, the arterial blood pressure was used to retrograde prime the arterial line, the arterial filter, and oxygenator, while concomitantly discharging clear prime via the oxygenator purge line into a transfer bag (Figure 1). During CPB, the activated coagulation time was kept $>480$ seconds. Myocardial preservation was provided by St.Thomas' No.1 solution. A single dose of approximately $800 \mathrm{~mL}(600$ to $1,000 \mathrm{~mL})$ at $4^{\circ} \mathrm{C}$ was infused via the aortic root. Target flow rates of $\geq 2.4 \mathrm{~L} / \mathrm{min} / \mathrm{m}^{2}$ were maintained throughout the CPB period. Normothermic $\left(\geq 36^{\circ} \mathrm{C}\right.$ ) pulsatile perfusion (radial artery pulse pressure $\geq 25 \mathrm{mmHg}$ ) was used during the period of cross clamping. Mean arterial blood pressure was maintained between 70 and $90 \mathrm{mmHg}$ and, if needed, phenylephrine $(0.4 \mathrm{mg} / \mathrm{mL})$ was titrated via an infusion pump. Pericardial blood was drained and washed with a cell saver device. All patients received tranexamic acid ( $2 \mathrm{~g})$ during CPB. The transfusion trigger during $\mathrm{CPB}$ was set at a haematocrit below 23\% [6].

After termination of $\mathrm{CPB}$, clamps $\mathrm{A}$ and $\mathrm{B}$ were positioned as shown in Figure 2. After venous decannulation, the cannula was immersed into a container filled with heparinized saline. Brief removal of clamp A allowed drainage from the container to 
the venous reservoir, enabling displacement of circuit blood volume to the patient. When the venous reservoir was empty, clamp B was removed. This allowed rinsing of the remaining part of the $\mathrm{CPB}$ system by volume displacement from the cardiotomy reservoir. While keeping central venous and pulmonary artery pressures optimal, reinfusion was stopped when the aortic cannula became assanguinous.

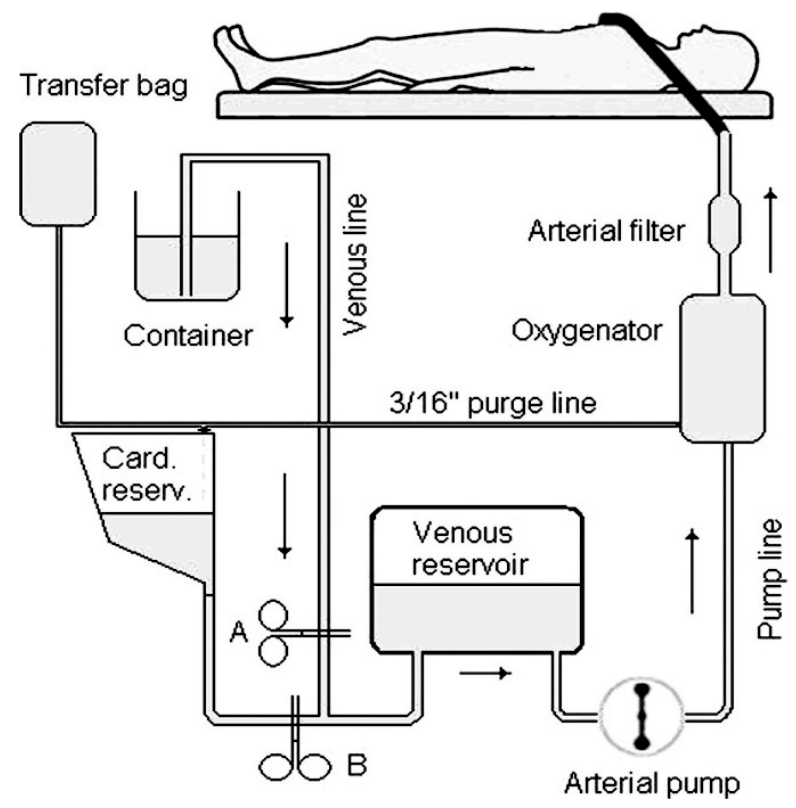

Figure 2 Replacing volume from the CPB circuit to the patient. The residual blood volume in the venous reservoir is pumped antegrade to the patient.

\section{Statistics}

A sample size of one hundred patients was based on an estimated reduction in transfusion requirements of $50 \%$ with a confidence interval of $95 \%$ and a power of $80 \%$. Clinical characteristics were compared using an independent-sample t-test whereas categorical data were analysed using the Chi-square test. Results are shown as number or mean \pm standard deviation.

Bivariate logistic regression analysis was performed to determine single predictors of increased risk for hemodilution (lowest hematocrit on bypass) and blood transfusion requirements. Besides the intervention (RAP), those candidate predictors that achieved significance in the separate bivariate tests were entered into two separate stepwise multivariate logistic regression analyses, one for lowest hematocrit and the other for PRBC use. Odds ratios and its 95\% confidence interval for risk factors for lowest hematocrit on bypass and transfusion of PRBC were derived from the multivariate logistic regression analysis. Patient characteristics expected to be at high risk 
for the primary outcome variables acute hemodilution (hematocrit $<23 \%$ ) and/or increased transfusion requirement of PRBC were female gender, preoperative hematocrit $<40 \%$, body mass index (BMI) $<25$, age $\geq 70$ years, perfusion time $\geq 100$ $\min$ and lowest hematocrit during perfusion $<23 \%$. Differences were considered significant at $p$-values less than 0.05 . Statistical analyses were performed using SPSS 15.0 (SPSS Inc., Chicago, IL, USA).

\section{RESULTS}

Demographic data and data with respect to the surgical procedures are shown in Table 1. Apart from sex, there were no significant differences between the two patient groups.

Table 1 Demographic data.

\begin{tabular}{llll}
\hline & \multicolumn{2}{l}{ Group } & \\
\cline { 2 - 3 } variable & NON-RAP & RAP & $\mathrm{ns}$ \\
\hline age $($ year $)$ & $65 \pm 10$ & $63 \pm 9$ & 0.032 \\
sex $(\mathrm{m} / \mathrm{f})$ & $34 / 16$ & $43 / 7$ & $\mathrm{~ns}$ \\
bodyweight $(\mathrm{kg})$ & $81 \pm 11$ & $80 \pm 9$ & $\mathrm{~ns}$ \\
body surface area $\left(\mathrm{m}^{2}\right)$ & $1.94 \pm 0.17$ & $1.94 \pm 0.13$ & $\mathrm{~ns}$ \\
body mass index $\left(\mathrm{kg} / \mathrm{m}^{2}\right)$ & $27 \pm 4$ & $26 \pm 3$ & $\mathrm{~ns}$ \\
preoperative hematocrit $(\%)$ & $41 \pm 3$ & $42 \pm 1$ & $\mathrm{~ns}$ \\
ejection fraction $(\%)$ & $39 \pm 3$ & $38 \pm 5$ & $\mathrm{~ns}$ \\
bypass time (minutes) & $72 \pm 32$ & $69 \pm 18$ & $\mathrm{~ns}$ \\
cross-clamp time (minutes) & $49 \pm 24$ & $46 \pm 18$ & $\mathrm{~ns}$ \\
number of grafts & $3.8 \pm 1.0$ & $3.7 \pm 1.0$ & \\
\hline
\end{tabular}

NON-RAP, standard cardiopulmonary bypass priming; RAP, retrograde autologous priming; ns, not significant.

Table 2 shows volumetric data. By RAP, the effective total prime volume was reduced by approximately $50 \%$. The net prime volume was significantly lower in the RAP group as compared to the NON-RAP group $(782 \pm 96 \mathrm{~mL}$ versus $1,627 \pm 108$ $\mathrm{mL}, p<0.001)$, whereas the volume given by the anaesthesiologist, cardioplegia volume, blood loss and diuresis during CPB were comparable in both groups. Hemofiltration volume, total volume received intraoperatively and pump blood returned to the patient were significantly lower in the RAP group compared to the NON-RAP group ( $p<0.001$ for all). In addition, blood loss 24 hours after surgery was significantly lower in the RAP group compared to the NONRAP group $(680 \pm 340 \mathrm{~mL}$ 
versus $857 \pm 439 \mathrm{~mL}, p<0.027)$. Three patients were excluded from the NON-RAP group and one patient from the RAP group because of perioperative excessive bleeding $(>1,000 \mathrm{~mL})$.

Table 2 Volumetric data and data on haematocrit and transfusion during perfusion.

\begin{tabular}{llll}
\hline & Group & & \\
\cline { 2 - 3 } variable & NON-RAP & RAP & $p$-value \\
\hline priming volume (mL) & $1,627 \pm 108$ & $782 \pm 96$ & 0.001 \\
volume given by the anaesthesiologist (mL) & $784 \pm 283$ & $813 \pm 239$ & $\mathrm{~ns}$ \\
cardioplegia (mL) & $840 \pm 334$ & $896 \pm 273$ & $\mathrm{~ns}$ \\
blood loss during surgery (mL) & $348 \pm 213$ & $293 \pm 161$ & $\mathrm{~ns}$ \\
diuresis (mL) & $485 \pm 317$ & $550 \pm 414$ & $\mathrm{~ns}$ \\
hemofiltration (mL) & $514 \pm 733$ & $32 \pm 226$ & 0.001 \\
total volume received during surgery (mL) & $4,462 \pm 990$ & $2,926 \pm 746$ & 0.001 \\
pump blood returned (mL) & $982 \pm 503$ & $371 \pm 499$ & 0.001 \\
blood loss 24 h postoperative (mL) & $857 \pm 439$ & $680 \pm 340$ & 0.027 \\
preoperative hematocrit (\%) & $41 \pm 3$ & $42 \pm 2$ & $\mathrm{~ns}$ \\
lowest hematocrit (\%) & $22 \pm 3$ & $26 \pm 2$ & 0.001 \\
hematocrit on arrival at ICU (\%) & $26 \pm 3$ & $28 \pm 3$ & 0.003 \\
number of patients receiving PRBC & 13 & 3 & 0.012 \\
number of PRBC transfused & 22 & 4 & 0.041 \\
\hline
\end{tabular}

NON-RAP, standard cardiopulmonary bypass priming; RAP, retrograde autologous priming; ns, not significant; ICU, intensive care unit; PRBC, packed red blood cells.

Table 2 also shows data on hematocrit and PRBC transfusion. Preoperative hematocrit data revealed no significant difference between the two groups. During $\mathrm{CPB}$, the lowest measured hematocrit was significantly higher in the RAP group compared to the NON-RAP group ( $26 \%$ and $22 \%$, respectively, $p<0.001)$. Also, on arrival at the intensive care unit, the hematocrit remained significantly higher in the RAP group compared to the NON-RAP group ( $28 \%$ and $26 \%$, respectively, $p<0.003)$. The number of patients who received a PRBC transfusion and the total number of PRBC units transfused were significantly lower in the RAP group compared to the NONRAP group. Three patients $(6 \%)$ in the RAP group versus 12 patients $(26 \%)$ in the NON- RAP group received PRBC transfusion $(p<0.012)$. The total number of PRBC transfused was four units in the RAP group compared to 22 units in the NON-RAP group $(p<0.041)$. None of the patients in either group received fresh frozen plasma or platelets. 
Table 3 Predictors for lowest hematocrit ( $<23 \%$ versus $\geq 23 \%$ ).

\begin{tabular}{llllll}
\hline predictor & & $\mathrm{N}$ & $p^{*}$-value & bivariate OR $(\mathrm{CI})^{*}$ & multivariate OR (CI) \\
\hline intervention & RAP & 50 & 0.0001 & 1.00 & \\
& NON-RAP & 50 & & $19.94(5.47-72.71)$ & $29.67(4.94-178.18)$ \\
gender & male & 77 & 0.0001 & 1.00 & \\
& female & 23 & & $7.15(2.58-19.81)$ & $8.46(2.05-34.94)$ \\
preoperative & $\geq 40 \%$ & 78 & 0.0001 & 1.00 & \\
hematocrit & $<40 \%$ & 21 & & $14.63(4.59-46.61)$ & $23.09(4.20-127.09)$ \\
BMI $\left(\mathrm{kg} / \mathrm{m}^{2}\right)$ & $\geq 25$ & 23 & 0.947 & 1.00 & ne \\
& $<25$ & 77 & & $1.04(0.38-2.84)$ & \\
perfusion time & $<100$ min & 83 & 0.467 & 1.00 & ne \\
& $\geq 100$ min & 17 & & $1.57(0.47-5.26)$ & \\
age & $<70$ year & 69 & 0.116 & 1.00 & $2.05(0.84-5.0)$ \\
& $\geq 70$ year & 31 & &
\end{tabular}

OR, odds ratio; $\mathrm{CI}$, confidence interval; RAP, retrograde autologous priming; NON-RAP, standard cardiopulmonary bypass priming; BMI, body mass index; ne, not entered based on non-significance in the bivariate model. Multivariate OR, Nagelkerke $\mathrm{R}^{2}$ 0.656. (significant $\left.p<0.05\right),\left(p^{*}\right.$-value for bivariate $\mathrm{OR})$.

A baseline difference in distribution of female patients was observed between the RAP group and the NON-RAP group ( $16 \%$ versus $47 \%$, respectively, $p<0.032$ ), and is shown in Table 3. Bivariate logistic regression analysis for hemodilution (lowest hematocrit on bypass, $<23 \%$ versus $\geq 23 \%$ ) revealed a significant effect for the intervention (RAP versus NON-RAP, $p<0.0001$ ), gender (female versus male patients, $p<0.0001)$, and preoperative hematocrit $(<40 \%$ versus $\geq 40 \%, p<0.0001)$. There was no significant effect for body mass index (BMI) (BMI $<25$ versus $B M I \geq 25, p=0.947$ ), age ( $<70$ years versus $\geq 70$ years, $p=0.116$ ), or bypass time (CPB time $<100$ minutes versus $\geq 100$ minutes, $p=0.514$ ). Moreover, multiple logistic regression analysis shows that intervention, gender and preoperative hematocrit together had a significant effect on the outcome variable hemodilution. Of these variables, the contribution of the intervention (RAP) was far more prominent than the contribution of gender. Bivariate logistic regression analysis for the transfusion of PRBC (yes versus no transfusion of PRBC) was significantly different for the intervention (RAP versus NONRAP, $p<0.012$ ), gender (female versus male patients, $p<0.0001$ ), hemodilution (lowest hematocrit on bypass, $<23 \%$ versus $\geq 23 \%, p<0.006)$, and age $(<70$ years versus $\geq 70$ years, $p<0.006$ ), but not for preoperative hematocrit ( $<40 \%$ versus $\geq 40 \%, p=0.693$ ), BMI (BMI $<25$ versus $\mathrm{BMI} \geq 25, p=0.109)$, and bypass time (CPB time $<100$ minutes versus $\geq 100$ minutes, $p=0.213$ ) (Table 4 ). The multiple logistic regression analysis showed that the intervention (RAP versus NON- RAP), gender (female sex) and 
perfusion time ( $\geq 100$ minutes) have a significant effect on the outcome variable PRBC transfusion requirement.

Table 4 Predictors for transfusion of packed red blood cells (yes versus no transfusion).

\begin{tabular}{llllll}
\hline predictor & & $\mathrm{N}$ & $p^{*}$-value & bivariate OR $(\mathrm{CI})^{*}$ & multivariate OR (CI) \\
\hline intervention & RAP & 50 & 0.012 & 1.00 & \\
& NON-RAP & 50 & & $5.51(1.5-20.8)$ & $6.12(1.20-31.54)$ \\
gender & male & 77 & 0.0001 & 1.00 & \\
& female & 23 & & $13.20(3.89-44.76)$ & $16.43(3.80-71.07)$ \\
perfusion time & $<100 \mathrm{~min}$ & 83 & 0.023 & 1.00 & \\
& $\geq 100 \mathrm{~min}$ & 17 & & $3.98(1.21-13.14)$ & $9.59(1.86-49.59)$ \\
lowest hemato- & $\geq 23$ & 69 & 0.003 & 1.00 & $\mathrm{~ns}$ \\
crit & $<23$ & 31 & & $5.00(1.62-15.42)$ & \\
age & $<70$ year & 69 & 0.003 & 1.00 & $\mathrm{~ns}$ \\
& $\geq 70$ year & 31 & & $5.00(1.62-15.42)$ & \\
preoperative & $<40 \%$ & 21 & 0.061 & 1.00 & ne \\
hematocrit & $\geq 40 \%$ & 78 & & $3.07(0.95-9.92)$ & \\
BMI $\left(\mathrm{kg} / \mathrm{m}^{2}\right)$ & $\geq 25$ & 77 & 0.082 & 1.00 & ne \\
& $<25$ & 23 & & $5.32(0.664-42.68)$ & \\
\hline
\end{tabular}

OR, odds ratio; $\mathrm{CI}$, confidence interval; RAP, retrograde autologous priming; NON-RAP, standard cardiopulmonary bypass priming; BMI, body mass index; ns, not significant; ne, not entered based on non-significance in the bivariate model. Multivariate $\mathrm{OR}$, Nagelkerke $\mathrm{R}^{2}$ 0.656. (significant $p<0.05)$, ( $p^{*}$-value for bivariate OR).

\section{DISCUSSION}

This study shows a reduced number of transfusions of packed red blood cells during cardiopulmonary bypass when using retrograde autologous priming (RAP) in patients undergoing elective coronary artery bypass grafting surgery.

Patients in the RAP group had a higher hematocrit on bypass and fewer patients needed transfusion of PRBC, which is in accordance with findings by other investigators [7-13]. Although the NON-RAP group counted more female patients, who have a predetermined higher transfusion risk as compared to male patients, both bivariate and multivariate logistic regression analysis indicated a prominent effect of RAP on transfusion of PRBC. A higher hematocrit was observed on CPB in the RAP group as compared to the NON-RAP group (Table 2), which is in accordance with findings by other investigators. The lowest hematocrit levels on $\mathrm{CPB}$ vary from 
22 to $29 \%$ in 'RAP groups' to as low as 20 to $26 \%$ in the 'control groups' [7-13]. The literature provides increasing evidence that a low hematocrit is associated with increased postoperative morbidity and mortality. Studies from Koch et al. show that a hematocrit $<22 \%$ resulted in an increased morbidity and decreased both short- and long-term survival [2,3]. Furthermore, Habib et al. showed that an hematocrit $<22 \%$ is an independent risk factor for mortality and can be detrimental to the neurological outcome of patients [14], and Karkouti et al. found an independent, but direct relationship between the degree of hemodilution during $\mathrm{CPB}$ and perioperative stroke [15]. To the best of our knowledge, there is no universally accepted hematocrit threshold value for allogeneic blood transfusion in cardiac surgery. The trigger to transfuse mostly depends on the level of hypothermia during CPB and departmental agreements on lowest acceptable hematocrit. Most studies referred to here adhere to two transfusion trigger points. The first is during hypothermic CPB with hematocrit levels of 16 to $20 \%$. The second is the postoperative trigger point with hematocrit levels of 22 to $25 \%$ and even $30 \%$ in debilitated patients [7-12]. A transfusion trigger of an hematocrit of $24 \%$ is advised by several authors for normother$\operatorname{mic} \mathrm{CPB}[6,16]$.

The results of our study on the number of patients transfused during $\mathrm{CPB}$ using the RAP technique are in conjunction with data from most other studies $[7,11,12,17]$. Rosengart et al. demonstrated that $3 \%$ of the patients in their RAP group and $23 \%$ in the control group required transfusion intraoperative [11]. Shapira et al.[12] found RAP reduced transfusion, although their outcome was less evident. Saczkowski et al. via meta-analysis assessed the clinical effectiveness of the RAP technique to reduce allogeneic packed red blood cell transfusion in adult cardiac surgery [18]. They concluded that RAP significantly reduced the number of patients receiving intraoperative PRBC transfusion, as well as total PRBC transfusion during hospital stay. In the number of intraoperative transfused units of PRBC, RAP, however, did not provide a clinical benefit. The authors highlighted the inherent limitations of their analyses, as the aggregate sample size for the RAP and control groups in most of the studies was small.

In contrast to the studies showing less transfusion of PRBC when using RAP, Murphy et al., in a retrospective study, found that RAP did not affect blood transfusion requirements [10]. Nevertheless, their study revealed a significant difference in the median lowest intraoperative hematocrit. Although they found a significant difference in the median lowest intraoperative hematocrit (RAP 26\% versus NON-RAP $22 \%$ ), this did not result in a significant reduction in the percentage of patients transfused. Differences regarding patient selection, local protocols and modifications of the RAP technique might explain the differences in results between these 
studies. Murphy et al. included coronary artery bypass graft (CABG), valve, CABG plus valve, re-do $C A B G$, re-do $C A B G$ plus valve surgery and emergency surgery in their study [10], compared to our study where only low-risk CABG surgery patients were included. In addition to the application of RAP to reduce hemodilution and transfusion of PRBC, Murphy et al. retrieved approximately $500 \mathrm{~mL}$ autologous blood (in cases of hematocrit $>30 \%$ ) after induction of anaesthesia. In our study, we only applied the RAP technique, not submitting the patients to autologous blood pre-donation at the same time. The autologous blood withdrawal of Murphy et al. resulted in a lower pre-bypass hematocrit level of 35\% in the NON-RAP group compared to $36 \%$ in the RAP group. In our study, the pre-bypass hematocrit levels were $41 \%$ in the NON-RAP group and $42 \%$ in the RAP group. Furthermore, in cases of haemodynamic instability, Murphy et al. replaced the RAP volume with 100 to $300 \mathrm{~mL}$ of crystalloid fluid to ensure a safe minimal systolic blood pressure $(>100$ $\mathrm{mmHg}$ ), diminishing the effect of RAP.

Since the first description of RAP by Panico et al. in 1960 [17] and later by Rozengart et al. [11], the technique led to many variations and local adaptations to reduce blood transfusion requirements. Numerous authors published modifications of the RAP technique, like differences in prime volume, kind of priming fluid, arterial and or venous blood drainage, safety limits adhered to lowest acceptable blood pressure, the use of the Trendelenburg position and phenylephrine infusion, lowest acceptable hematocrit level, the volume given by the anaesthesiologist, cardioplegic fluid volume administered, the use of a cell saver and the combination of RAP with autologous blood predonation $[11,12,19,20]$. The effect on outcome measures like hemodilution and transfusion of PRBC depend on the specific steps of the RAP technique and, therefore, differ per institution. Consequently, comparing the different studies remains difficult.

A subgroup analysis was performed to investigate whether there was a group of predetermined patients with a higher risk for acute hemodilution and or PRBC transfusions. Factors associated with increased transfusion risk were female gender, age ( $>70-75$ years), body surface area $\left(<1.7 \mathrm{~m}^{2}\right)$, body weight $(<70 \mathrm{~kg})$, initial hematocrit $(<32-34 \%)$, CPB time $(>120$ minutes), creatinine level $(>1.5 \mathrm{mg} / \mathrm{dL})$, combined procedures, re-do surgeries, urgency of surgery, preoperative use of aspirin and lowest temperature on CPB [10,15,20-23]. In 1997, Fang et al. reported, after accounting for differences in patients and disease characteristics, that a lowest hematocrit value of $\leq 14 \%$ for low-risk patients and a value of $\leq 17 \%$ for high-risk patients was an independent risk factor for mortality [24]. According to our data analysis, predictors for extreme hemodilution $(<23 \%)$ were the CPB technique (NON- RAP), female gender, and preoperative hematocrit $<40 \%$. Predictors for increased transfusion risk 
were the $\mathrm{CPB}$ technique (NON-RAP), female gender and a perfusion time $>100$ minutes (Table 3 and 4). The effect of the different variables on outcome such as hemodilution and number of PRBC units transfused depends also on how the parameter is defined in relation to institutional practice. From the multivariate analysis, the RAP technique appears to be a valuable instrument for the prevention of hemodilution and transfusion of PRBC (Table 3 and 4).

The amount of the RAP volume can be tailored to the individual patient margins of safety and can be effectively coupled to the use of the Trendelenburg position and/or small bolus doses of phenylephrine. As none of the studies referred to above could demonstrate adverse concerning the patient's haemodynamic variables, heart rate and/or changes in the electrocardiogram, the application of the RAP technique can be considered safe [25].

\section{Study limitations}

This study used data coming from a retrospective analysis. A prospective study would have definite advantages over a retrospective study. One main advantage is the prevention of bias and the most-likely reduction of data dispersion (variation). The data package that was used for this retrospective study was generated at a time in which, at our institution, the RAP technique was not yet a standard procedure. Moreover, only a single clinical perfusionist used RAP. As time progressed and the benefits of RAP became more evident, the technique was slowly, but surely, adapted by the other perfusionists. Nowadays, at our department, the RAP technique is applied to all patients requiring cardiopulmonary bypass.

\section{CONCLUSION}

Retrograde autologous priming of the cardiopulmonary bypass circuit attenuates acute hemodilution and blood transfusion requirements in coronary artery bypass surgery and is a safe and effective technique that should be considered as an integral part of a multimodal approach on blood conservation.

\section{ACKNOWLEDGEMENT}

The authors would like to thank Dr. Antoine P. Simons for editing assistance and critically reviewing of the final manuscript. 


\section{REFERENCES}

1. Oakes DA, Mangano CT. Cardiopulmonary bypass in 2009: achieving and circulating best practices. Anesth Analg 2009; 108:1368-1370.

2. Koch CG, Li L, Duncan AI, et al. Morbidity and mortality risk associated with red blood cell and blood-component transfusion in isolated coronary artery bypass grafting. Crit Care Med 2006; 34:1608-1616.

3. Koch CG, Li L, Duncan AI, et al. Transfusion in coronary artery bypass grafting is associated with reduced long- term survival. Ann Thorac Surg 2006; 81:1650-1657.

4. DeFoe GR, Ross CS, Olmstead EM, et al. Lowest hematocrit on bypass and adverse outcomes associated with coronary artery bypass grafting. Northern New England Cardiovascular Disease Study Group. Ann Thorac Surg 2001; 71:769-776.

5. Mathew JP, Mackensen GB, Phillips-Bute B, et al. Effects of extreme hemodilution during cardiac surgery on cognitive function in the elderly. Anesthesiology 2007; 107:577-584.

6. Vermeer H, Teerenstra S, de Sevaux RG, van Swieten HA, Weerwind PW. The effect of hemodilution during normothermic cardiac surgery on renal physiology and function: a review. Perfusion 2008; 23:329-338.

7. Balachandran S, Cross MH, Karthikeyan S, Mulpur A, Hansbro SD, Hobson P. Retrograde autologous priming of the cardiopulmonary bypass circuit reduces blood transfusion after coronary artery surgery. Ann Thorac Surg 2002; 73:1912-1918.

8. Beholz S, Kessler M, Konertz WF. PRECiSe (priming reduced extracorporeal circulation setup): results of a safety study. Heart Surg Forum 2003; 6:311-315.

9. Eising GP, Pfauder M, Niemeyer M, et al. Retrograde autologous priming: is it useful in elective on-pump coronary artery bypass surgery? Ann Thorac Surg 2003; 75:23-27.

10. Murphy GS, Szokol JW, Nitsun M, et al. The failure of retrograde autologous priming of the cardiopulmonary bypass circuit to reduce blood use after cardiac surgical procedures. Anesth Analg 2004; 98:1201-1207.

11. Rosengart TK, DeBois W, O'Hara M, et al. Retrograde autologous priming for cardiopulmonary bypass: a safe and effective means of decreasing hemodilution and transfusion requirements. J Thorac Cardiovasc Surg 1998; 115:426-438; discussion 438-439.

12. Shapira OM, Aldea GS, Treanor PR, et al. Reduction of allogeneic blood transfusions after open heart operations by lowering cardiopulmonary bypass prime volume. Ann Thorac Surg 1998; 65:724-730.

13. Srinivas K, Singh K. Combination of autologous transfu- sion and retrograde autologous priming decreases blood requirements. Ann Card Anaesth 2001; 4:28-32.

14. Habib RH, Zacharias A, Schwann TA, et al. Role of hemodilutional anemia and transfusion during cardiop- ulmonary bypass in renal injury after coronary revascularization: implications on operative outcome. Crit Care Med 2005; 33:1749-1756.

15. Karkouti K, Djaiani G, Borger MA, et al. Low hematocrit during cardiopulmonary bypass is associated with increased risk of perioperative stroke in cardiac surgery. Ann Thorac Surg 2005; 80:1381-1387.

16. Habib RH, Zacharias A, Schwann TA, Riordan CJ, Durham SJ, Shah A. Adverse effects of low hematocrit during cardiopulmonary bypass in the adult: should cur- rent practice be changed? J Thorac Cardiovasc Surg 2003; 125:1438-1450.

17. Panico FG, Neptune WB. A mechanism to eliminate the donor blood prime from the pumpoxygenator. Surg Forum 1960; 10:605-609. 
18. Saczkowski R, Bernier PL, Tchervenkov CI, Arellano R. Retrograde autologous priming and allogeneic blood transfusions: a meta-analysis. Interact Cardiovasc Thorac Surg 2009; 8:373-376.

19. Jansen PG, te Velthuis H, Bulder ER, et al. Reduction in prime volume attenuates the hyperdynamic response after cardiopulmonary bypass. Ann Thorac Surg 1995; 60:544-549; discussion 549-550.

20. Parr KG, Patel MA, Dekker R, et al. Multivariate predictors of blood product use in cardiac surgery. J Cardiothorac Vasc Anesth 2003; 17:176-181.

21. Despotis GJ, Filos KS, Zoys TN, Hogue CW, Jr., Spitznagel E, Lappas DG. Factors associated with excessive postoperative blood loss and hemostatic transfusion requirements: a multivariate analysis in cardiac surgical patients. Anesth Analg 1996; 82:13-21.

22. Hardy JF, Perrault J, Tremblay N, Robitaille D, Blain R, Carrier M. The stratification of cardiac surgical procedures according to use of blood products: a retrospective analysis of 1480 cases. Can J Anaesth 1991; 38:511-517.

23. McGovern PG, Pankow JS, Shahar E, et al. Recent trends in acute coronary heart disease mortality, morbidity, medical care, and risk factors. The Minnesota Heart Survey Investigators. N Engl J Med 1996; 334:884-890.

24. Fang WC, Helm RE, Krieger KH, et al. Impact of minimum hematocrit during cardiopulmonary bypass on mortality in patients undergoing coronary artery surgery. Circulation 1997; 96(9 Suppl II):194-199.

25. Ferraris VA, Ferraris SP, Saha SP, et al. Perioperative blood transfusion and blood conservation in cardiac surgery: the Society of Thoracic Surgeons and The Society of Cardiovascular Anesthesiologists clinical practice guide-line. Ann Thorac Surg 2007; 83:S27-S86. 



\section{CHAPTER 5}

\section{CAN MINIMIZED CARDIOPULMONARY BYPASS SYSTEMS BE SAFER?}

YM Ganushchak, EE Ševerdija, AP Simons, L van Garsse, PW Weerwind.

Published in Perfusion 2012; 27:176-182.

Awarded with the Best Scientific Paper presented at the 32nd Annual Seminar on Cardiovascular Perfusion, held January 27-30, 2011 in Reno, NV, USA. 


\section{Abstract}

Although a growing body of evidence indicates superiority of minimized cardiopulmonary bypass (mCPB) systems over conventional CPB systems, limited venous return can result in severe fluctuations of venous line pressure that can result in gaseous emboli. In this study, we investigated the influence of sub-atmospheric pressures and volume buffer capacity added to the venous line on the generation of gaseous emboli in the $\mathrm{mCPB}$ circuit.

Two different mCPB systems (MEC - Maquet, n=7 and ECC.O - Sorin, n=8) and a conventional closed cardiopulmonary bypass (cCPB) system $(n=12)$ were clinically evaluated. In the search for a way to increase volume buffer capacity of $\mathrm{mCPB}$ systems, we additionally evaluated the 'Better Bladder' (BB) in a mock circulation by simulating, repeatedly, decreased venous return while measuring pressure and gaseous embolic activity.

Arterial gaseous emboli activity during clinical perfusion with a cCPB system was the lowest in comparison to the $\mathrm{mCPB}$ systems $(312 \pm 465$ versus $311 \pm 421$ with MEC and 1,966 $\pm 1,782$ with ECC.O, counts per 10 minute time interval, respectively; $p=0.03$ ). The average volume per bubble in the arterial line was the highest in cases with $\mathrm{CCPB}(12.5 \pm 8.3 \mathrm{~nL}$ versus $8.0 \pm 4.2 \mathrm{~nL}$ with MEC and $4.6 \pm 4.8 \mathrm{~nL}$ with ECC.O; $p=0.04$ for both). Significant cross-correlation was obtained at various time offsets from 0 to $+35 \mathrm{~s}$ between sub-atmospheric pressure in the venous line and gaseous emboli activity in both the venous and arterial lines. The in vitro data showed that incorporation of the BB dampens fluctuations of venous line pressure by approximately $30 \%$ and decreases gaseous emboli by up to $85 \%$.

In conclusion, fluctuations of sub-atmospheric venous line pressure during kineticassisted drainage are related to gaseous emboli. Volume buffer capacity added to the venous line can effectively dampen pressure fluctuations resulting from abrupt changes in venous return and, therefore, can help to increase the safety of minimized cardiopulmonary bypass by reducing gaseous microemboli formation resulting from degassing. 


\section{INTRODUCTION}

A growing body of evidence indicates the superiority of minimized cardiopulmonary bypass (mCPB) systems compared to conventional cardiopulmonary bypass $(\mathrm{cCPB})$ systems, regarding inflammatory reactions and transfusion requirements. Additionally, a more complex patient population has renewed the interest in further improvement of cardiopulmonary bypass (CPB) circuits in terms of reducing priming volume and subsequent hemodilution [1-4].

Evident benefits of $\mathrm{mCPB}$ systems, however, do not come without consequences [5]. In $\mathrm{mCPB}$ systems, the pump flow is dependent on the venous filling [6]. The equilibrium of venous filling is a delicate one: for myocardial preservation, one needs a very limited venous filling (an empty right heart); on the other hand, for an acceptable pump flow, a certain venous filling is necessary. Moreover, venous filling is, among others, dependent on the position of the venous cannula and repositioning of the heart. So, in a $\mathrm{mCPB}$ system, the pump flow is directly related to the conditions of (reduced) venous return. During limited venous return, kineticassisted drainage, as used in these circuits, can result in severe fluctuations of venous line pressures. Some studies demonstrate that sub-atmospheric venous line pressures can cause large amounts of gaseous microemboli (GME) [7-9]. These air emboli may be sucked into the venous line at the site of cannulation. Also, there might be the introduction of GME to the circuit by degassing of blood-dissolved gasses whenever venous line pressure drops severely to sub-atmospheric levels.

Without safety mechanisms to remove or circuit modifications to handle venous air, gaseous emboli can easily travel through a $\mathrm{mCPB}$ system, causing a greater potential risk for continuous micro air embolization during perfusion [8,10-14]. A bubble trap embedded in the venous line can decrease the amount of gross air entering the centrifugal pump [15-17]. Such traps are mainly intended to act as buoyancy. They prevent larger bubbles from entering the pump in which they can be milled to smaller emboli [18]. These emboli will then become suspended in the blood.

It is clear that every effort should be made to prevent air from being entrained in the venous line to decrease the risk of arterial GME. A possible way of reducing the risk of arterial GME is by reducing sub-atmospheric pressure peaks in the venous line. As described by Tamari et al., adding volume buffer capacity (i.e. 'windkessel') to the venous line by using the 'Better Bladder' can reduce pressure fluctuations at the inlet of roller or centrifugal pumps during kinetic-assisted venous drainage [19] and might, therefore, reduce patient embolic load and improve clinical neurological outcome. 
The aim of this study was to investigate the influence of sub-atmospheric pressures and volume buffer capacity added to the venous line on the generation of GME in extracorporeal bypass circuits. The influence of sub-atmospheric pressure was performed clinically, whereas the effect of volume buffer capacity was tested in vitro.

\section{MATERIALS AND METHODS}

\section{Clinical}

Bubble counts and pressure data of patients who were routinely scheduled for elective coronary artery bypass surgery using CPB were evaluated. Perfusions were performed with three different $\mathrm{CPB}$ circuits routinely used at our institution:

1) The first system, MEC (Figure 1), is a custom designed mCPB (Maquet Cardiopulmonary AG, Hirrlingen, Germany). This system consists of coated 3/8-inch tubing (Bioline, Maquet), a centrifugal pump (Rotaflow, Maquet), and an oxygenator with integrated arterial filter (Quadrox-I BE-HMO71000, Maquet). Additionally, a hardshell venous reservoir (VHK 2001, Maquet) is connected in parallel to the venous line (Figure 1), but clamped out during perfusion. In case of an emergency, the circuit can be converted to an open system using a vacuum source. The total bypass circuit requires a priming volume of approximately $800 \mathrm{~mL}$. The needle vent is attached to the venous line and cardiotomy blood is transferred to a cell saver.

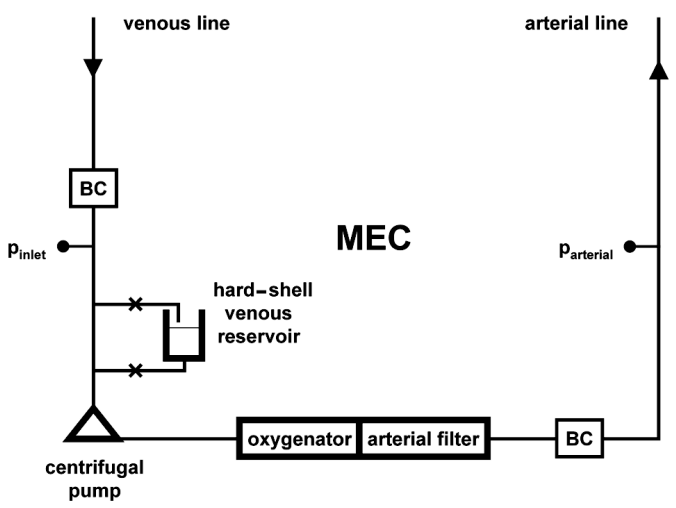

Figure 1 Minimized cardiopulmonary bypass circuit (MEC) using a centrifugal pump, oxygenator with integrated arterial filter, bubble counters $(B C)$ and pressure measurement near the pump inlet and in the arterial line.

2) The ExtraCorporeal Circulation Optimized (ECC.O) system (Sorin Group Italia, Mirandola, Italy) is a mCPB phosphorylcholine-coated system (3/8-inch tubing) 
equipped with an active venous air removal device (VARD). The arterial line filter (Leukoguard-6, Pall, East Hills, NY, USA) is incorporated in the arterial line and a hardshell venous reservoir (Dideco D970 s/v PHISIO, Sorin Group, Italy) is connected in parallel to the venous line (Figure 2), but clamped out during perfusion. As in the MEC circuit, the circuit can be converted to an open system using a vacuum source. The priming volume of this system is approximately $900 \mathrm{~mL}$. Separate roller pumps are used for the needle vent and cardiotomy suction, and blood is transferred to the cardiotomy reservoir from which it is given back to the circulation by occasionally opening the clamped reservoir outlet line.

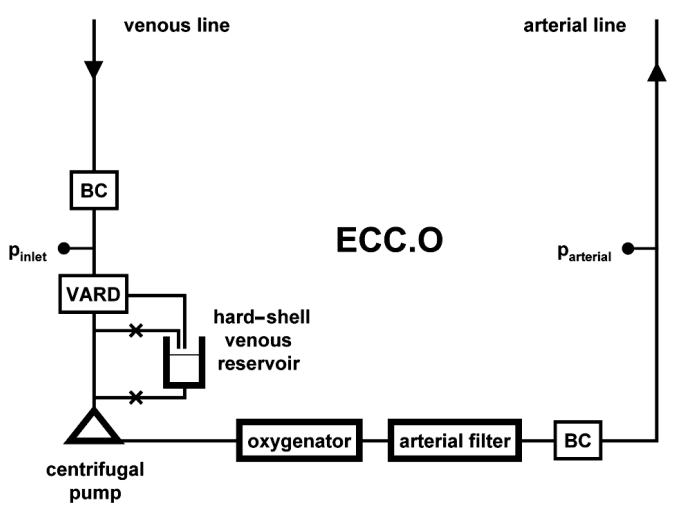

Figure 2 Minimized bypass circuit with active venous air removal device (VARD), oxygenator, arterial filter, bubble counters $(\mathrm{BC})$ and pressure measurement near the pump inlet and in the arterial line.

3) The cCPB) system (Figure 3) consists of a hollow-fibre oxygenator (Capiox SX18, Terumo Cardiovascular Systems, Tokyo, Japan), 1/2-inch venous and 3/8-inch arterial line tubing, 1/2-inch medical grade silicone arterial pump tubing, an arterial line filter (Leukoguard-6, Pall), a collapsible venous reservoir (JVR 1900, Maquet), and a cardiotomy reservoir (Capiox SX hardshell reservoir, Terumo). This system requires approximately $1600 \mathrm{~mL}$ of prime. Separate roller pumps are used for the needle vent and cardiotomy suction, and blood is transferred to the cardiotomy reservoir from which it is given back to the circulation.

A colloidal solution was used for system prime and normothermic perfusion was standardized by clinical practice. Pump flow was maintained around $2.5 \mathrm{~L} \cdot \mathrm{min} \cdot \mathrm{m}^{2}$ to keep venous saturation in the range of $65-70 \%$. The mean arterial pressure was kept around $80 \mathrm{mmHg}$ using phenylephrine infusion, if necessary. 


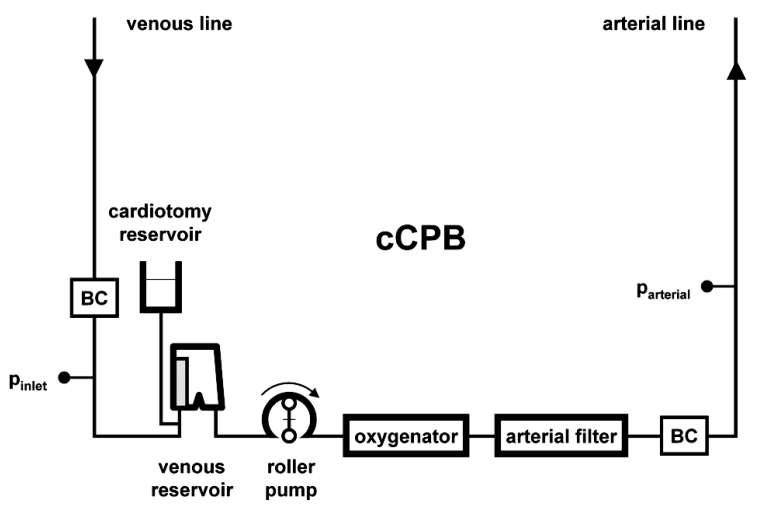

Figure 3 Conventional cardiopulmonary bypass circuit with soft-shell venous reservoir, cardiotomy reservoir, roller pump, oxygenator, arterial filter, bubble counters $(\mathrm{BC})$ and pressure measurement near the inlet of the venous reservoir and in the arterial line.

Microbubble activity was recorded in the venous line and in the arterial line downstream of the arterial filter at a sample frequency of $0.2 \mathrm{~Hz}$, using a bubble counting device (Bubble Counter BC200, Gampt GmbH, Zappendorf, Germany). Flow was measured at the outlet of the oxygenator using an ultrasonic clamp-on flow probe (H9XL, Transonic Systems Inc., Ithaca, NY, USA). Pressures were measured in the venous line, approximately $80 \mathrm{~cm}$ from the cannulae, and at the outlet of the oxygenator, using pressure transducers (PX604, TruWave, Edwards Lifesciences, Irvine, CA, USA). Electronic data were acquired with a sampling frequency of $250 \mathrm{~Hz}$ using a programmable PC-based acquisition system (MPAQ amplifier with IDEEQ software, Instrument Development Engineering \& Evaluation, Maastricht University Medical Centre, Maastricht, the Netherlands).

\section{In vitro}

The effect of volume buffer capacity added to the venous line on the generation of sub-atmospheric pressure and GME was studied in a mock circulation of a mCPB circuit primed with $0.9 \% \mathrm{NaCl}$ solution (Figure 4). Volume buffer capacity was provided by a Better Bladder (Circulatory Technology Inc., Oyster Bay, NY, USA). The centrifugal pump flow (Rotaflow, Maquet) was set to approximately $5 \mathrm{~L} / \mathrm{min}$ with an initial pressure of- $80 \mathrm{mmHg}$ at the inlet side of the pump (p $\mathrm{p}_{\text {venous line), where- }}$ as a non-occlusive single-roller roller pump (20 rpm) partially, periodically and transiently obstructed the venous line, thereby, simulating recurring short-lasting reduced venous return as it may occur in clinical minimized cardiopulmonary bypass. A hollow-fibre oxygenator was used intermittently for the elimination of gaseous bubbles from the circulation to minimize re-entering using vacuum, or to restore gaseous dissolved content in the fluid. The effect of the Better Bladder 
during transient reduced venous return on pressure and bubble count was evaluated by respectively opening clamp A while closing clamp B and vice versa.

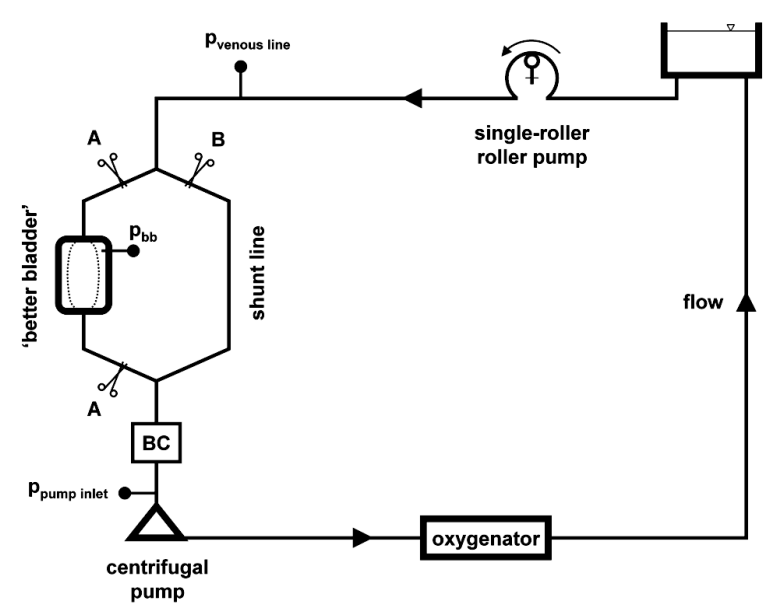

Figure 4 Mock circulation of a minimized circuit with incorporated Better Bladder, pressure measurement and bubble counters (BC). The single-roller roller pump is set non-occlusive and simulates repeatedly developing transient reduced venous return.

\section{Statistical analysis}

The ANOVA procedure was used to test the difference of mean values in groups. The relationship between venous sub-atmospheric line pressure and GME activity in both venous and arterial lines was analysed by cross-correlation function and regression procedure (SPSS version 16.0, SPSS Inc., Chicago, IL, USA). P-values less than 0.05 were considered statistically significant. All values are expressed as mean \pm standard deviation.

\section{Results}

\section{Clinical data}

GME activity in the arterial line during clinical perfusion with a CCPB system $(n=12)$ was the lowest in comparison to the minimized systems $(312 \pm 465$ with cCPB versus $311 \pm 421$ with MEC $(n=7)$ and 1,966 $\pm 1,782$ with ECC.O $(n=8)$ cumulative counts per 10 minute time interval, respectively; $p=0.03$ ) (Figure 5). Figure 6 shows the corresponding cumulative volume of gas bubbles registered in the venous and arterial lines per $10 \mathrm{~min}$ intervals. However, the average volume per bubble in the arterial line was highest in cases with a CCPB $(12.5 \pm 8.3 \mathrm{~nL}$ versus $8.0 \pm 4.2 \mathrm{~nL}$ in MEC and $4.6 \pm 4.8 \mathrm{~nL}$ in ECC.O; $p=0.04$ for both; data not graphically displayed). Overflow bubble count, i.e. signals coming from bubbles of more than $500 \mu \mathrm{m}$ in diameter, 
were registered during 2 cases with MEC (28\%), 2 cases with ECC.O (25\%) and 3 cases with cCPB (25\%). In all cases, the postoperative period was uneventful.
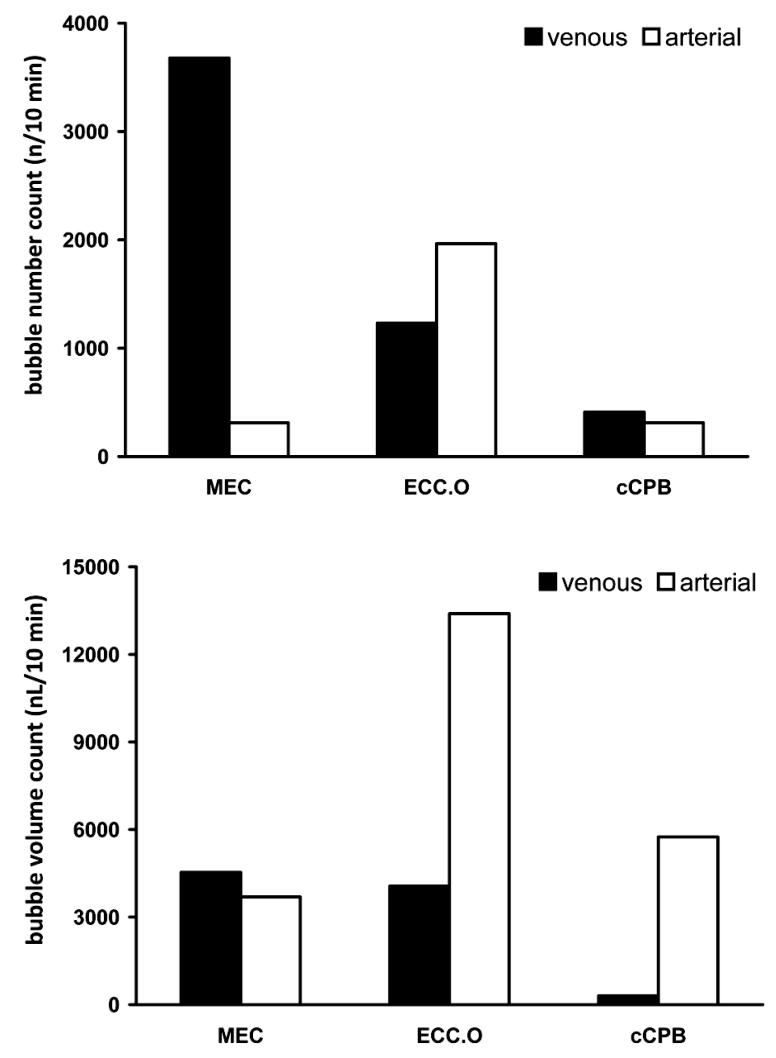

Figure 5 Cumulative number of microbubbles registered in both venous and arterial lines, per cardiopulmonary bypass circuit, per 10 minute interval.

Cross-correlation function showed a significant correlation between gas bubbles and sub-atmospheric pressure peaks in the venous line in $56 \%$ of MEC cases, in $43 \%$ of the ECC.O cases, and in one case with the CCPB system (12\%). In other words, the appearance of GME in the venous line of MEC was directly related to peaks of subatmospheric pressure. In cases with $\mathrm{CCPB}$ using gravity drainage, GME in the venous line cannot be explained by 'extreme' suction. The bivariate correlation procedure showed a significant correlation between sub-atmospheric pressure peaks and GME in the venous line (Pearson's correlation factor -0.35 for MEC). Much lower was this relationship in ECC.O cases (0.02) and in cases using the cCPB (-0.06). 


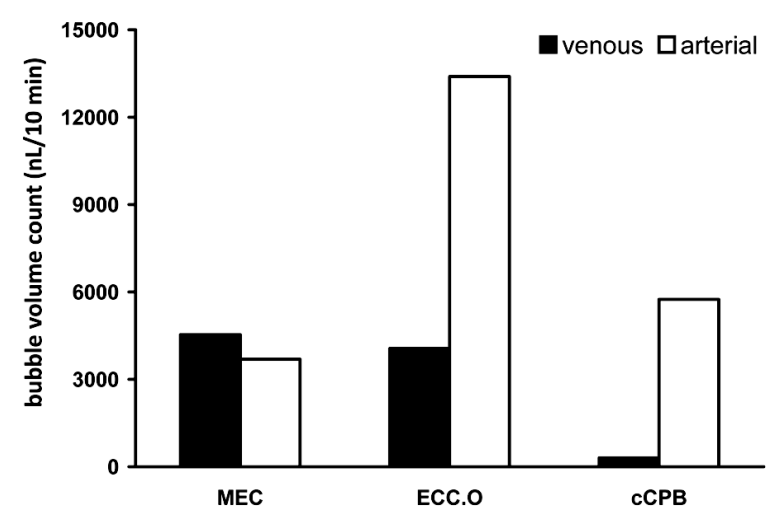

Figure 6 Cumulative volume of gas bubbles registered in venous and arterial lines, per cardiopulmonary bypass circuit, per $10 \mathrm{~min}$ interval.

Gas bubble activity in the arterial line was significantly related to gas bubbles in the venous line (Pearson's correlation factor for MEC=0.25; ECC.O=0.65). There was no such correlation in cases of $\mathrm{CCPB}$.

Table 1 shows the average venous line and venous line peak pressures during periods with and without emboli counts. Pump flow values in the three groups are comparable. With the ECC.O system, both average venous line pressures and venous line peak pressures are higher than when using the MEC.

\section{In vitro data}

The incorporation of the BB can dampen fluctuations of the venous line pressure during transient conditions of reduced venous return in $\mathrm{mCPB}$ by approximately $30 \%$. Figure 7 shows the effect of the Better Bladder during limited venous return on venous line pressure and gaseous emboli measured in the mock circulation. By dampening, the Better Bladder decreased the number of GME by up to $85 \%$. 
Table 1 Venous line pressures and corresponding pump flows.

\begin{tabular}{llll}
\hline & mean \pm SD & mean \pm SD & $p$-value \\
\hline MEC & without gas emboli n=6,653 & with gas emboli $\mathbf{n = 4 , 2 1 1}$ \\
venous pressure peaks (mmHg) & $-51 \pm 38$ & $-81 \pm 60$ & 0.0001 \\
venous pressure (mmHg) & $-44 \pm 33$ & $-66 \pm 48$ & 0.0001 \\
flow ( $/$ /min) & $4.0 \pm 1.4$ & $3.9 \pm 1.2$ & 0.0001 \\
ECC.O & without gas emboli $\mathbf{n = 6 , 9 7 7}$ & with gas emboli $\mathbf{n = 3 , 1 0 4}$ \\
venous pressure peaks (mmHg) & $-23 \pm 46$ & $-37 \pm 48$ & 0.0001 \\
venous pressure (mmHg) & $-19 \pm 42$ & $-29 \pm 42$ & 0.0001 \\
flow (L/min) & $4.1 \pm 1.4$ & $4.3 \pm 1.0$ & 0.0001 \\
cCPB system & without gas emboli $\mathbf{n = 1 , 3 6 2}$ & with gas emboli $\mathbf{n = 5 , 2 4 7}$ \\
venous pressure peaks (mmHg) $28 \pm 20$ & $23 \pm 12$ & 0.0001 \\
venous pressure (mmHg) & $38 \pm 19$ & $35 \pm 10$ & 0.0001 \\
flow (L/min) & $3.9 \pm 1.4$ & $4.2 \pm 0.9$ & 0.0001 \\
\hline
\end{tabular}

MEC, minimized cardiopulmonary bypass; ECC.O, extracorporeal circulation optimized; CCPB, conventional closed cardiopulmonary bypass; $\mathrm{SD}$, standard deviation.

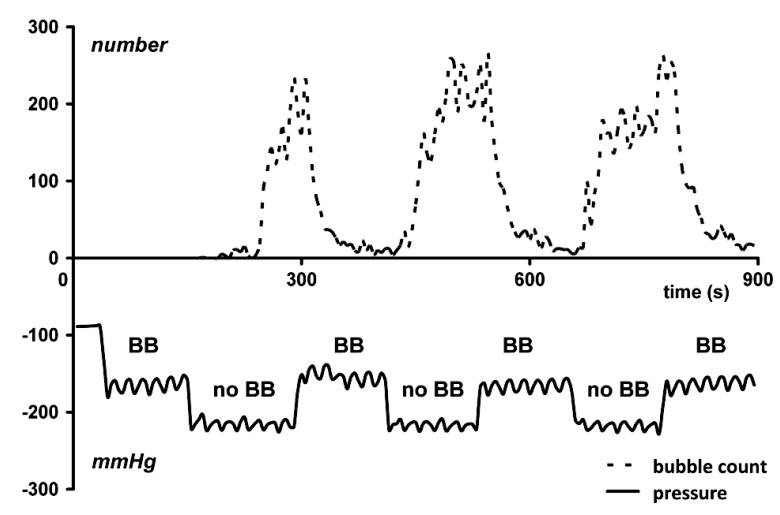

Figure 7 Venous pressure and resultant bubble count during conditions of reduced venous return with (BB) and without (no BB) Better Bladder in-line the minimized bypass circuit. With the Better Bladder included, venous pressure is higher and bubble count is clearly diminished.

\section{Discussion}

This study investigated the influence of sub-atmospheric pressures and added volume buffer capacity on the generation of GME in $\mathrm{mCPB}$ systems. Lower subatmospheric pressures tend to induce higher amounts of GME, whereas volume buffer capacity added to the venous line dampens fluctuations of venous line pressure and reduces GME generation. 
The use of CPB may result in the introduction of gaseous emboli into the patient's arterial circulation. These may be introduced during drug infusion via the central venous lines of the anaesthesia or via infusion into the CPB circuit itself [20,21]. Although decreasing venous line pressure increases the risk of air aspiration at the cannulation site, to the best of our knowledge, there is no clinical data available correlating data on GME occurrence with low venous line pressure and degassing in CPB systems. According to Henry's Law, a sudden decrease of line pressure results in gaseous bubble formation in the blood [22], as a pressure decrease disturbs the dissolved gas equilibrium. This study discusses the often underestimated, or even unknown, but present risk of bubble formation when blood is exposed to sub-atmospheric pressures.

The venous line pressures measured in the MEC group were significantly lower than to those in the ECC.O group (Table 1). This is due to the fact that the circuit and, in our cases, the pressure measurement site is located lower in relation to the patient's position when compared to the MEC system, where it is located nearly at table height. The positive pressure measured in the $\mathrm{CCPB}$ group can be explained by the hydrostatic column pushing on the sensor located in the venous line near the reservoir inlet. In the ECC.O group, arterial GME count and volume were higher than in the MEC and $\mathrm{CCPB}$ group. This can be explained by the fact that both the ECC.O and CCPB use cardiotomy suction, which can introduce bubbles into the circuit, but the CCPB features a collapsible venous reservoir that can collect bubbles. In contrast, the average arterial bubble volume was highest in the $\mathrm{CPPB}$ group, which can be explained by the absence of a centrifugal pump that can mill air emboli into smaller bubbles. Moreover, GME resulting from degassing are expected to be smaller, which is seen in the MEC and ECC.O groups.

GME can be quantified using bubble-counting devices, commercially available for clinical application. Two common devices used are the GAMT BCC200 and the Emboli Detection and Classification quantifier (Luna Innovations, Roanoke, VA, USA) [23]. Both devices, however, show major limitations when used for studying 'worst case' scenarios. A worst-case scenario can be a situation of embolic showers or macro air emboli; conditions in which the bubble counters cannot discriminate between individual bubbles (bubble count overflow). Threshold levels, however, can vary between devices and results obtained by one device in a first study cannot be compared or exchanged with results from another device in a second study [24]. Therefore, great care should be taken when correlating measured data with neurocognitive outcome. 
As mentioned before, $\mathrm{mCPB}$ systems have an increased risk of air entrainment $[25,26]$. The data in this study suggest that there is also the risk of introducing GME, even if venous blood is GME free. GME might come from degassing and could add to the explanation that some studies fail to translate the salutary effects of mCPB into clinical benefit $[5,27]$.

Bubbles found in the arterial line can have their origin in the venous line when entering the circuit at the cannulation site. With $\mathrm{mCPB}$ systems, some surgeons, therefore, suggest using a double purge-string suture to prevent any air from being sucked into the circulation. This double snaring, however, cannot prevent the induction of GME resulting from degassing. The degassing occurs in the venous line and inside the centrifugal pump during conditions of reduced venous return. With extreme blood loss, luxation of the heart, cannula obstruction or tube kinking, pump flow is drastically diminished and venous line pressure can transiently peak down to $-300 \mathrm{mmHg}$ or even less. Like Tamari et al., we also noticed the Better Bladder dampened pressure fluctuations (Figure 7) [19]. In addition to the reduction of sub-atmospheric peak pressures, we found a decrease in GME formation. Nevertheless, the Better Bladder remains a passive device that adds volume buffer capacity to the venous line. It does not solve the underlying mismatch of venous return and pump flow. Pump control using servo-regulation and improved venous cannula design has been proposed to optimize venous drainage [28-30]. Minimized CPB systems with Better Bladder and pump servo-regulation, combined with anti-obstructive venous cannula design, could prevent venous line pressures from peaking down to excessively low levels with concomitant GME formation, while pump speed adapts to venous drainage to maintain the maximal level of support available at that instance.

In conclusion, severe sub-atmospheric fluctuations of venous line pressure during kinetic-assisted drainage, as used in minimized cardiopulmonary bypass systems, are related to gaseous microemboli. Volume buffer capacity added to the venous line can effectively dampen pressure fluctuations resulting from abrupt changes in venous return and, therefore, can help to increase the safety of minimized cardiopulmonary bypass by reducing gaseous microemboli formation resulting from degassing.

\section{ACKNOWLEDGEMENTS}

The authors would like to acknowledge Miss Anouk A.M.A. Lindelauf for her assistance during data collection. The authors are grateful to the American Academy of Cardiovascular Perfusion who distinguished this work with the Best Paper Award at the 2011 Annual Academy Meeting. 


\section{REFERENCES}

1. Anastasiadis K, Asteriou C, Deliopoulos A, et al. Haematological effects of minimized compared to conventional extracorporeal circulation after coronary revascularization procedures. Perfusion 2010; 25:197-203.

2. Benedetto U, Angeloni E, Refice S, et al. Is minimized extracorporeal circulation effective to reduce the need for red blood cell transfusion in coronary artery bypass grafting? Metaanalysis of randomized controlled trials. J Thorac Cardiovasc Surg 2009; 138:1450-1453.

3. Vohra HA, Whistance R, Modi A, Ohri SK. The inflammatory response to miniaturised extracorporeal circulation: A review of the literature. Mediators Inflamm 2009; 2009:707042.

4. Immer FF, Ackermann A, Gygax E, et al. Minimal extracorporeal circulation is a promising technique for coronary artery bypass grafting. Ann Thorac Surg 2007; 84: 1515-1520; discussion 1521.

5. Nollert G, Schwabenland I, Maktav D, et al. Miniaturized cardiopulmonary bypass in coronary artery bypass surgery: marginal impact on inflammation and coagulation but loss of safety margins. Ann Thorac Surg 2005; 80:2326-2332.

6. Simons AP, Reesink KD, Lance MD, et al. Dynamic filling index: a novel parameter to monitor circulatory filling during minimized extracorporeal bypass. Eur J Cardiothorac Surg 2009; 36:330-334.

7. Wang $\mathrm{S}$, Undar A. Vacuum-assisted venous drainage and gaseous microemboli in cardiopulmonary bypass. J Extra Corpor Technol 2008; 40:249-256.

8. Lapietra A, Grossi EA, Pua BB, et al. Assisted venous drainage presents the risk of undetected air microembolism. J Thorac Cardiovasc Surg 2000; 120:856-862.

9. Willcox TW, Mitchell SJ, Gorman DF. Venous air in the bypass circuit: a source of arterial line emboli exacerbated by vacuum-assisted drainage. Ann Thorac Surg 1999; 68:1285-1289.

10. Norman MJ, Sistino JJ, Acsell JR. The effectiveness of low-prime cardiopulmonary bypass circuits at removing gaseous emboli. J Extra Corpor Technol 2004; 36:336-342.

11. Jones TJ, Deal DD, Vernon JC, Blackburn, N, Stump, DA. How effective are cardiopulmonary bypass circuits at removing gaseous microemboli? J Extra Corpor Technol 2002; 34:34-39.

12. Huybregts RM, Veerman DP, Vonk AB, et al. First clinical experience with the air purge control and electrical remote-controlled tubing clamp in mini bypass. Artificial organs 2006; 30:721-724.

13. Mitsumaru A, Yozu R, Matayoshi T, et al. Efficiency of an air filter at the drainage site in a closed circuit with a centrifugal blood pump: an in vitro study. ASAIO J 2001; 47:692-695.

14. Morita M, Yozu R, Matayoshi T, Mitsumaru, A, Shin, H, Kawada, S. Closed circuit cardiopulmonary bypass with centrifugal pump for open-heart surgery: new trial for air removal. Artif Organs 2000; 24:442-445.

15. Issitt RW, Mulholland JW, Oliver MD, et al. Aortic surgery using total miniaturized cardiopulmonary bypass. Ann Thorac Surg 2008; 86:627-631.

16. Kutschka I, Schonrock U, El Essawi A, Pahari, D, Anssar, M, Harringer, W. A new minimized perfusion circuit provides highly effective ultrasound controlled deairing. Artif Organs 2007; 31:215-220.

17. Roosenhoff TP, Stehouwer MC, De Vroege R, Butter, RP, Van Boven, WJ, Bruins, P. Air removal efficiency of a venous bubble trap in a minimal extracorporeal circuit during coronary artery bypass grafting. Artif Organs 2010; 34:1092-1098.

18. Rider SP, Simon LV, Rice BJ, Poulton, CC. Assisted venous drainage, venous air, and gaseous microemboli transmission into the arterial line: an in-vitro study. J Extra Corpor Technol 1998; 30:160-165. 
19. Tamari Y, Lee-Sensiba K, Ganju R, Chan, R, Hall, MH. A new bladder allows kinetic venous augmentation with a roller pump. Perfusion 1999; 14:453-459.

20. Sauren L, Mooren E, Severdija E, Weerwind, P, Maessen, J. Emboli occurrence during coronary artery bypass surgery: the influence of a new method of perfusionist blood sampling. Perfusion 2008; 23:261-265.

21. Taylor RL, Borger MA, Weisel RD, Fedorko, L, Feindel, CM. Cerebral microemboli during cardiopulmonary bypass: increased emboli during perfusionist interventions. Ann Thorac Surg 1999; 68:89-93.

22. Butler BD. Gaseous micro emboli: concepts and considerations. J Extra Corpor Technol 1983; 15:148-155.

23. Willcox TW, Mitchell SJ. Microemboli in our bypass circuits: a contemporary audit. J Extra Corpor Technol 2009; 41:31-37.

24. De Somer FM, Vetrano MR, Van Beeck JP, Van Nooten, GJ. Extracorporeal bubbles: a word of caution. Interact cardiovasc Thorac Surg 2010; 10:995-1001.

25. Norman MJ, Sistino JJ, Acsell JR. The effectiveness of low-prime cardiopulmonary bypass circuits at removing gaseous emboli. J Extra Corpor Technol 2004; 36:336-342.

26. Murkin JM. Pulsatile versus nonpulsatile perfusion revisited. J Card Surg 2006; 21:355-356.

27. Fromes Y, Gaillard D, Ponzio O, et al. Reduction of the inflammatory response following coronary bypass grafting with total minimal extracorporeal circulation. Eur J Cardiothorac Surg 2002; 22:527-533.

28. Pedersen TH, Videm V, Svennevig JL, et al. Extracorporeal membrane oxygenation using a centrifugal pump and a servo regulator to prevent negative inlet pressure. Ann Thorac Surg 1997; 63:1333-1339.

29. Simons AP, Reesink KD, Lance MD, et al. Reserve-driven flow control for extracorporeal life support: proof of principle. Perfusion 2010; 25:25-29.

30. Simons AP, Ganushchak Y, Wortel, P et al. Laboratory performance testing of venous cannulae during inlet obstruction. Artif Organs 2008; 32:566-571. 


\section{CHAPTER 6}

\section{IMPACT OF INTRAOPERATIVE EVENTS ON CEREBRAL TISSUE OXIMETRY IN PATIENTS UNDERGOING CARDIOPULMONARY BYPASS}

EE Ševerdija*, NP Vranken*, S Teerenstra, YM Ganuschchak, PW Weerwind.

Published in J Extra Corpor Technol 2015; 47:32-37.

* These authors contributed equally to this study.

Presented at the 52nd International Conference of the American Society of Extracorporeal Technology, held March 19-22, 2014 in San Diego, CA, USA. 


\section{Abstract}

Background: Previous studies showed that decreased cerebral saturation during cardiac surgery is related to adverse postoperative outcome. Therefore, we investigated the influence of intraoperative events on cerebral tissue saturation in patients undergoing cardiac surgery with cardiopulmonary bypass (CPB).

Methods: A total of 52 adult patients who underwent cardiac surgery using pulsatile $\mathrm{CPB}$ were included in this prospective explorative study. Cerebral tissue oxygen saturation $\left(\mathrm{S}_{\mathrm{c}} \mathrm{O}_{2}\right)$ was measured in both the left and right cerebral hemisphere. Intraoperative events, involving interventions performed by anesthesiologist, surgeon, and clinical perfusionist were documented. Simultaneously, in-line hemodynamic parameters (partial oxygen pressure, partial carbon dioxide pressure, hematocrit, arterial blood pressure and CPB flow rates) were recorded.

Results: Cerebral tissue saturation was affected by anesthetic induction $(p<0.001)$, placement of the sternal retractor $(p<0.001)$, and initiation $(p<0.001)$ as well as termination of CPB $(p<0.001)$. Placement $(p<0.001)$ and removal of the aortic cross clamp ( $p=0.026$ for left hemisphere, $p=0.048$ for right hemisphere) led to changes in cerebral tissue saturation. In addition, when placing the aortic cross clamp, hematocrit $(p<0.001)$ as well as arterial $(p=0.007)$ and venous $(p<0.001)$ partial oxygen pressures changed.

Conclusion: Cerebral tissue oximetry effectively identifies changes related to surgical events or vulnerable periods during cardiac surgery. Future studies are needed to identify methods of mitigating periods of reduced cerebral saturation. 


\section{INTRODUCTION}

Despite impressive improvements in the overall safety of cardiac surgery, perioperative cerebral injury remains a major concern [1]. The two major causative factors for neuropsychological dysfunction after cardiac surgery are global brain hypoperfusion and cerebral emboli generated by either surgical or perfusion-related interventions [2-6]. Furthermore, worsened control of cerebral blood flow due to hypertension, diabetes or other conditions, imposes patients intraoperatively to increased risk of neurological complications [7,8]. However, evaluation of cerebral hemodynamics may still not be part of routine practice [9].

Intraoperative cerebral monitoring to identify vulnerable periods during cardiac surgery that require prompt intervention (e.g. adjusting the partial carbon dioxide gas pressure or fraction of inspired oxygen) should be a major goal in the fields of cardiac anesthesia, surgery, and perfusion [10,11]. In a randomized, blinded, prospective study of 200 patients, Murkin et al. demonstrated that non-invasive regional cerebral saturation monitoring is associated with a significant improvement in overall outcome after cardiac surgery [12]. Moreover, using a protocol-based interventional strategy to maintain cerebral saturation within $75 \%$ of baseline values during cardiopulmonary bypass (CPB) may improve both neurological and multiorgan dysfunction outcomes in cardiac surgery [12,13]. Using the brain as an index organ for adequate tissue perfusion may therefore be beneficial for all vital organs [14]. Routine monitoring of cerebral saturation during cardiac surgical interventions may therefore detect early signs of post-surgery neurological deficits.

In this study intraoperative events were recorded in order to qualify the effects on cerebral tissue oxygen saturation in patients undergoing cardiac surgery with pulsatile CPB.

\section{MATERIALS AND METHODS}

\section{Patients}

This prospective, explorative non-randomized clinical study included 52 adult patients (38 male and 14 female) that underwent elective cardiac surgery using pulsatile CPB between November 2011 and May 2012. No restrictions or inclusion criteria were applied. Institutional approval was received for this evaluation and since the study did not influence the routine care of the patient, informed consent was waived. 
Non-invasive absolute cerebral tissue oxygen saturation $\left(\mathrm{S}_{\mathrm{ct}} \mathrm{O}_{2}\right)$ was routinely measured via near-infrared spectroscopy (FORE-SIGHT, Casmed, Branford, Connecticut, USA), by placing a fiber optic sensor on each side of the patient's forehead. Cerebral oximetry was measured in both the left and right hemisphere. $\mathrm{S}_{\mathrm{ct}} \mathrm{O}_{2}$ data were simultaneously recorded every two seconds. All intraoperative events from anesthetic induction to discharge from the operating room were marked including the corresponding time in the data file. No interventions based on $\mathrm{S}_{\mathrm{c}} \mathrm{O}_{2}$ changes were applied intraoperatively and data used for analysis were routine measurements.

\section{Anaesthesia}

After establishing standard anesthetic monitoring including ECG, oxygen saturation and invasive arterial blood pressure measurement, general anesthesia was induced with $0.5 \mathrm{mcg} / \mathrm{kg}$ sufentanil, $1.5 \mathrm{mg} / \mathrm{kg}$ propofol and $0.6 \mathrm{mg} / \mathrm{kg}$ rocuronium. After endotracheal intubation the patients were ventilated with volume-controlled ventilation with tidal volumes of $7-8 \mathrm{ml} / \mathrm{kg}$, positive end-expiratory pressure of 5 $\mathrm{cm} \mathrm{H}_{2} \mathrm{O}$, respiratory rate of $12 / \mathrm{min}$, and a fraction of inspired oxygen of 0.4 , which resulted in normocapnia and normal oxygen oxygen saturation. Anesthesia was maintained with sevoflurane at a minimal alveolar concentration of approximately 0.8. Perioperative analgesic regime contained continuous intravenous administration of s-ketamin, lidocaine and boluses of sufentanil. Prior to surgery a warming blanket (Bair Hugger, 3M Health Care, Delft, the Netherlands) was positioned to maintain normothermia.

\section{Cardiopulmonary bypass}

The CPB system included a standard hollow-fiber membrane oxygenator (Capiox SX18R, Terumo, Tokyo, Japan), a roller pump (S5, Sorin Group S.p.A, Mirandola, Italy), a cardiotomy reservoir (Capiox CXCRXA, Terumo), a collapsible venous reservoir (JVR 1900, Maquet Cardiopulmonary AG, Rastatt, Germany) and an arterial line filter (Leukogard-6, Pall, East Hills, NY, USA). The standard priming of the CPB circuit consisted of $1,500 \mathrm{~mL}$ of $4 \%$ gelofusin (B Braun AG, Melsungen,

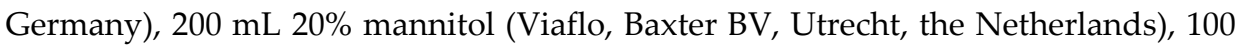
$\mathrm{mL} 20 \%$ human albumin (Albuman, Sanquin, Utrecht, the Netherlands), $50 \mathrm{~mL} \mathrm{8.4 \%}$ $\mathrm{NaHCO}_{3}$, and $20 \mathrm{~mL} \mathrm{10 \%} \mathrm{Calciumgluconate} \mathrm{(B} \mathrm{Braun} \mathrm{AG).} \mathrm{The} \mathrm{total} \mathrm{volume} \mathrm{of} \mathrm{the}$ $\mathrm{CPB}$ priming amounted to $1,870 \mathrm{~mL}$ clear fluid, containing 7,500 IU heparin (Leo Pharmaceutical Products BV, Weesp, the Netherlands). The activated coagulation time was kept $>400$ seconds during bypass. Myocardial preservation was provided via the aortic root or selectively via the coronary ostia by a single dose of cardioplegic solution $\left(800 \pm 200 \mathrm{~mL}\right.$ St. Thomas' hospital No.1) at $4^{\circ} \mathrm{C}$. Depending on the patients' body surface area, the ascending aorta was cannulated using either a 22 or 24 Fr cannula (Maquet Cardiopulmonary AG). A dual stage venous cannula (32/40 
or 36/51 Fr, Edwards Lifesciences BV, Breda, the Netherlands) was used for gravity drainage during CABG and aortic valve surgery. In case mitral or tricuspid valve surgery was involved, the venae cavae were cannulated separately using a DLP single stage metal tip cannula (28 and 31 or 24 and 28 Fr, Medtronic, Minneapolis, USA).

Target flow rates of $\geq 2.6 \mathrm{~L} / \mathrm{min} / \mathrm{m}^{2}$ body surface area were maintained throughout normothermic $\left(36.3^{\circ} \mathrm{C}\right) \mathrm{CPB}$. Pulsatile flow (radial artery pulse pressure $\geq 25 \mathrm{mmHg}$ ) was used only during the period of cross clamping with a frequency of $70 \mathrm{bpm}$, a base flow of $28 \%(1.4 \mathrm{~L} / \mathrm{min})$, and a pulse width of $50 \%(0.42 \mathrm{~s})$. Mean arterial blood pressure was maintained at $80 \pm 10 \mathrm{mmHg}$ by titration of phenylephrine $(0.4 \mathrm{mg} / \mathrm{mL})$ via an infusion pump if necessary. The sweep gas and fraction of inspired oxygen settings for the oxygenator were titrated to maintain normocapnia (arterial partial carbon dioxide pressure - $\mathrm{p}_{2} \mathrm{CO}_{2} 4.5-5.5 \mathrm{kPa}$ ) and normoxia (partial arterial oxygen pressure - $\mathrm{p}_{\mathrm{a}} \mathrm{O}_{2} 11.0$ - $14.0 \mathrm{kPa}$ ). All patients received tranexamic acid (2 mg) during $\mathrm{CPB}$. The transfusion trigger during CPB was set at a hematocrit level $<25 \%$. Pericardial blood was drained and washed with a cell saver device. During valve and aortic root procedures carbon dioxide flooding was routinely used. By maintaining in-line normocapnia, no episodes of high $\mathrm{p}_{\mathrm{a}} \mathrm{CO}_{2}$ that could have potentially influenced the cerebral saturation occurred.

\section{Near-infrared spectroscopy}

Cerebral tissue oximetry is measured non-invasively as described by Murkin and Arango (13). In short, oxygen content in the frontal lobes is measured by near infrared light penetrating the skin, skull and other protective tissues. Near-infrared light $(660-940 \mathrm{~nm})$ is partly scattered by chromophores within the tissue, absorbed by oxyhemoglobin $\left(\mathrm{HbO}_{2}\right)$ or deoxyhemoglobin $(\mathrm{Hb})$. The fiber optic sensors used in this study emit light at four different wavelengths to obtain greater precision for estimation of oxygen content.

\section{Data processing}

To be able to relate changes in cerebral saturation to occurring events, several hemodynamic parameters were recorded continuously during CPB: pump flow, arterial blood pressure (ABP), as well as continuous in-line $\mathrm{p}_{\mathrm{C}} \mathrm{CO}_{2}$ and $\mathrm{p}_{\mathrm{a}} \mathrm{O}_{2}$, venous saturation $\left(\mathrm{S}_{\mathrm{v}} \mathrm{O}_{2}\right)$, and electrolytes measurement via an optical fluorescence and reflectance-based system (CDI-500, Blood Parameter Monitoring System, Terumo, Japan). Pump flow was recorded by an ultrasonic flow monitor (Transonic Systems Europe BV, Maastricht, the Netherlands). All in-line measurements except for $\mathrm{S}_{\mathrm{ct}} \mathrm{O}_{2}$, were collected using a data acquisition system (M-PAQ, Maastricht Instruments, Maastricht, the Netherlands). To combine all data, sample frequencies had to be 
equalized in all files. To achieve this, data were either averaged (decreasing the frequency of measuring), or the same data point was duplicated and added after its original data point (increasing the frequency of measuring). Subsequently, data synchronization was performed. For further data analysis, samples of 5 minutes were selected. One time sample was selected prior to the event, the other one during the event.

\section{Statistical analysis}

Data are shown as mean \pm standard deviation (SD) or median [interquartile range], depending on data distribution. A p-value of $<0.05$ was considered statistically significant.

For events occurring before or after $\mathrm{CPB}$, only cerebral $\mathrm{S}_{\mathrm{c}} \mathrm{O}_{2}$ and $\mathrm{ABP}$ were compared between samples prior and during the event. For placement and removal of the aortic cross clamp, cerebral $\mathrm{S}_{\mathrm{ct}} \mathrm{O}_{2}$, mean $\mathrm{ABP}$, pump flow, and blood parameters $\left(\mathrm{p}_{\mathrm{a}} \mathrm{CO}_{2}, \mathrm{p}_{\mathrm{a}} \mathrm{O}_{2}, \mathrm{p}_{\mathrm{v}} \mathrm{O}_{2}\right.$ and hematocrit) were compared. If one or more parameters differed significantly between the two samples, a possible cause of the difference in $\mathrm{S}_{\mathrm{ct}} \mathrm{O}_{2}$ could be determined.

Statistical analysis was performed using the Statistical Package for Social Sciences version 15.0 (SPSS inc. Chicago, IL, USA). Distribution of data was tested using the Shapiro-Wilk test. The paired student's t-test or Wilcoxon signed-rank test was used to compare cerebral saturation measurement before and during events.

\section{Results}

Demographic and baseline data for the 52 enrolled patients are listed in Table 1. Surgical and perfusion related data are presented in Table 2. 
Table 1 Demographic and baseline data.

\begin{tabular}{ll}
\hline Gender (male/female) & $38 / 14$ \\
Age (years) & $68[59.3-75.8]$ \\
BMI $\left(\mathrm{kg} / \mathrm{m}^{2}\right)$ & $26.0[24.4-27.8]$ \\
Diabetes Mellitus (y/n) & $7 / 45$ \\
Peripheral vascular disease (y/n) & $4 / 48$ \\
Mean ABP pre CPB (mmHg) & $102.1 \pm 11.3$ \\
$\mathrm{Sct}_{2}$ mean pre CPB $(\%)$ & $70[66-71]$ \\
Mean Hct pre CPB (\%) & $41.0 \pm 3.9$ \\
\hline
\end{tabular}

$\mathrm{ABP}$, arterial blood pressure; $\mathrm{BMI}$, body mass index; $\mathrm{CPB}$, cardiopulmonary bypass; Hct, hematocrit; $\mathrm{S}_{\mathrm{ct}} \mathrm{O}_{2}$, cerebral tissue oxygen saturation. Parameters in italics are shown as median (interquartile range), and remaining parameters are shown as absolute numbers or mean $\pm \mathrm{SD}$.

Table 2 Surgical and perfusion data.

\begin{tabular}{ll}
\hline Isolated CABG surgery & $59.7 \%(\mathrm{n}=31)$ \\
Isolated valve surgery & $23.1 \%(\mathrm{n}=12)$ \\
CABG + valve surgery & $13.5 \%(\mathrm{n}=7)$ \\
Ascending aorta replacement & $3.8 \%(\mathrm{n}=2)$ \\
CPB time (minutes) & $80[69-105]$ \\
Aortic cross clamp time (minutes) & $55[43-70]$ \\
Mean Hct (\%) during CPB & $28[25-29]$ \\
Mean pump flow (L/min) & $4.3 \pm 0.5$ \\
Mean ABP (mmHg) during CPB & $75[71-80]$
\end{tabular}

$\mathrm{ABP}$, arterial blood pressure; $\mathrm{CABG}$, coronary artery bypass grafting; Hct, hematocrit. Data for mean pump flow is presented as mean \pm standard deviation. Data for CPB time, aortic cross-clamp time, Hct and ABP are presented as median (interquartile range).

During the entire intraoperative period, cerebral $\mathrm{S}_{\mathrm{c}} \mathrm{O}_{2}$ showed comparable values for both left and right hemisphere. Left and right mean $\mathrm{S}_{\mathrm{ct}} \mathrm{O}_{2}$ values of $71 \pm 4 \%$ and $70 \pm 4 \%$ were found prior to $\mathrm{CPB}, 66 \pm 4 \%$ and $65 \pm 4 \%$ during $\mathrm{CPB}$, and $70 \pm 4 \%$ and $69 \pm 5 \%$ after $\mathrm{CPB}$, respectively. Since the difference between the left and right hemisphere can be neglected, the influence of intraoperative events on $\mathrm{S}_{\mathrm{c}} \mathrm{O}_{2}$ are depicted in Figure 1 using mean values. 


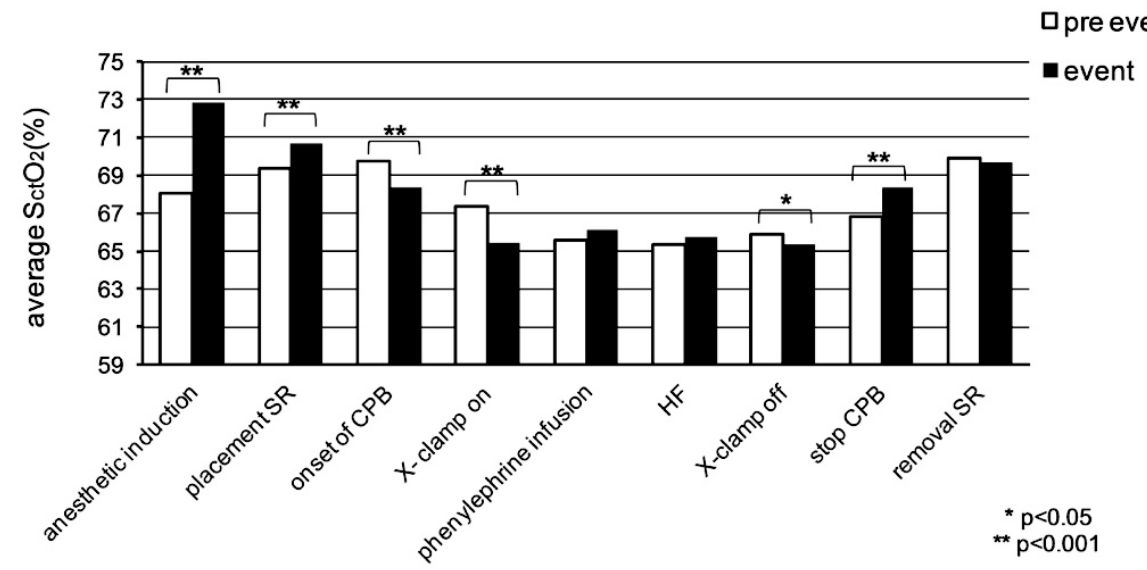

Figure 1 Influence of intraoperative events on mean cerebral $\mathrm{S}_{\mathrm{c}} \mathrm{O}_{2} . \mathrm{CPB}$, cardiopulmonary bypass; $\mathrm{HF}$, hemofiltration; $\mathrm{S}_{\mathrm{ct}} \mathrm{O}_{2}$, cerebral oxygenation; $\mathrm{SR}$, sternal retractor; $\mathrm{X}$-clamp, aortic cross clamp.

Onset of $\mathrm{CPB}$, placement and removal of the aortic cross clamp (difference in significance between hemispheres, $p=0.026$ for the left and $p=0.048$ for right hemisphere) resulted in a decrease in $\mathrm{S}_{\mathrm{c}} \mathrm{O}_{2}$, whereas anesthetic induction $(p<0.001)$, placement of the sternal retractor $(p<0.001)$ and termination of CPB $(p<0.001)$ showed to be related to an increase in $\mathrm{S}_{\mathrm{ct}} \mathrm{O}_{2}$ (Figure 1). Furthermore, phenylephrine infusion $(p=0.356)$, hemofiltration $(p=0.892)$ and removal of the sternal retractor $(p=0.692$ for the left hemisphere, $p=0.123$ for the right hemisphere) did not result in a significant $\mathrm{S}_{\mathrm{c}} \mathrm{O}_{2}$ change. Aortic cross-clamping showed to have a statistically significant impact on cerebral saturation as shown in Figure 1, which may in part be explained by differences in arterial and venous blood gas parameters and hematocrit. During placement of the aortic cross clamp, hematocrit decreased significantly $(p<0.001)$, as well as arterial $(p=0.007)$ and venous $(p<0.001)$ oxygen levels (Table 3$)$. The changes in hematocrit, arterial and venous $\mathrm{pO}_{2}$ did not occur during removal of the aortic cross clamp. 
Table 3 Influence of aortic cross clamping on hemodynamic parameters.

\begin{tabular}{lllll}
\hline X-clamp on & & Prior to X-clamp & During X-clamp & $p$-value \\
\hline & $\mathrm{Mean} \mathrm{ABP}(\mathrm{mmHg})$ & $72.4[63.4-80.3]$ & $73.9[63.5-79.2]$ & 0.420 \\
& $\mathrm{p}_{\mathrm{a}} \mathrm{CO}_{2}(\mathrm{kPa})$ & $5.5[5.1-5.6]$ & $5.4[5.0-5.6]$ & 0.792 \\
& $\mathrm{p}_{\mathrm{a}} \mathrm{O}_{2}(\mathrm{kPa})$ & $14.9[12.6-18.0]$ & $13.0[12.3-16.5]$ & 0.007 \\
& $\mathrm{p}_{\mathrm{v}} \mathrm{O}_{2}(\mathrm{kPa})$ & $5.9 \pm 1.0$ & $5.3 \pm 0.6$ & $<0.001$ \\
& $\mathrm{Hct}(\%)$ & $28.7[26.5-31.6]$ & $26.4[24.6-29.0]$ & $<0.001$ \\
& $\mathrm{CPB}$ flow $(\mathrm{L} / \mathrm{min})$ & $4.3[3.8-4.7]$ & $4.4[4.0-4.7]$ & 0.680 \\
X-clamp off & & Prior to X-clamp removal & After X-clamp removal & $p$-value \\
& & $74.4[68.7-80.7]$ & $71.6[67.2-77.7]$ & 0.196 \\
& $\mathrm{Mean} \mathrm{ABP}(\mathrm{mmHg})$ & $5.5[5.3-5.7]$ & 0.017 \\
& $\mathrm{p}_{\mathrm{aCO}}(\mathrm{kPa})$ & $5.5[5.2-5.7]$ & $14.4 \pm 2.7$ & 0.255 \\
& $\mathrm{p}_{\mathrm{a}} \mathrm{O}_{2}(\mathrm{kPa})$ & $14.0 \pm 2.9$ & $5.1 \pm 0.6$ & 0.535 \\
& $\mathrm{p}_{\mathrm{v}} \mathrm{O}_{2}(\mathrm{kPa})$ & $5.1 \pm 0.5$ & $27.5[23.7-29.6]$ & 0.761 \\
& $\mathrm{Hct}(\%)$ & $27.4[24.0-29.0]$ & $3.7[0.1-4.6]$ & 0.093 \\
\hline
\end{tabular}

$\mathrm{ABP}$, arterial blood pressure; $\mathrm{CPB}$, cardiopulmonary bypass; Hct, hematocrit; $\mathrm{p}_{\mathrm{a}} \mathrm{CO}_{2}$, arterial carbon dioxide level; $\mathrm{p}_{\mathrm{a}} \mathrm{O}_{2}$, arterial oxygen level; $\mathrm{p}_{\mathrm{v}} \mathrm{O}_{2}$, venous oxygen level; $\mathrm{X}$-clamp, aortic cross clamp.

In all cases, the postoperative period was uneventful and no intraoperative cerebral ischemic episode occurred.

\section{DISCUSSION}

Intraoperative events showed to affect cerebral oximetry in patients undergoing cardiac surgery with $\mathrm{CPB}$. Since previous studies suggest that a fall in cerebral saturation is related to adverse neurological outcome, routine measurement of cerebral saturation warrants early detection of brain ischemia during surgery [12-14].

Our results showed subtle changes in $\mathrm{S}_{\mathrm{c}} \mathrm{O}_{2}$ readings following several events which appeared statistically significant while absolute differences were relatively small and far from the suggested $20 \%$ decrease when intervention is required [14]. Presumably the events did not provoke any therapeutically relevant changes in cerebral tissue saturation in our study. One can speculate that maintaining normocapnia, normoxia and a tight blood pressure control led to minimized fluctuations in cerebral saturation. Iatrogenic events i.e. placement of the aortic cross clamp can still induce changes in cerebral saturation which do not necessarily require intervention. On the other hand, the extent of cerebral desaturation requiring an intervention may vary between different sensors, implying that no fixed thresholds have 
been set [15]. Nonetheless, cerebral oximetry enables clinicians to observe slight changes in cerebral saturation, which may help to prevent further desaturations.

Induction of general anesthesia resulted in a steep increase in cerebral $\mathrm{S}_{\mathrm{ct}} \mathrm{O}_{2}$, which may be explained by pre-oxygenation with a high-inspired fraction of oxygen and unchanged cardiac output [16]. Conversely, a significant decrease in mean $\mathrm{S}_{\mathrm{ct}} \mathrm{O}_{2}$ occurred with onset of $\mathrm{CPB}$, which can presumably be explained by acute hemodilution, as the hematocrit dropped from approximately $41 \%$ to $28 \%$ (Tables 1 and 2). These findings are in line with the study of Han and colleagues who showed that acute normovolemic hemodilution is associated with a fall in cerebral saturation [17]. Rapid initiation of CPB mostly provoked a drop in $\mathrm{S}_{\mathrm{ct}} \mathrm{O}_{2}$ as resultant of assanguinous priming solution passage through the cerebral vasculature with inadequate oxygen delivery to the brain.

Placement of the sternal retractor is another factor influencing the cerebral saturation as measured by near-infrared spectroscopy. One could hypothesize that the change in cerebral saturation is caused by strong pain signals transported via the spinal cord during the event. In theory, this causes an immediate elevation in arterial blood pressure. However, this effect is not observed in this study, which is potentially due to adequate anesthesia and analgesia. Another theory is that opening the thoracic cavity influenced intrathoracic pressures and venous return, resulting in an increased cerebral saturation. On the other hand, removal of the sternal retractor did not show a significant difference in $\mathrm{S}_{\mathrm{ct}} \mathrm{O}_{2}$. A plausible explanation for this observation is that the hypothesized pain signals were not activated or not in an extent large enough to cause a significant difference. Also, instead of generating pressure on the site of the sternum and surrounding tissue (as in placement of the sternal retractor), the opposite effect could have taken place i.e. relaxation.

Another event that showed to affect cerebral saturation is aortic cross clamping, which may in part be explained by differences in arterial and venous blood gas parameters and hematocrit (Table 3). Placement of the aortic cross clamp resulted in sudden excessive withdrawal of blood volume from patient to the heart-lung machine by lowering the CPB flow. This resulted in loss of cardiac output and a drop in arterial blood pressure with concomitant negative consequences on oxygen delivery to the brain, as reflected by significantly lowered values of $\mathrm{pO}_{2}$ in both arterial and venous blood. CPB flow was not significantly different between samples of placement and removal of the cross clamp, most likely because the duration of lowered flow was too short and the heart-lung machine was at optimal flow before and after both these events. In contrast, the decrease in arterial and venous $\mathrm{pO}_{2}$ did not appear while removing the cross clamp as by routine during removal of 
the aortic cross clamp the CPB flow and arterial blood pressure are not actively lowered. Vasoconstriction using phenylephrine infusion did not appear to affect cerebral saturation, which is in contrast with the results of a previous study by Moerman and colleagues [18]. However, Brassard et al. recently showed that the negative effect might only be present in diabetic patients [19].

Finally, a study limitation is the lack of an intervention-guided design. Physiologic parameters are kept within a certain range, preventing major fluctuations in cerebral tissue saturation during the intraoperative period. Furthermore, data synchronization involving the equalization of the sample frequency led to data (pump flow and $\mathrm{ABP}$ ) to be leveled out and small fluctuations to be diminished compared to the raw data.

In conclusion, cerebral tissue oximetry by near-infrared spectroscopy effectively identifies subtle changes in cerebral saturation related to surgical events or vulnerable periods during cardiac surgery. Future studies in larger cohorts are required in order to identify therapeutically relevant changes in cerebral saturation as measured by cerebral oximetry. 


\section{REFERENCES}

1. Wolman RL, Nussmeier NA, Aggarwal A, et al. Cerebral injury after cardiac surgery: Identification of a group at extraordinary risk. Multicenter Study of Perioperative Ischemia research group (McSPI) and the Ischemia Research Education Foundation (IREF) investigators. Stroke. 1999; 30:514-522.

2. Roach GW, Kanchuger M, Mangano CM, et al. Adverse cerebral outcomes after coronary bypass surgery. N Engl J Med 1996; 335:1857-1863.

3. Taylor RL, Borger MA, Weisel RD, et al. Cerebral microemboli during cardiopulmonary bypass: increased emboli during perfusionist interventions. Ann Thorac Surg 1999; 68:89-93.

4. Fearn SJ, Pole R, Wesnes K, et al. Cerebral injury during cardiopulmonary bypass: emboli impair memory. J Thorac Cardiovasc Surg 2001; 121:1150-1160.

5. Prasongsukarn K, Borger MA. Reducing cerebral emboli during cardiopulmonary bypass. Semin Cardiothoracic Vasc Anesth 2005; 9:153-158.

6. Stockard JJ, Bialford RG, Schauble JF. Pressure-dependent cerebral ischemia during cardiopulmonary bypass. Neurology 1973; 23:521-529.

7. Caplan LR, Hennerici M. Impaired clearance of emboli (washout) is an important link between hypoperfusion, embolism, and ischemic stroke. Arch Neurol 1998; 55:1475-1482.

8. Millar SM, Alston RP, Andrews PJ, et al. Cerebral hypoperfusion in immediate postoperative period following coronary artery bypass grafting, heart valve, and abdominal aortic surgery. Br J Anaesth 2001; 87:229-236.

9. Kasman N, Brady K. Cerebral oximetry for pediatric anesthesia: why do intelligent clinicians disagree? Paediatr Anaesth 2011; 21:473-478.

10. Edmonds HL, Pro: All cardiac surgical patients should have intraoperative cerebral oxygenation monitoring. J Cardiothoracic Vasc Anesth 2006; 20:445-449.

11. Yao FSF, Tseng CCA, Ho CYA, et al. Cerebral oxygen desaturation is associated with early postoperative neuropsychological dysfunction in patients undergoing cardiac surgery. J Cardiothorac Vasc Anesth 2004; 18:552-558.

12. Murkin JM, Adams SJ, Novick RJ, et al. Monitoring brain oxygen saturation during coronary bypass surgery: A randomized, prospective study. Anesth Analg 2007; 104:51-58.

13. Slater JP, Guarino T, Stack J, et al. Cerebral oxygen desaturation predicts cognitive decline and longer hospital stay after cardiac surgery. Ann Thorac Surg 2009; 87:36-45.

14. Murkin JM, Arango M. Near-infrared spectroscopy as an index of brain and tissue oxygenation. Br J Anaesth 2009; 103(Suppl 1):i3-i13.

15. Apostolidou I, Morrissette G, Sarwar MF, et al. Cerebral oximetry during cardiac surgery: the association between cerebral oxygen saturation and perioperative patient variables. J Cardiothorac Vasc Anesth 2012; 6:1015-1021.

16. Ravussin P, Guinard JP, Ralley F, Thorin D. Effect of propofol on cerebrospinal fluid pressure and cerebral perfusion pressure in patients undergoing craniotomy. Anaesthesia 1988; 43:37-41.

17. Han SH, Ham BM, Oh YS, et al. The effect of acute normovolemic haemodilution on cerebral oxygenation. Int J Clin Pract 2004; 58:903-906.

18. Moerman A, Denys W, De Somer F, Wouters PF, De Hert SG. Influence of variations in systemic blood flow and pressure on cerebral and systemic oxygen saturation in cardiopulmonary bypass patients. Br J Anaesth 2013; 111:619-626.

19. Brassard P, Pelletier C, Martin M, et al. Influence of norepinephrine and phenylephrine on frontal lobe oxygenation during cardiopulmonary bypass in patients with diabetes. J Cardiothorac Vasc Anesth 2014; 28:608-617. 


\section{CHAPTER 7}

\section{GENERAL DISCUSSION}


Despite remarkable progress in equipment and technology of extracorporeal circulation, neurological complications after cardiac surgery are still present and may be linked to altered brain perfusion [1,2]. The two major causative factors for neuropsychological dysfunction after cardiac surgery are global brain hypoperfusion and cerebral emboli generated by either surgical or perfusion-related interventions [3-6]. Furthermore, pre-existing impaired cerebral autoregulation and/or reduced vasomotor reactivity have been associated with adverse cognitive outcome and even risk of death [2]. Worsened control of cerebral blood flow due to hypertension, diabetes or other comorbid conditions, also imposes patients to intraoperative increased risk for neurological complications [7,8]. Moreover, two of the most important factors influencing cerebral blood flow ( $\mathrm{CBF})$, i.e. arterial blood pressure (ABP) and arterial carbon dioxide $\left(\mathrm{p}_{\mathrm{a}} \mathrm{CO}_{2}\right)$ level, are still not tightly controlled during cardiopulmonary bypass (CPB). Blood pressure management is often based on maintaining a mean $\mathrm{ABP}$ between 50 and $60 \mathrm{mmHg}$ [9], and $\mathrm{p}_{\mathrm{a}} \mathrm{CO}_{2}$ is measured intermittently. On the other hand, monitoring of cerebral hemodynamics during CPB is still not a common practice. Consequently, there is no control for adequate functionality of cerebral autoregulation and/or cerebral carbon dioxide reactivity $\left(\mathrm{CO}_{2} \mathrm{R}\right)$. Other adverse factors include uncontrolled hemodilution and transfusion of packed red blood cells. Thus, the focus of this thesis is on aforementioned factors that potentially negatively influence patients' wellbeing after CPB.

According to the Cerebral Autoregulation Research Network (CARNet), the most appropriate method to measure dynamic cerebral autoregulation is transfer function analysis (TFA). It quantifies the transfer of $\mathrm{ABP}$ oscillations to cerebral blood flow velocity (CBFV) as a measure of autoregulation by gain, phase shift and coherence. However, TFA is only reliable with sufficient variation of the input signal, i.e. the $\mathrm{ABP}$. Since in patients undergoing cardiac surgery using non-pulsatile $\mathrm{CPB}$ with a centrifugal pump, hardly any spontaneous oscillations of ABP occurs when the heart is arrested, it was necessary to evoke ABP changes. Therefore, a novel technique was introduced to induce ABP-step disturbances in a 6/min cycles (Chapter 2). Using stepwise changes in pump flow by repetitively switching between three pump flow levels, resulted in a staircase-shaped pump flow pattern with sufficient $\mathrm{ABP}$ variations to change CBFV. The resemblance of $\mathrm{ABP}$ and $\mathrm{CBFV}$ signals to 'pure' sine waves was confirmed by their power spectral densities, which showed a clear peak at $0.1 \mathrm{~Hz}$ and an almost hundredfold lower peak at the third harmonic at $0.3 \mathrm{~Hz}$ (Figure 3 in Chapter 2). On the other hand, it is hypothesized that CPB provokes a highly protective mechanism [10], thereby reducing CBF fluctuations by deactivation of so-called $\mathrm{B}$ waves $(70 \mathrm{mHz})$ revealing monotonous so-called UB waves $(9 \mathrm{mHz})$. However, no significant coherence between $\mathrm{ABP}$ and $\mathrm{CBFV}$ during $\mathrm{CPB}$ was found. This could possibly be due to different dominant frequencies 
occurring in ABP $(9 \mathrm{mHz})$ and CBFV $(70 \mathrm{mHz})$. Conversely, the $0.1 \mathrm{~Hz}$ used in the study described in chapter 2 , induced very high $(\geq 0.9)$ coherence between ABP and $\mathrm{CBFV}$, reflecting a strong linear relation between variability in $\mathrm{ABP}$ and $\mathrm{CBFV}$. The sinusoidal oscillations of ABP and CBFV signals also allowed visual appreciation of phase shift between ABP and CBFV. Due to variation in individual wave shapes, actual value of this phase shift can only consistently be estimated through TFA. Studying coherence showed that apart from changes in ABP, other causes for CBFV variations also exist, i.e. changes in $\mathrm{p}_{\mathrm{a}} \mathrm{CO}_{2}$ and/or sympathetic tone [11,12].

$\mathrm{CO}_{2}$ is a potent cerebral vasodilator that influences $\mathrm{CBF}$ and thereby the dynamic cerebral autoregulation. Subsequently, the observation that gain decreased with increasing $\mathrm{p}_{\mathrm{a}} \mathrm{CO}_{2}$, can be explained by increased vessel dilation causing less responsiveness to changes in ABP. Other studies in which thigh cuff deflation or TFA was used, confirmed impairment of dynamic cerebral autoregulation with hypercapnia $[13,14]$. In addition to the observed findings, reduced phase during CPB may be partly influenced by anaesthetics other than propofol $[15,16]$ and hemodilution. Ogawa et al. [17] showed an impaired dynamic cerebral autoregulation due to hypervolemic hemodilution with an increased gain and a reduced phase. Hemodilution during $\mathrm{CPB}$, therefore, seems to be a plausible explanation for the reduced dynamic cerebral autoregulation capability as seen in the study described in chapter 2.

Assessing dynamic cerebral autoregulation, based on high coherence and worsened autoregulation during hypercapnia, demonstrated that stepwise changes in pump flow is feasible and permits dynamic cerebral autoregulation quantification during $\mathrm{CPB}$. In this way, testing of dynamic cerebral autoregulation may facilitate e.g. the effect of different perfusion strategies or the outcome of impaired dynamic cerebral autoregulation on post-surgery stroke incidence.

Obviously, cerebral autoregulation is a complex physiological mechanism, which is influenced by several factors including hematocrit and $\mathrm{p}_{\mathrm{a}} \mathrm{CO}_{2}[18,19]$. The latter plays an intricate part in the vascular autoregulatory system of the brain, and aims at minimizing the effects of fluctuations in ABP on cerebral perfusion. To the best of our knowledge, however, there is no literature available that combines cerebral autoregulation and/or cerebral vasomotor reactivity with both hematocrit level and $\mathrm{p}_{\mathrm{a}} \mathrm{CO}_{2}$. In the study described in chapter 3 the influence of hemodilution on cerebral autoregulation and cerebral vascular $\mathrm{CO}_{2} \mathrm{R}$ was studied during normothermic nonpulsatile $\mathrm{CPB}$. Cerebral autoregulation during CPB showed to be lower compared to preoperative values, and was affected by both intraoperative hematocrit and $\mathrm{p}_{\mathrm{a}} \mathrm{CO}_{2}$. With impaired cerebral autoregulation being reflected by a decreased autoregulation index (ARI) [20], comparable ARI values as described by Park et al. [21] and 
Engelhard [22] were observed in chapter 3. In that way our baseline and perioperative normocapnic measurements of ARI may be considered clinically representative for intact cerebral autoregulation. Additionally, our baseline values measured in awake unanaesthetized patients may also be applicable to surgical patients in general, in who impaired cerebral autoregulation have been associated with increased occurrence of perioperative stroke [23] or even risk of death [2].

Combining hypercapnia with low hematocrit $(<28 \%)$ showed the largest decrease in ARI compared to baseline (median ARI baseline=7.5). The difference in ARI between patients with higher $(\geq 28 \%)$ and lower $(<28 \%)$ hematocrit $(\triangle \mathrm{ARI}=4.2$ and $\triangle \mathrm{ARI}=4.9$, respectively) was most pronounced at the lower limit of cerebral autoregulation (2.8 [2.3-3.8]), which is found at a $\mathrm{paCO}_{2}$ level of $6.6 \mathrm{kPa}$. A possible explanation for this finding is that hemodilution induces a reduction in viscosity and compensatory vasodilatation therefore increasing $\mathrm{CBFV}$, which results in a decreased autoregulatory capacity [24]. Despite the observed decrease in ARI, none of the study patients experienced any adverse neurological complication as expressed by delirium, cerebral vascular accident, and transient ischemic attack during the surgical procedure or in a 30-day follow-up. This could be attributed to the short duration (5 minutes) in which hypercapnia was induced. Another explanation can be found in our clinical protocol of keeping the mean $\mathrm{ABP}$ in the 70 to $90 \mathrm{mmHg}$ range, which is close to the baseline values of our patients, and in which cerebral autoregulation is generally considered present [25]. Nevertheless, the potential detrimental effect of combined hypercapnia and hemodilution underlines once more the importance of adequate $\mathrm{p}_{\mathrm{a}} \mathrm{CO}_{2}$ monitoring and tight perioperative $\mathrm{p}_{\mathrm{a}} \mathrm{CO}_{2}$ control, while avoiding excessive hemodilution.

A technique to limit hemodilution during normothermic CPB using retrograde autologous priming (RAP) was explored in patients undergoing coronary artery bypass grafting surgery (Chapter 4 ). This study shows a reduced number of blood transfusions during both $\mathrm{CPB}$ and the postoperative period when using RAP. As a resultant, patients in the RAP group had a higher hematocrit on bypass and fewer patients needed blood transfusion compared to the NON-RAP group. These findings are in accordance with other studies $[9,26]$. Although the NON-RAP group counted more female patients, who have a predetermined higher transfusion risk as compared to male patients, both bivariate and multivariate logistic regression analysis indicated a prominent effect of RAP on blood transfusion. Further, the literature provides increasing evidence that a low hematocrit is associated with increased postoperative morbidity and mortality. Studies from Koch et al. [32,33] show that a hematocrit $<22 \%$ resulted in an increased morbidity and decreased both short- and long-term survival. Moreover, Habib et al. [34] showed that a hematocrit 
$<22 \%$ is an independent risk factor for mortality and can be detrimental to the neurological outcome of patients. Similarly, Karkouti et al. [35] found direct relationship between the degree of hemodilution during $\mathrm{CPB}$ and perioperative stroke.

The findings described in chapter 4 showed that retrograde autologous priming of the CPB circuit attenuates acute hemodilution and blood transfusion requirements in coronary artery bypass surgery. It is a safe and effective technique that should be considered as an integral part of a multimodal approach on blood conservation.

Beside the proven RAP technique, minimizing the CPB system in the recent years has become more and more popular. A growing body of evidence indicates the superiority of minimized cardiopulmonary bypass (mCPB) systems compared to conventional cardiopulmonary bypass $(\mathrm{cCPB})$ systems, in regards to inflammatory reactions and transfusion requirements [36-39]. Evident benefits of $\mathrm{mCPB}$ systems, however, do not come without consequences like loss of safety margins [40]. In $\mathrm{mCPB}$ systems, the pump flow is dependent on the venous filling [41]. The equilibrium of venous filling is a delicate one: for myocardial preservation, one needs a very limited venous filling (an empty right heart); on the other hand, for an acceptable pump flow, a certain venous filling is necessary. Moreover, venous filling is, among others, dependent on the position of the venous cannula and repositioning of the heart. So, in a $\mathrm{mCPB}$ system, the pump flow is directly related to the conditions of (reduced) venous return. During limited venous return, kineticassisted drainage, as used in these circuits, can result in severe fluctuations of venous line pressures. Some studies demonstrate that sub-atmospheric venous line pressures can cause large amounts of gaseous microemboli (GME) [42-44]. These air emboli may be sucked into the venous line at the site of cannulation. Also, there might be the introduction of GME to the circuit by degassing of blood-dissolved gasses whenever venous line pressure drops severely to sub-atmospheric levels.

Without safety mechanisms to remove or circuit modifications to handle venous air, gaseous emboli can easily travel through a $\mathrm{mCPB}$ system, causing a greater potential risk for continuous micro air embolization during perfusion [42,45-49]. A bubble trap embedded in the venous line can decrease the amount of gross air entering the centrifugal pump [50-52]. Such traps are mainly intended to act as buoyancy. They prevent larger bubbles from entering the pump in which they can be milled to smaller emboli [53]. These emboli will then become suspended in the blood. Although decreasing venous line pressure increases the risk of air aspiration at the cannulation site, to the best of our knowledge, there is no clinical data available correlating data on GME occurrence with low venous line pressure and degassing in $\mathrm{mCPB}$ systems. Clearly, every effort should be made to prevent air from being 
entrained in the venous line to decrease the risk of arterial GME. A possible way of reducing the risk of arterial GME is by reducing sub-atmospheric pressure peaks in the venous line. As described by Tamari et al. [54], adding volume buffer capacity i.e. 'windkessel' to the venous line by using the 'Better Bladder', can reduce pressure fluctuations at the inlet of roller or centrifugal pumps during kinetic-assisted venous drainage and might, therefore, reduce patient embolic load and improve clinical neurological outcome. In chapter 5, we studied the often underestimated, or even unknown, but present risk of bubble formation when blood is exposed to subatmospheric pressures in $\mathrm{mCPB}$. The influence of sub-atmospheric pressure was performed clinically, whereas the effect of volume buffer capacity was tested in vitro. Severe sub-atmospheric fluctuations of venous line pressure during kineticassisted drainage, as used in $\mathrm{mCPB}$ systems, are related to gaseous microemboli. Volume buffer capacity added to the venous line effectively dampens pressure fluctuations resulting from abrupt changes in venous return and, therefore, can help to increase the safety of minimized cardiopulmonary bypass by reducing gaseous microemboli formation resulting from degassing.

Finally, intraoperative events-related cerebral tissue oxygen saturation changes were evaluated in patients undergoing cardiac surgery using pulsatile CPB (Chapter 6). Induction of anaesthesia, placement of the sternal retractor, onset and cessation of $\mathrm{CPB}$, placement, and removal of the aortic cross-clamp showed to significantly affect cerebral tissue oxygen saturation. However, absolute differences were relatively small and far from the $25 \%$ decrease when intervention is required [55]. This latter could be explained by lack of an intervention-guided study design. Since no interventions were applied, it was not possible to isolate the events from all actions performed by anesthesiologist, surgeon, and clinical perfusionist. Though, previous studies showed that decreased cerebral oxygen saturation during cardiac surgery is associated with early postoperative neuropsychological dysfunction [56] and that monitoring cerebral oxygen saturation during $\mathrm{CPB}$ significantly reduced the incidence of postoperative neurocognitive decline [57,58]. Additionally, Murkin et al. [55] demonstrated that avoiding profound regional cerebral desaturation is associated with significantly fever incidences of major organ dysfunction after coronary bypass surgery. Next to the literature and the results described in chapter 6 , one can conclude that routine monitoring of regional cerebral tissue oxygenation by near-infrared spectroscopy may help identify vulnerable periods during cardiac surgery, which require immediate intervention in order to avoid adverse neurological outcome. 


\section{CONCLUSION}

The potential detrimental effect of combined hypercapnia and hemodilution underlines the importance of tight perioperative $\mathrm{p}_{\mathrm{a}} \mathrm{CO}_{2}$ control during $\mathrm{CPB}$, while avoiding excessive hemodilution. Furthermore, routine monitoring of regional cerebral tissue oxygenation helps to identify vulnerable periods during cardiac surgery, which may require immediate interventions. All in order to diminish adverse neuropsychological outcome. 


\section{REFERENCES}

1. Roach GW, Kanchuger M, Mangano, et al. Adverse cerebral outcomes after coronary bypass surgery. Multicenter study of perioperative ischemia research group and the ischemia research and education foundation investigators. N Engl J Med 1996; 335:1857-1863.

2. Portegies ML, de Bruijn RF, Hofman A, et al. Cerebral vasomotor reactivity and risk of mortality: the Rotterdam study. Stroke 2014; 45:42-47.

3. Taylor RL, Borger MA, Weisel RD, et al. Cerebral microemboli during cardiopulmonary bypass: increased emboli during perfusionist interventions. Ann Thorac Surg 1999; 68:89-93.

4. Fearn SJ, Pole R, Wesnes $\mathrm{K}$, et al. Cerebral injury during cardiopulmonary bypass: emboli impair memory. J Thorac Cardiovasc Surg 2001; 121:1150-1160.

5. Prasongsukarn K, Borger MA. Reducing cerebral emboli during cardiopulmonary bypass. Semin Cardiothoracic Vasc Anesth 2005; 9:153-158.

6. Stockard JJ, Bialford RG, Schauble JF. Pressure-dependent cerebral ischemia during cardiopulmonary bypass. Neurology 1973; 23:521-529.

7. Caplan LR, Hennerici M. Impaired clearance of emboli (washout) is an important link between hypoperfusion, embolism, and ischemic stroke. Arch Neurol 1998; 55:1475-1482.

8. Millar SM, Alston RP, Andrews PJ, et al. Cerebral hypoperfusion in immediate postoperative period following coronary artery bypass grafting, heart valve, and abdominal aortic surgery. Br J Anaesth 2001; 87:229-236.

9. Murphy GS, Hessel EA II, Groom RC. Optimal perfusion during cardiopulmonary bypass: an evidence-based approach. Anest Analg 2009; 108:1394-1417.

10. Nicolet J, Gillard T, Gindre G, Cervenansky F, Duale C, Bazin JE, et al. Modifications of spontaneous cerebral blood flow oscillations during cardiopulmonary bypass. Acta Neurochir 2005; 95(Suppl):337-339.

11. Panerai RB, Eames PJ, Potter JF. Multiple coherence of cerebral blood flow velocity in humans. Am J Physiol Heart Circ Physiol 2006; 291:H251-H259.

12. Peng T, Rowley A, Ainslie P, Poulin M, Payne S. Multivariate system identification for cerebral autoregulation. Ann Biomed Eng 2008; 36:308-320.

13. Aaslid R, Lindegaard KF, Sorteberg W, Nornes H. Cerebral autoregulation dynamics in humans. Stroke 1989; 20:45-52.

14. Ainslie PN, Celi L, Mc Grattan K, Peebles K, Ogoh S. Dynamic cerebral autoregulation and baroreflex sensitivity during modest and severe step changes in arterial $\mathrm{PCO}_{2}$. Brain Res 2008; 1230:115-124.

15. Petersen KD, Lamdsfeldt U, Cold GE, Petersen CB, Mau S, Hauerberg J, Holst, SkovgaardOlsen K. Intracranial pressure and cerebral hemodynamic in patients with cerebral tumors: a randomized prospective study of patients subjected to craniotomy in propofol-fentanyl, isoflurane-fentanyl, or sevoflurane-fentanyl anesthesia. Anesthesiology 2003; 98:329-336.

16. Strebel S, Lam AM, Matta B, Mayberg TS, Aaslid R, Newell DW. Dynamic and static cerebral autoregulation during isoflurane, desflurane, and propofol anesthesia. Anesthesiology 1995; 83:66-76.

17. Ogawa Y, Iwasaki K, Aoki K, Shibata S, Kato J, Ogawa S. Central hypervolemia with hemodilution impairs dynamic cerebral autoregulation. Anesth Analg 2007; 105:1389-1396.

18. Buhre W, Weyland A, Grune F, et al: Influence of arterial carbon dioxide tension on systemic vascular resistance in patients undergoing cardiopulmonary bypass. Acta Anaesthesiol Scand $1998 ; 42: 167-171$. 
19. Rudolph JL, Sorond FA, Pochay VE, et al. Cerebral hemodynamics during coronary artery bypass graft surgery: the effect of carotid stenosis. Ultrasound Med Biol 2009; 35:1235-1241.

20. Tiecks FP, Lam AM, Aaslid R, Newell DW. Comparison of static and dynamic cerebral autoregulation measurements. Stroke 1995; 26:1014-1019.

21. Park CW, Sturzenegger M, Douville $\mathrm{CM}$, et al. Autoregulatory response and $\mathrm{CO}_{2}$ reactivity of the basilar artery. Stroke 2003; 34:34-39.

22. Engelhard K, Werner C, Mollenberg O, et al. Effects of remifentanil/propofol in comparison with isoflurane on dynamic cerebrovascular autoregulation in humans. Acta Anaesthesiol Scand 2001; 45:971-976.

23. Ono M, Joshi B, Brady K, et al. Risks for impaired cerebral autoregulation during cardiopulmonary bypass and postoperative stroke. Br J Anaesth 2012; 109:391-398.

24. von Kummer R, Scharf J, Back T, et al. Autoregulatory capacity and the effect of isovolemic hemodilution on local cerebral blood flow. Stroke 1988; 19:594-597.

25. Lassen NA. Cerebral blood flow and oxygen consumption in man. Physiol Rev 1959; 39:183-238.

26. Balachandran S, Cross MH, Karthikeyan S, Mulpur A, Hansbro SD, Hobson P. Retrograde autologous priming of the cardiopulmonary bypass circuit reduces blood transfusion after coronary artery surgery. Ann Thorac Surg 2002; 73:1912-1918.

27. Beholz S, Kessler M, Konertz WF. PRECiSe (priming reduced extracorporeal circulation setup): results of a safety study. Heart Surg Forum 2003; 6:311-315.

28. Eising GP, Pfauder M, Niemeyer M, et al. Retrograde autologous priming: is it useful in elective on-pump coronary artery bypass surgery? Ann Thorac Surg 2003; 75:23-27.

29. Rosengart TK, DeBois W, O'Hara M, et al. Retrograde autologous priming for cardiopulmonary bypass: a safe and effective means of decreasing hemodilution and transfusion requirements. J Thorac Cardiovasc Surg 1998; 115:426-438; discussion 438-439.

30. Shapira OM, Aldea GS, Treanor PR, et al. Reduction of allogeneic blood transfusions after open heart operations by lowering cardiopulmonary bypass prime volume. Ann Thorac Surg 1998; 65:724-730.

31. Srinivas K, Singh K. Combination of autologous transfusion and retrograde autologous priming decreases blood requirements. Ann Card Anaesth 2001; 4:28-32.

32. Koch CG, Li L, Duncan AI, et al. Morbidity and mortality risk associated with red blood cell and blood-component transfusion in isolated coronary artery bypass grafting. Crit Care Med 2006; 34:1608-1616.

33. Koch CG, Li L, Duncan AI, et al. Transfusion in coronary artery bypass grafting is associated with reduced long-term survival. Ann Thorac Surg 2006; 81:1650-1657.

34. Habib RH, Zacharias A, Schwann TA, et al. Role of hemodilutional anemia and transfusion during cardiopulmonary bypass in renal injury after coronary revascularization: implications on operative outcome. Crit Care Med 2005; 33:1749-1756.

35. Karkouti K, Djaiani G, Borger MA, et al. Low hematocrit during cardiopulmonary bypass is associated with increased risk of perioperative stroke in cardiac surgery. Ann Thorac Surg 2005; 80:1381-1387.

36. Anastasiadis K, Asteriou C, Deliopoulos A, et al. Haematological effects of minimized compared to conventional extracorporeal circulation after coronary revascularization procedures. Perfusion 2010; 25:197-203.

37. Benedetto U, Angeloni E, Refice S, et al. Is minimized extracorporeal circulation effective to reduce the need for red blood cell transfusion in coronary artery bypass grafting? Metaanalysis of randomized controlled trials. J Thorac Cardiovasc Surg 2009; 138:1450-1453. 
38. Vohra HA, Whistance R, Modi A, Ohri SK. The inflammatory response to miniaturised extracorporeal circulation: A review of the literature. Mediators Inflamm 2009; 2009:707042.

39. Immer FF, Ackermann A, Gygax E, et al. Minimal extracorporeal circulation is a promising technique for coronary artery bypass grafting. Ann Thorac Surg 2007; 84:1515-1520; discussion 1521.

40. Nollert G, Schwabenland I, Maktav D, et al. Miniaturized cardiopulmonary bypass in coronary artery bypass surgery: marginal impact on inflammation and coagulation but loss of safety margins. Ann Thorac Surg 2005; 80:2326-2332.

41. Simons AP, Reesink KD, Lance MD, et al. Dynamic filling index: a novel parameter to monitor circulatory filling during minimized extracorporeal bypass. Eur J Cardiothorac Surg 2009; 36:330-334.

42. Wang S, Undar A. Vacuum-assisted venous drainage and gaseous microemboli in cardiopulmonary bypass. J Extra Corpor Technol 2008; 40:249-256.

43. Lapietra A, Grossi EA, Pua BB, et al. Assisted venous drainage presents the risk of undetected air microembolism. J Thorac Cardiovasc Surg 2000; 120:856-862.

44. Willcox TW, Mitchell SJ, Gorman DF. Venous air in the bypass circuit: a source of arterial line emboli exacerbated by vacuum-assisted drainage. Ann Thorac Surg 1999; 68:1285-1289.

45. Norman MJ, Sistino JJ, Acsell JR. The effectiveness of low-prime cardiopulmonary bypass circuits at removing gaseous emboli. J Extra Corpor Technol 2004; 36:336-342.

46. Jones TJ, Deal DD, Vernon JC, Blackburn, N, Stump DA. How effective are cardiopulmonary bypass circuits at removing gaseous microemboli? J Extra Corpor Technol 2002; 34:34-39.

47. Huybregts RM, Veerman DP, Vonk AB, et al. First clinical experience with the air purge control and electrical remote-controlled tubing clamp in mini bypass. Artificial organs 2006; 30:721-724.

48. Mitsumaru A, Yozu R, Matayoshi T, et al. Efficiency of an air filter at the drainage site in a closed circuit with a centrifugal blood pump: an in vitro study. ASAIO J 2001; 47:692-695.

49. Morita M, Yozu R, Matayoshi T, Mitsumaru, A, Shin, H, Kawada S. Closed circuit cardiopulmonary bypass with centrifugal pump for open-heart surgery: new trial for air removal. Artif Organs 2000; 24:442-445.

50. Issitt RW, Mulholland JW, Oliver MD, et al. Aortic surgery using total miniaturized cardiopulmonary bypass. Ann Thorac Surg 2008; 86:627-631.

51. Kutschka I, Schonrock U, El Essawi A, Pahari, D, Anssar, M, Harringer, W. A new minimized perfusion circuitprovides highly effective ultrasound controlled deairing. Artif Organs 2007; 31:215-220.

52. Roosenhoff TP, Stehouwer MC, De Vroege R, Butter, RP, Van Boven, WJ, Bruins, P. Air removal efficiency of a venous bubble trap in a minimal extracorporeal circuit during coronary artery bypass grafting. Artif Organs 2010; 34:1092-1098.

53. Rider SP, Simon LV, Rice BJ, Poulton, CC. Assisted venous drainage, venous air, and gaseous microemboli transmission into the arterial line: an in-vitro study. J Extra Corpor Technol 1998; 30:160-165.

54. Tamari Y, Lee-Sensiba K, Ganju R, Chan, R, Hall, MH. A new bladder allows kinetic venous augmentation with a roller pump. Perfusion 1999; 14:453-459.

55. Murkin JM, Adams SJ, Novick RJ, Quantz M, Bainbridge D, Iglesias I, et al. Monitoring brain oxygen saturation during coronary bypass surgery: a randomized, prospective study. Anesth Analg 2007; 104:51-58.

56. Yao F-SF, Tseng C-CA, Ho C-YA, Levin SK, Illner P. Cerebral oxygen desaturation is associated with early postoperative neuropsychological dysfunction in patients undergoing cardiac surgery J Cardiothorac Vasc Anesth, 2004; 18:552-558. 
57. Mohandas BS, Jagadeesh AM, Vikram SB. Impact of monitoring cerebral oxygen saturation on the outcome of patients undergoing open heart surgery. Ann Card Anaesth 2013; 16:102-106.

58. Slater JP, Guarino T, Stark S, Vinod K, et al. Cerebral oxygen desaturation predicts cognitive decline and long hospital stay after cardiac surgery. Ann Thorac Surg 2009; 87:36-45. 

SUMMARY 
During cardiopulmonary bypass (CPB) a host of physiologic factors like temperature, $\mathrm{p}_{\mathrm{a}} \mathrm{CO}_{2}, \mathrm{p}_{\mathrm{a}} \mathrm{O}_{2}$, haematocrit, central venous pressure, and mean arterial pressure are maintained using the heart-lung machine. Each of these variables may act independently or together to alter cerebral hemodynamics, i.e. cerebral blood flow $(\mathrm{CBF})$ and cerebral $\mathrm{CO}_{2}$ reactivity $\left(\mathrm{CO}_{2} \mathrm{R}\right)$. Consequently, preserving the cerebral autoregulatory capacity during $\mathrm{CPB}$ is in part a function of how these variables are managed. However, evaluating dynamic cerebral autoregulation (dCA) during CPB is challenging, since it is necessary to compare two waveforms, i.e. the arterial blood pressure and cerebral blood flow velocity. During nonpulsatile CPB using a centrifugal pump, however, hardly any pulsation occurs when the aorta is cross-clamped; therefore, a new and original technique was introduced to assess the dCA and $\mathrm{CO}_{2} \mathrm{R}$ (Chapter 2). This clinical study involved the measurement of systemic and cerebral hemodynamic parameters and their response to physiological challenges. Study results clearly showed an impaired dCA during hypercapnia, suggesting that hypercapnia during normothermic CPB should be avoided.

Further, the influence of hemodilution and $\mathrm{p}_{\mathrm{a}} \mathrm{CO}_{2}$ levels on the dCA during normothermic CPB is elaborated in Chapter 3. It was shown that hemodilution down to a hematocrit $<28 \%$ combined with hypercapnia negatively affects the dCA during $\mathrm{CPB}$. This underlines the importance of tight control of both hematocrit and $\mathrm{p}_{\mathrm{a}} \mathrm{CO}_{2}$. Next, several methods to avoid excessive hemodilution during CPB were evaluated. A technique to reduce the large assanguinous priming volume of the CPB circuit is the so-called retrograde autologous priming (RAP). RAP showed to be a safe and effective technique for attenuating acute hemodilution and subsequent blood transfusion requirements in coronary artery bypass surgery (Chapter 4 ). It should therefore be considered as an integral part of a multimodal approach on blood conservation. Another approach to restrict hemodilution is the development of lowvolume circuits, also referred to as minimized cardiopulmonary bypass (mCPB) systems. Evident benefits of these systems, however, do not come without consequences as the pump flow depends on adequate preload, i.e. venous filling. Kineticassisted drainage used in such systems may produce excessive sub-atmospheric pressures in the venous line, generating a large amount of gaseous microemboli that can enter the arterial line. Volume buffer capacity added to the venous line showed to effectively dampen pressure fluctuations resulting from abrupt changes in venous drainage. Consequently, it increases safety of $\mathrm{mCPB}$ systems by reducing gaseous microemboli formation and load resulting from degassing (Chapter 5).

Aside from the influence of aforementioned physiologic factors on cerebral perfusion during $\mathrm{CPB}$, the final study investigated the impact of intraoperative events on cerebral tissue oxygen saturation in patients undergoing cardiac surgery with 
pulsatile CPB (Chapter 6). Cerebral tissue oximetry effectively identified subtle changes in cerebral saturation related to surgical events (placement of the sternal retractor, placement and removal of the aortic cross-clamp) or vulnerable periods (onset and cessation of $\mathrm{CPB}$ ) during cardiac surgery. Therefore, routine monitoring of cerebral tissue oximetry may help to identify vulnerable periods during cardiac surgery requiring immediate intervention in order to prevent adverse neurological outcome.

Conclusively, the present thesis contributes to a better understanding of cerebral perfusion processes related to the use of the heart-lung machine, and shows ways to attenuate possible deleterious effects. 

SAMENVATTING 
Tijdens cardiopulmonale bypass (CPB) wordt een hele reeks van factoren zoals temperatuur, $\mathrm{p}_{\mathrm{a}} \mathrm{CO}_{2}, \mathrm{p}_{\mathrm{a}} \mathrm{O}_{2}$, hematocriet, centraal veneuze bloeddruk alsook de arteriële bloeddruk door de hart-longmachine in stand gehouden. Elk van deze variabelen gedraagt zich onafhankelijk danwel afhankelijk van andere variabelen en verandert zo de cerebrale hemodynamiek, dat wil zeggen de cerebrale bloedstroom $(\mathrm{CBF})$ en cerebrale $\mathrm{CO}_{2}$ reactiviteit $\left(\mathrm{CO}_{2} \mathrm{R}\right)$. Behoud van cerebrale autoregulatie is dus feitelijk een functie van hoe deze variabelen worden gemanipuleerd. Evaluatie van dynamische cerebrale autoregulatie (dCA) tijdens CPB is echter niet eenvoudig gezien dit een vergelijk van twee golfvormen vereist, namelijk die van de arteriële bloeddruk en van de cerebrale bloedstroomsnelheid. Echter, tijdens nonpulsatiele $\mathrm{CPB}$ met behulp van een centrifugaalpomp ontstaan nauwelijks of geen pulsaties wanneer de aorta is afgeklemd; hiertoe werd een nieuwe methode geïntroduceerd om de dCA en $\mathrm{CO}_{2} \mathrm{R}$ te bepalen (hoofdstuk 2). Deze klinische studie betrekt metingen van de systemische en cerebrale hemodynamische parameters, alsook hun reactie op fysiologische veranderingen. De verkregen studieresultaten laten duidelijk zien dat dCA tijdens hypercapnie beperkt is, hetgeen suggereert dat hypercapnie tijdens normotherme CPB vermeden dient te worden.

Vervolgens is in hoofdstuk 3 de invloed van hemodilutie en het niveau van $\mathrm{p}_{\mathrm{a}} \mathrm{CO}_{2}$ op dCA tijdens normotherme CPB uitgewerkt. Er werd aangetoond dat hemodilutie tot een hematocriet $<28 \%$ in combinatie met hypercapnie een negatieve invloed heeft op de dCA. Dit toont het belang aan van een nauwgezette bewaking van zowel het hematocriet als de $\mathrm{p}_{\mathrm{a}} \mathrm{CO}_{2}$. Ook zijn verschillende methoden geëvalueerd welke excessieve hemodilutie tijdens CPB trachten te vermijden. Een techniek om een groot volume aan bloedloze priming te voorkomen is de zogenaamde retrograde autologe priming (RAP). RAP bij coronaire bypassoperatie bleek een veilige en effectieve techniek om acute hemodilutie te verminderen en zo homologe erytrocytentransfusie te beperken (hoofdstuk 4). Deze techniek zou daarom integraal deel moeten uitmaken van de multimodale aanpak ten behoeve van bloedconservatie. Een andere aanpak om hemodilutie te minimaliseren is de ontwikkeling van circuits met een laag priming volume, ook wel geminimaliseerde cardiopulmonale bypass $(\mathrm{mCPB})$ genoemd. Dergelijke circuits hebben echter niet enkel evidente voordelen, maar ook nadelen. Zo is bijvoorbeeld de pompvolumestroom afhankelijk van voldoende aanbod, de zo genaamde veneuze vulling. Ook kan de kinetisch ondersteunde drainage van $\mathrm{mCPB}$ resulteren in excessief lage sub-atmosferische drukken in de veneuze slang. Hierdoor kunnen grote hoeveelheden aan gasvormige microembolieën ontstaan, welke tot in de arteriële slang kunnen worden waargenomen. Het toevoegen van een volumebuffer capaciteit bleek effectief in het dempen van druk fluctuaties, welke tijdens abrupte veranderingen van de veneuze drainage ontstonden. De volumebuffer capaciteit verhoogt dus de veiligheid van $\mathrm{mCPB}$ 
circuits door de formatie van en de belasting door gasvormige microemboliën te reduceren (hoofdstuk 5).

Naast de invloed van hierboven genoemde fysiologische factoren op de cerebrale perfusie tijdens $\mathrm{CPB}$, onderzocht de laatste studie de invloed van intra-operatieve gebeurtenissen op cerebrale weefselzuurstofsaturatie bij patiënten welke hartchirurgie met behulp van pulsatiele $\mathrm{CPB}$ ondergingen (hoofdstuk 6). Cerebrale weefsel oxymetrie tijdens hartchirurgie kon effectief kleine veranderingen in cerebrale saturatie aan chirurgische gebeurtenissen (plaatsing van de sternumspreider, klemmen en ontklemmen van de aorta) danwel kwetsbare perioden (start en beëindiging van $\mathrm{CPB}$ ) relateren. Daarom kan het routinematig monitoren van cerebrale weefsel oxymetrie in de hartchirurgie helpen bij het identificeren van kwetsbare perioden, waarbij directe interventie nodig is om slechte neurologische uitkomst te voorkomen.

Concluderend kan gesteld worden dat dit proefschrift bijdraagt aan een beter begrip van cerebrale perfusie beïnvloedende processen die gerelateerd zijn aan het gebruik van een hart-longmachine, met als doel het verminderen van mogelijk schadelijke effecten. 

SAŽETAK 
Tijekom kardiopulmonalnog bypassa (CPB) brojni fiziološki čimbenici kao što su temperatura, $\mathrm{P}_{\mathrm{a}} \mathrm{CO}_{2}, \mathrm{P}_{\mathrm{a}} \mathrm{O}_{2}$, hematokrit, središnji venski tlak, te srednji arterijski tlak se održavaju pomoću aparata srce-pluća. Svaki od navedenih čimbenika može djelovati bilo samostalno bilo zajedno u mijenjanju moždane hemodinamike, odnosno protoka krvi kroz mozak (CBF) i moždane reaktivnosti na $\mathrm{CO}_{2}\left(\mathrm{CO}_{2} \mathrm{R}\right)$.

Prema tome, očuvanje cerebralnog autoregulacijskog kapaciteta tijekom CPB leži dijelimično i u načinu kako se ovim čimbenicima upravlja. Međutim, procjena dinamične cerebralne autoregulacije (dCA) u CPB predstavlja izazov, budući da je neophodno usporedjivati dva valna oblika, odnosno arterijskog krvnog tlaka i brzine cerebralnog protoka krvi. Tijekom ne pulsnog CPB pomoću centrifugalne pumpe, međutim, teško da se bilo kakvo pulsiranje događa kada je aorta klemana; stoga je uvedena nova i originalna tehnika za procijenu dCA i CO $2 \mathrm{R}$ (Poglavlje 2). U ovo kliničko istraživanje je uključeno mjerenje sustavnih i moždanih hemodinamskih parametara i njihov odgovor na fiziološke izazove. Rezultati istraživanja jasno su pokazali oslabljenu dCA za vrijeme hiperkapnije, sugerirajući da hiperkapnija u normotermičkom CPB treba izbjegavati.

Nadalje, utjecaj hemodilucije i nivoa $\mathrm{p}_{\mathrm{C}} \mathrm{CO}_{2}$ na dCA za vrijeme normotermnog $\mathrm{CPB}$ je elaboriran u 3. poglavlju. Pokazano je da hemodilucija sa hematokritom $<28 \% \mathrm{u}$ kombinaciji sa hiperkapnijom ima negativan utjecaj na dCA za vrijeme CPB. To naglašava važnost striktne kontrole hematokrita i $\mathrm{p}_{\mathrm{a}} \mathrm{CO}_{2}$ tijekom zahvata. Nadalje, procjenjeno je nekoliko metoda izbjegavanja pretjerane hemodilucije. Tehnika za smanjenje velikog beskrvnog volumena punjenja sustava za izvantjelesni krvotok je tzv. retrogradno autologno punjenje (RAP). RAP se pokazao kao sigurna i učinkovita tehnika smanjenja akutne hemodilucije i naknadnih zahtjeva za transfuzijom krvi prilikom operacija obilaznica koronarnih arterija (Poglavlje 4). Trebalo bi je dakle, smatrati kao sastavni dio multimodalnog pristupa očuvanju krvi. Drugi pristup za ograničavanje hemodilucije je razvoj sustava sa minimalnim volumenom punjenja, također poznat kao minimalni kardiopulmonalni bypass (mCPB) sustav. Vidljive prednosti ovih sustava, međutim, ne dolaze bez posljedica, jer protok pumpe ovisi od adekvatnog preload-a odnosno venskog punjenja. Kinetički asistirana drenaža koja se upotrijebljava $\mathrm{u}$ takvim sustavima može proizvesti prekomjerni podatmosferski tlak u venskoj liniji, generirajući veliku količinu plinovitih mikroembolusa koji mogu ući u arterijsku liniju. Pokazalo se da puferski kapacitet volumena dodan u venskoj liniji, učinkovito prigušuje oscilacije tlaka uslijed naglih promjena u venskoj drenaži. Na taj način se povećava sigurnost mCPB sustava, smanjujući formiranje plinovitih mikroembolusa i opterećenje uslijed otplinjavanja (Poglavlje 5). Osim utjecaja spomenutih fizioloških čimbenika na moždanu perfuziju tijekom $\mathrm{CPB}$, konačna studija istražuje utjecaj intraoperacijskih događaja na zasićenje kisi- 
kom cerebralnih tkiva u bolesnika podvrgnutih kardijalnoj kirurgiji s pulsnim CPB (poglavlje 6). Cerebralna oksimetrija tkiva učinkovito identificira suptilne promjene u moždanoj saturaciji koji su u odnosu na kirurške događaje (plasman sternalnog retraktora, postavljanje i uklanjanje aortne kleme) ili osjetljivih razdoblja (početak i prestanak (PB) tijekom kirurškog zahvata na srcu. Dakle, rutinsko praćenje oksimetrije moždanih tkiva može pomoći identificirnjui ranjivih razdoblja tijekom operacije srca, koje zahtijevaju hitnu intervenciju kako bi se spriječio negativan neurološki ishod.

Zaključno, ovaj rad doprinosi boljem razumijevanju procesa cerebralne perfuzije vezanih uz korištenje aparata srce-pluća, ukazujućina načine za ublažavanje mogućih štetnih posljedica. 



\section{VALORISATION}


Cardiac surgery, because of its complexity (extensive monitoring and equipment), is one of the most expensive surgical treatments. It is not surprising that healthcare is increasingly interested in cost and cost-effectiveness of this kind of treatments. For the majority of cardiac surgical operations, the use of cardiopulmonary bypass $(\mathrm{CPB})$ or heart-lung machine (HLM) is a conditio sine qua non. $\mathrm{CPB}$ is a technique that uses a HLM to temporarily take over the function of the heart and lungs during surgery. A HLM mechanically circulates and oxygenates blood for the body while bypassing the heart and lungs. The HLM is maintaining perfusion to all body organs and tissues while the surgeon works in a bloodless surgical field. The present thesis contributes to a better understanding of cerebral perfusion processes related to the use of the heart-lung machine, and shows ways to attenuate possible deleterious effects.

In the last decade, mortality of patients operated on while using a CPB drastically decreased. Reduction in neurocognitive impairment, however, did not reach the same magnitude, with a growing body of evidence showing the negative impact of $\mathrm{CPB}$ on clinical outcome. The two major causative factors for neuropsychological dysfunction after cardiac surgery are global brain hypoperfusion and cerebral emboli generated by either surgical or perfusion-related interventions. Additionally, it was found that the minority of patients having cardiac procedures (15\% to $20 \%$ ) consume more than $80 \%$ of the blood products transfused during operations. To counteract these problems, CPB technology has evolved with advances in oxygenators design, surface biocompatibility, blood-pump technology and, more recently, in reducing circuit size and priming volume. In an attempt to attenuate the adverse effects of $\mathrm{CPB}$ such as inflammatory reactions, transfusion requirements and extreme hemodilution, recently the use of minimized cardiopulmonary bypass systems (mCPB) has gradually increased. Evident benefits of $\mathrm{mCPB}$, however, do not come without consequences. Venous air emboli may be sucked into the venous line at the site of cannulation, which can result in arterial microemboli. Additionally, excessively low sub-atmospheric venous line pressures can cause in-pump gaseous microemboli in abundance as well. It is clear that every effort should be made to prevent air from being entrained or formed de novo in the circuit to decrease the total arterial embolic load. Recent literature shows that $\mathrm{mCPB}$ using a volume buffer capacity embedded into the venous line and enhanced pump servo-regulation, combined with anti-obstructive venous cannula design, can prevent venous line pressures from peaking down to excessively low levels with concomitant gaseous microbubble formation, while pump speed adapts to venous drainage to maintain a maximal level of support available at that instance. Based on the positive results of clinical and preclinical trials the use of $\mathrm{mCPB}$ as well as the use of retrograde autologous priming technique can lead to significant cost reduction in health care. 
Because cardiac surgery is still associated with blood transfusion, our second challenge was to attenuate the negative effect of hemodilution and homologous blood transfusion on clinical outcome, another issue that could have both social and economic importance. Next to allergic reactions, transmission of infectious diseases and acute lung injury, there is mounting evidence that transfusion of packed red blood cells increases morbidity and mortality. Moreover, acute hemodilution and resulting low haematocrit during $\mathrm{CPB}$ has demonstrated to have a detrimental effect on cognitive function. Additionally, transfusion of red blood cells is not only related to poorer early and late outcome, but also makes surgery more expensive. In our centre, in 2014, cardiac surgical patients consumed $12 \%$ of the total amount of blood products that amounted to $€ 560.000$. Additionally, a systemic review performed in 6 western European countries has shown that mean costs of transfusing 2 units of packed red blood cells were $€ 878$ providing a burden to the health care system. We found that both retrograde autologous priming of the cardiopulmonary bypass circuit and the use of $\mathrm{mCPB}$ significantly attenuate acute hemodilution and blood transfusion requirements in coronary artery bypass surgery. Obviously, our both attempts proved to have a significantly positive effect on both patient safety and cost-effectiveness. The knowledge transfer of retrograde autologous priming might be an interesting technique that can be shared through continuous education. The industry, however, should make additional effort to create safer mCPB systems. Therefore, using retrograde autologous priming as well as applying mCPB should be considered to be an integral part of a multimodal approach for conservation of blood transfusion. 



\section{ACKNOWLEDGMENT}

Gloria discipuli, gloria magistri. 
Endless thanks to my promotor prof. Jos Maessen, professor of Cardiothoracic Surgery, who allowed me to start and finish my PhD program. Dear Jos, you literally saved me in the most difficult time of my life. Thanks for the trust you placed in me.

I'm eternally grateful to Dick de Jong, clinical perfusionist, former head of the Department of Extracorporeal Circulation and prof. Olaf Penn, former head of the department of Cardiothoracic Surgery, who enabled me to come to Maastricht and to begin my Dutch career. I'm also grateful to Kees Prenger, cardiothoracic surgeon, who provided me with a permanent contract as a clinical perfusionist in Maastricht.

A special place in my heart is reserved for the former and present staff of the Department of Extracorporeal Circulation: Yuri Ganushchak, Yvonne Bosch, Nicole Caberg, Diana van Dijk, Rik Hendrix, Erik Körver, Anouk Lindelauf, Nico Pijnappel, Ajay Sharma, Ellen Heerdt, Antoine Simons, Cees Visser, Nousjka Vranken, Pieter Wortel and Zaheer ud din Babar. Thanks for your support!

A special thanks to the staff of the department of Cardiothoracic Surgery, especially Gijs Geskes for the co-operation and continuous support.

Thanks to the staff of the department of Anaesthesia. Lion Stassen and Réne Roubben (anaesthesia assistants), I appreciate your friendship and collaboration in the operating theatre.

Etiënne van den Heuvel, thank you for the technical support in the operating theatre. Without your generous support many data from my investigation would be probably lost. You always had the right answer at the right moment.

My deepest gratitude is reserved for Patrick Weerwind, my copromotor, friend, colleague, head of the Department of Extracorporeal Circulation, and my coach. Patrick, your contribution to achieve my lifelong academic goal of a $\mathrm{PhD}$ cannot be adequately expressed in a few words but I'm forever grateful to you. Your guidance and training throughout the entire time of my work on the dissertation, your composure and always the right word at the right time, gave me the strength and faith that I would succeed. Without your unrestricted support this thesis would not be completed.

John Heijmans, my other copromotor; dear John we started together this extensive demanding research and I'm very thankful for your contribution and especially your serenity during the start of this investigation. I also wish to thank all the patients who gave informed consent for participation in this research. 
Dear members of the assessment committee: prof. Otto Bekers (chairman), prof. Wolfgang Buhre, prof. Bas Mochtar, prof. John Murkin and prof. Ronney Panerai, thank you for your contribution to my dissertation.

And last but not least, my paranymphs: Antoine Simons and Nousjka Vranken. Antoine, I owe you many thanks for your professional and technical contribution to this thesis. I'll never forget our visit to many jazz sessions in the city. You've been my friend through the years and that is why I wanted to have you stand by my side during this ceremony. Dear Nousjka, as a young PhD student, you have been very actively involved in preparing and presenting our work. Special thanks for your brilliant presentations, both here and abroad. I wish you all the best for your own academic promotion very soon. 



\section{CURRICULUM VITAE}

Parce mihi Domine, quia Dalmata sum. 
Ervin Emil Ševerdija, was born on May 30 1943 in Dubrovnik, Croatia. He grew up in Zadar, Croatia, finishing classical gymnasium in 1961. In the same year he started health care education at the Medical Core School for Active Officers and graduated in 1965, becoming a medical officer in Yugoslav Army. In 1972, he started education in Military Medical Academy Belgrade for Anaesthesia, Reanimation and Perfusion, becoming a graduate clinical perfusionist in 1974. In 1978, he attended the first international course of membrane oxygenators in London, UK. In May 1987, he helped Prof. Sokolic, colonel and head of the Clinic for Cardiac Surgery, to open a paediatric surgical centre in Belgrade where he worked voluntary until October 1988, teaching a student perfusionist. Two years later, he helped to open a new cardiac surgical centre in Skopje, Macedonia. In 1991, Ervin was demobilized with the rank of lieutenant colonel and transferred to Zagreb, Croatia, where he became the chief perfusionist of the Cardiothoracic Surgery department at the university hospital centre. Finally, in 1992, he moved to the Netherlands as a staff perfusionist at the University Hospital Maastricht. In November 1996, he received the Dutch certification as a certified clinical perfusionist by the Dutch Hospital Board, after which he was appointed as a senior clinical perfusionist. In 1996 and 1997, he was project consultant of the advisory board of neurobehavioral outcome. From 1989 to 1995, he was an organizing committee member of the Foundation European Congress on Extracorporeal Circulation Technology (FECECT). He entered the registry of certified clinical perfusionist of the Netherlands Society for Extracorporeal Circulation in 2005. Ervin retired in May 2008. 


\section{PubliCATIONS}


Ševerdija EE, Vranken NP, Teerenstra S, Ganushchak YM, Weerwind PW.

Impact of intraoperative events on cerebral tissue oximetry in patients undergoing cardiopulmonary bypass. J Extra Corpor Technol 2015; 47:32-37.

Ševerdija EE, Vranken NP, Simons AP, Gommer ED, Heijmans JH, Maessen JG, Weerwind PW. Hemodilution combined with hypercapnia impairs cerebral autoregulation during normothermic cardiopulmonary bypass. J Cardiothorac Vasc Anesth 2015; 29:1194-1199.

Ševerdija EE, Gommer ED, Weerwind PW, Reulen JP, Mess WH, Maessen JG. Assessment of dynamic cerebral autoregulation and carbon dioxide reactivity during normothermic cardiopulmonary bypass. Med Biol Eng Comput 2015; 53:195-203.

Ganushchak YM, Ševerdija EE, Simons AP, van Garsse L, Weerwind PW. Can minimized cardiopulmonary bypass systems be safer? Perfusion 2012; 27:176-182.

Severdija EE, Heijmans JH, Theunissen M, Maessen JG, Roekaerts PH, Weerwind PW. Retrograde autologous priming reduces transfusion requirements in coronary artery bypass surgery. Perfusion 2011; 26:315-321.

Sauren L, Mooren E, Severdija E, Weerwind P, Maessen J. Emboli occurrence during coronary artery bypass surgery: the influence of a new method of perfusionist blood sampling. Perfusion 2008; 23:261-265.

Simons AP, Reesink KD, Molegraaf GV, van der Nagel T, de Jong MM, Severdija EE, de Jong DS, van der Veen FH, Maessen JG. An in vitro and in vivo study of the detection and reversal of venous collapse during extracorporeal life support. Artif Organs 2007; 31:154-159.

Ševerdija EE. Extracorporeal circuit prime reduces blood transfusion requirements in coronary artery surgery. NeSECC editie 2007; 2:9-16.

Severdija E. Säure-Basen-Management während hypothermem kardiopulmonalem bypass. In: Extrakorporale Zirkulation in Theorie und Praxis, 2nd ed. 2005; pp 109120, Rudolf J. Tschaut (Ed.); Pabst Science Publishers, Lengerich, Germany.

Severdija E. Akzidentelle Hypothermie. In: Extrakorporale Zirkulation in Theorie und Praxis, 2nd ed. 2005; pp 546-553, Rudolf J. Tschaut (Ed.); Pabst Science Publishers, Lengerich, Germany. 


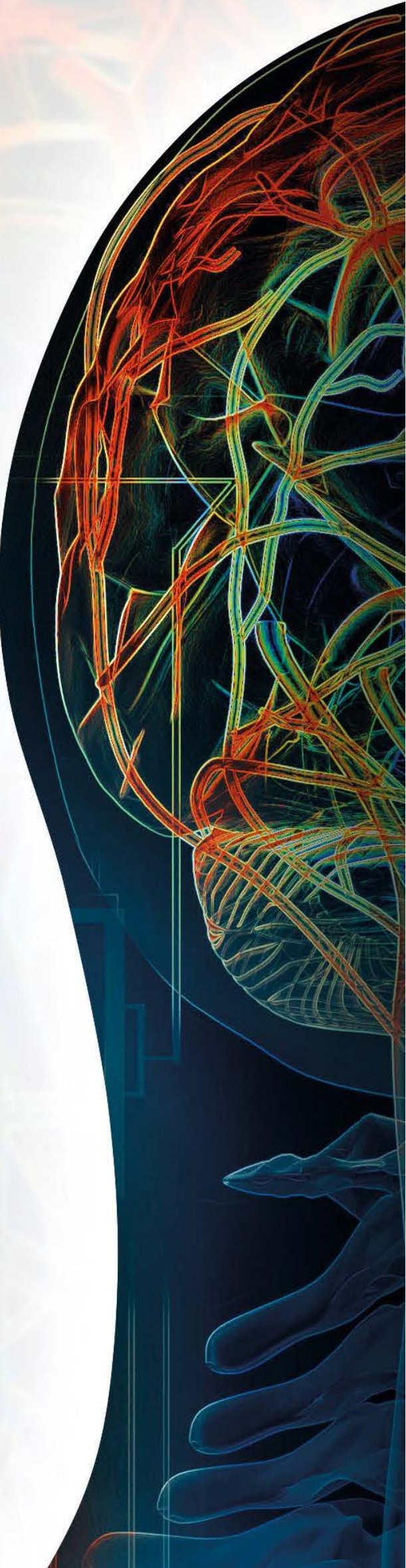

